UCID--20622-90-1

DE91 000495

\title{
Chemistry \& Materials Science Research Report
}

\author{
Weapons-Supporting Research \\ and \\ Departmental Institutional Research \& Development
}

May 31, 1990 


\section{FOREWORD}

The research reported here in summary form was conducted under the auspices of Weapons Supporting Research (WSR) and Iastitutional Research and Development (IR\&D). The period covered is the first half of FY90.

WSR is the principal source of discretionary funds to support fundamental research in the Chemistry \& Materials Science Department (C\&MS). The purpose of WSR is to provide the scientific and technical base that is required in the longer tem for success of the Weapons Program.

Administratively, WSR is organized into block-funded programs ("thrust areas") and a few smaller projects led by individual investigators. A thrust area is designed to provide a coordinated approach to a focused scientific or technological area and typically involves several senior scientists.

IR\&D is intended to broaden the exploratory research base of C\&MS. In FYO(), IR\&D funds have underwritten several single-investigator projects and (in part) reiatively large programs such as Spin Polarization and High-Temperature Superconductivity.

In practice, research programs carried out under WSR auspices are similar in spirit and substance to those supported by IR\&D. Indeed, some of the work is funded by both sources.

The results reported here are for work in progress; thus, they may be preliminary, fragmentary, or incomplete. Interested readers should consult one of the authors of a report before quoting it or otherwise referring to it. 


\section{CONTENTS}

\section{WEAPONS-SUPPORTING RESEARCH}

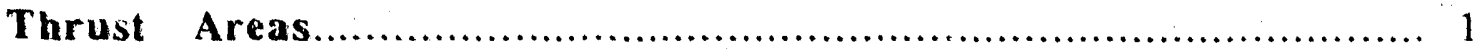

ENERGETIC MATERIALS ................................................ 3

R. L. Simpson

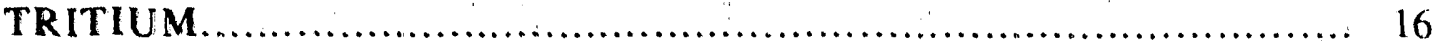

P.C. Sauers

HIGH-TRANSITION-TEMPERATURE SUPERCONDUCTIVITY M. J. Fluss

INTERFACES, ADHESION, AND BONDING

W. E. King

FUNDAMENTAL ASPECTS OF METALS PROCESSING .................... 52 J. N. Kass

PLUTONIUM.

L. R. Newkirk

SYNCHROTRON-RADIATION-BASED MATERIALS SCIENCE J. Wong

Individual Projects

STRUCTURAL TRANSFORMATION AND PRECURSOR PHENOMENA IN

ADVANCED MATERIALS: THEORY AND EXPERIMENTS.

P. E. A. Turchi, S. C. Moss, R. H. Howell, M. J. Fluss, L. E. Tanner

PHOTOCATALYSIS ON DOPED AEROGELS

C. Calmenares, M. Comnor, J. Raymond, E. Fought, R. Gaver

LASER-INDUCED CHEMISTRY

W. E. Conaway, C. G. Stevens

LASER-PRODUCED MOLECULAR PLASMAS

A. Droege, C. Stevens, G. Haugen, W. Conaway, S. Steward, R. Pekala

CHEMISTRY OF DEFECTS

I.De Yoreo

DTA EQUIPMENT DEVELOPMENT

J. De Yoreo

70

\section{DEPARTMENTAL INSTITUTIONAL RESEARCH \& DEVELOPMENT}

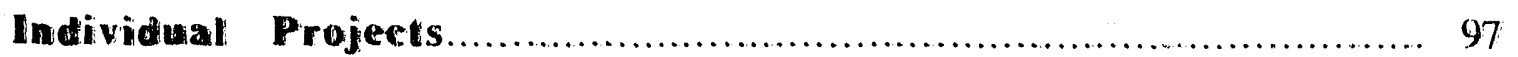

ELECTRONIC STRUCTURE STUDY OF THE THERMODYNAMIC AND MECHANICAL PROPERTIES OF Al-Li ALLOYS

A. Gomis

THE STRUCTURE-PROPERTY LINK IN SUIB-NANOMETER MATERIALS. IOI A. F. Jiankiowski 


\section{WEAPONS-SUPPORTING RESEARCH}

Thrust Areas 


\section{ENERGETIC MATERIALS}

\section{R. L. Simpson (Thrust Area Leader)}

In the last year, the emphasis in explosives research has changed direction, from developing and characterizing materials with extremely high energy to producing an understanding of materials with enhanced safety properties. The iss'le of explosive safety encompasses physics and chemistry at many levels, and it is necessary to develop both theories and probes for processes from the molecular to the hydrodynamic. It is also important to create new compounds upon which we can test our understanding and our qualitative models.

The work summarized here falls into three areas:

- First, new molecules are being synthesized based on our qualitative understanding of the insensitive high explosive TATB.

- Second, we are probing more deeply into the nature of chemistry under the hightemperature, high-pressure environment.

- Third, we are improving our understanding of the hydrodynamic behavior of the energetic materials.

There is significant overlap among the three areas to improve the interaction between the diverse spectrum of talents within the section.

\section{Synthesis of New Insensitive Explosives}
C. L. Coon
P. F. Pagoria
A. R. Mitchell

\section{Overview}

TATB is currently accepted as the standard "insensitive high explosive," Because of its extreme stability and lack of sensitivity to shock, friction, spark, ctc., it plays an important role in the design of weapons systems. However, there is continuing interest in "improved TATB," that is, in an explosive that retains all (or nearly all) of the safety properties of TATB while possessing a higher energy-density ratio.

The following qualitative factors are widely accepted as contributing to the insensitivity of TA'TB and other insensitive high explosives:

- Incorporation of only moderate amounts of energy into a molecule.

- Extensive hydrogen bonding, both inter-and intra-molecularly.

- The opportunity for the removal of water as the first step in decomposition.

- A graphitic crystalline structure.

The chemical properties of TATB have been reviewed by S. Rice and will be published shortly.

For this project, we have chosen specific target materials that incorporate these factors to some degree. As specific target compounds are synthesized, they are fully characterized to determine if they are replacements for TATB, as predicted. 


\section{Progress}

Our research efforts were directed in three specific areas:

(1) High-nitrogen insensitive explosives.

(2) Nitrate ester-alcohol explosives.

(3) $\mathrm{HK}-6$.

\section{High-Nitrogen Insensitive Explosives}

Our research has been directed towards the synthesis of insensitive energetic. compounds based on 3-amino-5-nitro-1,2,4-triazole (1). The synthesis of (1)|Rer. EM-1| is shown in Fig. IM-1 and consists of acetylating the commercially available 3-imino1,2,4-triazole (2) to give 3-acetamido-2-acetyl-1,2,4-triazole (3) in $80 \%$ yield, partial hydrolysis at 5()$^{\circ} \mathrm{C}$ to yield 3-acetamido-1,2,4-tritzole (4) in $80 \%$ yield, nitration with $\mathrm{Ac}_{2} \mathrm{O} / \mathrm{HNO}_{3}$ at () to $7{ }^{\circ} \mathrm{C}$ to give 3-acetamido-5-nitro-1,2,4-triazole (5), and hydrolysis of the acetamido group with aqueous $\mathrm{HCl}$ to give the target compound. We have completed the first two steps of the synthesis but have run into some difficulties reproducing the nitration step. Several attempts have been made using both $\mathrm{Ac}_{2} \mathrm{O} / \mathrm{HNO}_{3}$ and $\mathrm{N}_{2} \mathrm{O}_{5} / I \mathrm{INO}_{3}$ as the nitrating agent at various reaction temperatures, but little or no yield of (5) wats obtained. This prompted us to investigate allernative methods for synthesis of (1) (Fig. E:M-2). The method we envision involves the nucleophilic displacement of - $\mathrm{Br}$ or $-\mathrm{NO}_{2}$ from a protected 3,5-disubstituted-5-nitro-1,2,4-triazole. Protection of the amino group at the 2 -position is recuired because it has been shown that unprotected triazoles have, instead of nucleophilic displacement, deprotonation of the acidic hydrogen at the 2-position occurring |Ref. EM-2|. Protection of the ring nitrogen with the tertbutyloxycarbonyl (BOC) [Rer. EM-3/ group (which is easily removed by mild acid hydrolysis) should allow nucleophilic displacement with ammonia to give the desired compound.

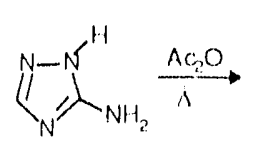

(2)

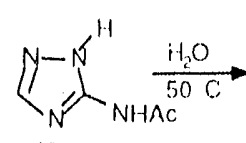

(3)

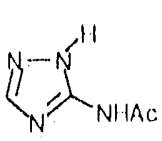

(4)
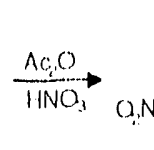

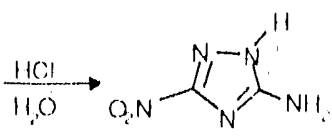

(1)

Fig. EM-1. Reported symbesis of 3-amino-5-nitro-1,2,4-triande (1).

We have completed the symthesis of $3-n i t r(0-1,2,4-$ triarole (6) and 3 -hromo-5-nitro. 1,2,4-triazole (7) |Fig. I:M-2. Compound (6) wats synthesized in 50 to $6(0) \%$ yield by

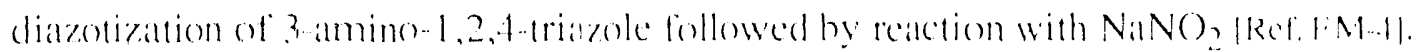

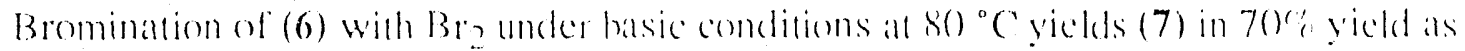

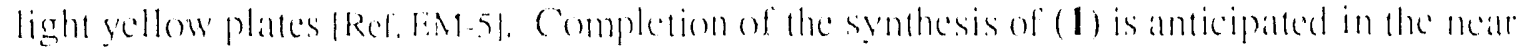

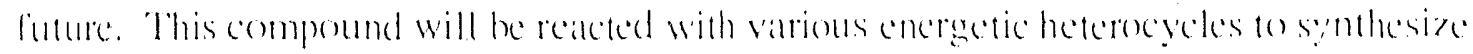
high-nitrogen, insensitive energeric materials. 

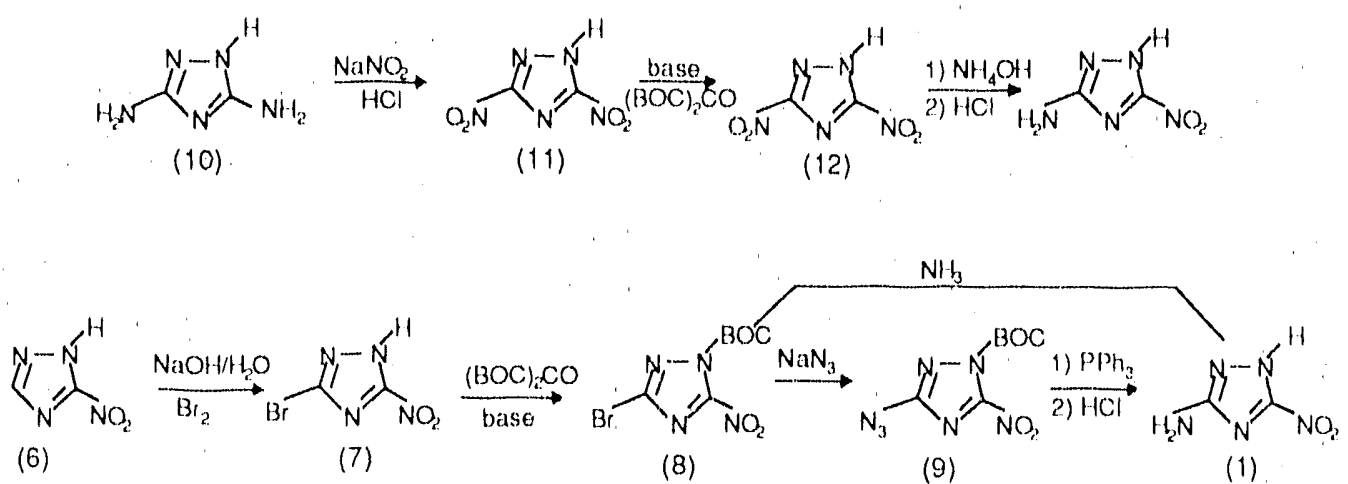

Fig. EM-2. Alternative syntheses of (1).

Nitrate Ester-Alcohol Explosives

In this work, a target material was prepared that had moderate energy and hydrogen bonding involving hydroxyl groups rather than the usual amino groups. This is a one-step synthesis in which 2,5-dinitro-1,3,4,6-tetrahydroxycyclohexane, a relatively inexpensive material, is partially nitrolyzed. The target compound, IDN, was prepared in small quantity $(\sim 20) \mathrm{mg})$. Larger quantities will be synthesized for characterization and evaluation.

$H K-6$

The goal of the HK-6 project is to develop a partially nitrated urea that outperforms DNGU (large failure diameter) but retains comparable insensitivity. The complete nitration of triazone, an inexpensive component of a commercially available fertilizer, yields K-6 (keto-RDX), which is about 5 to 7\% more energetic than HMX. K-6 is comparable to RDX in sensitivity tests and cannot be considered an insensitive high explosive. We are exploring ways to partially nitrate triazone and obtain HK- 6 free of K-6 and other nitration products.

\section{Related Work}

The synthesis group and $B T a$ o began work last year in the synthesis of a series of TATB analogues, including deuterated $\left({ }^{2} \mathrm{H}\right)$-TATB, ${ }^{2} \mathrm{H}-\mathrm{DATB}$, and ${ }^{2} \mathrm{H}$-picramide |Fig. EM-3|. The synthesis of ${ }^{2} \mathrm{H}-\mathrm{TATB}$ and ${ }^{2} \mathrm{H}$-picramide is essentially complete; only analysis for extent of deuteration remains. The synthesis of ${ }^{2} \mathrm{H}$-DATB is ready to be scaled to $50 \mathrm{~g}$ as model reactions indicate that our synthetic method gives the desired compound. Both ${ }^{2} \mathrm{H}-\mathrm{DATB}$ and ${ }^{2} \mathrm{H}$-picramide are unknown compounds; a publication of their synthesis is being prepared. We have also completed the synthesis or acquisition of 50 grams each of trinitrophloroglocinol, styphnic acid, picric acid, picramide, DATB, TATB, and trinitrobenzene. These compounds have been formulated and are waiting to be pressed into parts for shipping and evaluation using single-pulse spectroscopic techniques (with cooperation from A. Renlund). 


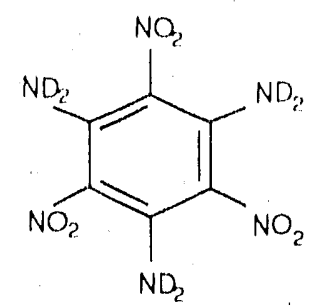<smiles>O=[N+]([O-])c1cc([N+](=O)[O-])c([N+](=O)[O-])c([N+](=O)[O-])c1[N+](=O)[O-]</smiles><smiles>O=[N+]([O-])c1cc([N+](=O)[O-])c([N+](=O)[O-])c([N+](=O)[O-])c1</smiles>

Fig. EM-3. Deuterated TA'TB, DA'TB, and picramide.

\title{
High-Pressure Reactivity
}

\author{
I. Beucer D. Calef
}

\section{Overview}

This project was started in FY90 with the intent of studying the electronic state of molecules in shocked fluids. It is known that highly compressed solids can transition from a "molecular" phase to an "atomic:" phase. This project is intended to discover what happens when the material is hot, hence lacking any crystalline order. The ultimate goal is to probe the limits of conventional chemical kinctics caused by the breakdown of the molecular electronic state.

\section{Progress}

We have started two related projects that deal with the electronic structure of atomic fluids. The first project involves trying to determine the thermodynamics of shockcompressed diatomic fluids. It is believed that fluids composed of diatomic molecules undergo dissociation under shock conditions. In order to study this hypothesis, we have considered a model of binary hard-spheres in which one component is inert while the other component has an electronic degree of freedom associated with each sphere. We have given the inert component vibrational degrees of freedom. This is a very simple model for the reaction $\mathrm{A}_{2} \rightarrow 2 \mathrm{~A}$. However, the dissociation is not of diatomic molecules to free atoms, as it would be in the gaseous state, but to atoms in a liquid state. The effective dissociation energy thus becomes lowered as compared to the gaseous state that results from the energy difference caused by electronic band formation. Our model is a chemical picture in which the total free energy of the system is the sum of hard-sphere, molecular, and electronic terms. The condition of chemical equilibrium for dissociation is imposed, and a dissociation fraction is thus determined. Once the dissociation fraction is determined, the thermodynamics of the system can be calculated and compared to Hugoniot data. It is evident that, in order to perform this calculation, an understanding of band structure in liquids is necessary.

We have written a program that calculates the equilibrium dissociation fraction of our model system. This program uses the mean spherical approximation result for the density of states. We have also written programs to calculate such relevant thermodynamics as 
P vs. V. We are now trying to get reasonable estimates for the relevant parameters that are used in this program.

Our other project has been exploring the wave functions (or Green's functions) for these systems. With models for the Green's function, experimentally accessible quantities such as conductivities can be calculated. We have written programs that generate the Green's functions for different densities and energies and are performing these calculations now. In order to understand the range of liquid densities over which this theory is valid, we have undertaken a numerical simulation. To this end, we have written a hard-sphere Monte Carlo program that generates configurations of particles with liquid-like structure. The electronic structure is studied through a tight-binding Hamiltonian whose off-diagonal matrix elements are a function of interparticle distance. They thus depend on the liquid structure. Direct diagonalization of the Hamiltonians for different configurations allows us to calculate the density of states of the system as well as the Green's functions. We can then test the analytic theories with the Monte Carlo data.

At very low densities, there is large discrepancy between the density of states determined by the two methods. This is not unexpected since the theory is for the licjuid state. There is better agreement at higher densities, but more work needs to be done. We are in the process of generating the Green's functions.

\title{
Molecular Kinetics and 'Transport
}

\author{
A. I. Nichols, III \\ D. I. Calef
}

\section{Overview}

The objective of this project is to understand the hehavior of molecules under highpressure conditions. Since molecules undergoing a reaction are not spherical, we have heen studying non-spherical molecules. Thus far, we have studied hard-core linear molecules both as a solvent and as a solute undergoing bond stretching. Our goal this year is to extend our previous work, both by using more realistic potentials and by reducing the number of symmetry reguirements so that we can study molecules of interest to the explosives eommunity (e.g., nitromethane and 'TA'T'B).

\section{Progress}

We finished the paper on linear triatomic dipolar fludes. In addition, we studied the solvation of a lincar triatomic dipolar molecule in a fluid of linear triatomic molecules as a function of bond length.

As an initial study of molecules with non-hard core repulsions, we cokled and implemented a test case of a Stockmayer molecule, It is a spherical Lennard Jones potential with a point dipole embeded in the core. We were able to achieve very high densities without trouble. Thus, we have begun calculations on realistic fludes. In particular, we have begun looking at acelonitrile, which has been computationally modeled as three I ennard-Jones spheres with electrostatic: interactions. This should conable us to compare 
our calculations with the Monte Carlo work of Jorgenson |Ref. EM-6|. The resulting correlation functions from our calculation will be used in our solvation dynamics theory to be, again, the first realistic fluid modeled. We have seen the expected lack of convergence of our calculation as we increase the density from gas phase through the low-density metastable region of the phase diagram.

We have also made significant progress in developing a code that will deal with even more realistic fluids (e.g., those without linear symmetry). We have limited ourselves at this time to those systems that have a plane of symmetry. This avoids mathematical complexity, yet allows us to model such fluids as $\mathrm{H}_{2} \mathrm{O}$, nitromethane, $\mathrm{NH}_{3}$, benzene, and even TATB! There remain a few details to be worked out and some straightforward coding chores to be done.

Another important part of our effort has been in the area of transport coefficients for mixtures of molecular fluids. This is intended to give us a handle on, for example, the rates of diffusion in binary, mixed-fluid explosives. We have modified the CHEQ code to allow us to extract the reference hard-sphere properties underlying its thermodynamic calculation. We have also fit the molecular dynamics data for diffusion in hard-sphere fluids. This, combined with an estimate of an effective mass, should allow us to estimate diffusion rates.

\title{
High-Pressure Reaction Chemistry
}

\author{
M. F. Foltz
}

\section{Overview}

The first half of $\mathrm{FY} 9()$ has been productive in running both experiments and a complementary model ng effort. Equipment was set up in a new functioning laboratory, and burn-rate experiments were resumed that successfully duplicated earlier work in a different laboratory. Higher-pressure deflagration data than previously obtained were accuired for nitromethane $\left(\mathrm{CH}_{3} \mathrm{NO}_{2}\right)$, which unequivocally confirmed the burn-rate turnover with pressure. Attempts to theoretically understand this phenomenon progressed from one-dimensional to two-dimensional modeling. The effect on burn-front propagation as a function of different bulk thermal and chemical kinetic properties was studied. A set of new experiments, dispersed streaked chemiluminescence (DISC) of laser-ignited $\mathrm{CH}_{3} \mathrm{NO}_{2}$, was started with promising initial results. The previous modeling results are being compared to and refined by these new spectral/temperature measurements.

\section{Progress}

Flame-front propagation rates for $\mathrm{CH}_{3} \mathrm{NO}_{2}$ for pressures up to $4($ ).8 (iPa (greater than the 30.0) (SPa attained for FY89) in the diamond anvil cell (DAC) have been measured. These measurements corroborate the trend mapped out earlier of an initial increase in burn rate followed by a decrease with increasing pressure. The bum rate for nitromethane appears to maximize around 30.() GPa (Fig. l:M-4). This behavior would appear to reflect a 
decrease in chemical reactivity with an increase in density above a maximum threshold value. At the same time, the thermal properties (e.g., thermal conductivity) of both the reactive material and products scale with pressure to act simultaneously with chemical reactivity in slowing the propagation of the burn front. This new technique will be used to examine other energetic materials in an attempt to better understand reactive-bum propagation in a confined environment.

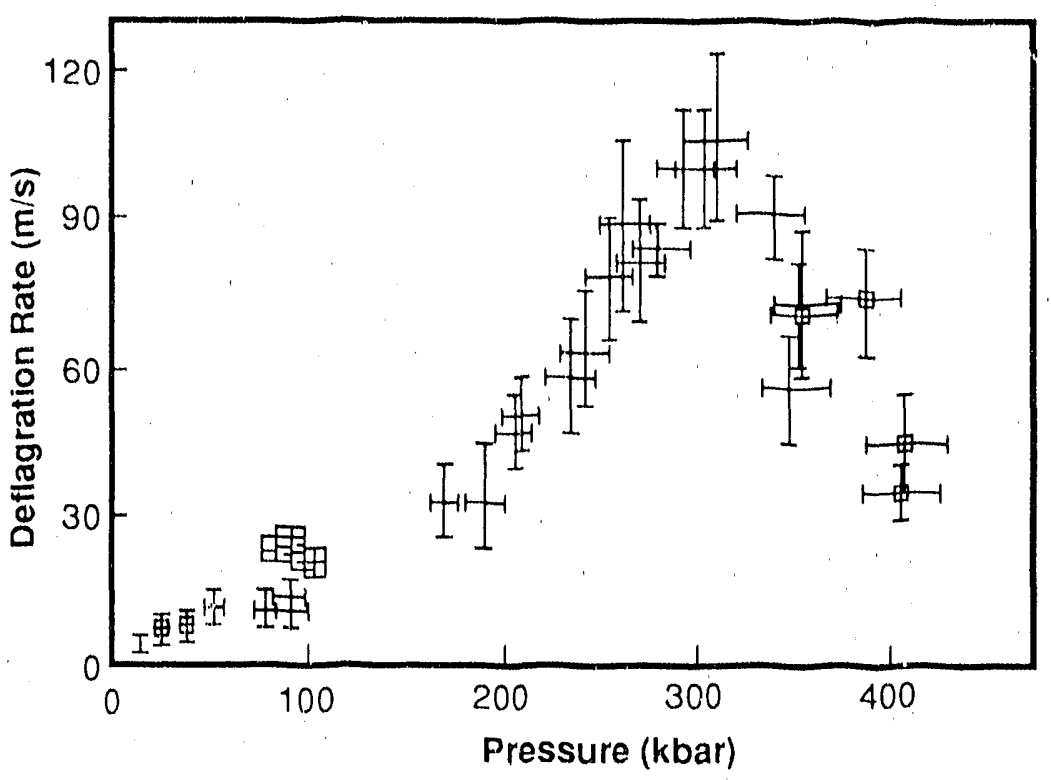

Fig. EM-4. Burn rate as a function of pressure for laser-ignited nitromethane in a diamond anvil cell (DAC). Progressively darker product is produced for pressures up to about 20 GPa, starting with oily, chear product at the lowest pressures. Above 20 GP produced. Some new data poinls taken in the first six months of FY9() and after the new laturatory was set up are marked with @. The turnover in deflagration rate above a threshold of 30) GPa is corroborated by these new points.

TOPAZCHEM, a version of the finite-element heat-flow code TOPAZ, has been modiiied by $A$. Nichols to incorporate up to 40 chemical reactions. The choice of a simple reaction scheme and Arrhenius kinetics coupled with a high ignition temperature results in a self-propagating flame front. Variation of material (density), bulk thermal (thermal conductivity, heat capacity), and molecular kinetic (pre-exponential factor, activation energy, ignition temperature) properties causes the burn to go from self-extinguishing to rapid propagation. A $16 \%$ decrease in activation energy translates to a difference between an extinguished reaction and a sustained burn rate of $24 \mathrm{~m} / \mathrm{s}$. The observed variation in burn rates can thus be shown to be related to the chemistry of the reacting material. Two-dimensional modeling results using TOPAZCHEM produces propagating burn fronts using parameter values comparable to those of the one-dimensional model. The $67 \mathrm{~m} / \mathrm{s}$ burn front represented by the temperature contour plot of Fig. EM-5 is within the velocity range measured for nitromethane under moderate pressure ( 25 GPa, Fig. EM-4). The example, a $10 \%$ increase in activation energy for 10 - and 20 - $\mu$ m-thick samples shows 
decrease in burn rate for both samples. The greater decrease, however, oceurred with the thinner sample. This effect can be traced to the thermal conductivity of the confining diamond anvils, which is orders of magnitude greater than that of the reacting nitromethane. The contribution of the bulk themal properties of the enviromment surrounding the energetic material is clearly shown to play an integral part in controlling the rate of reaction.

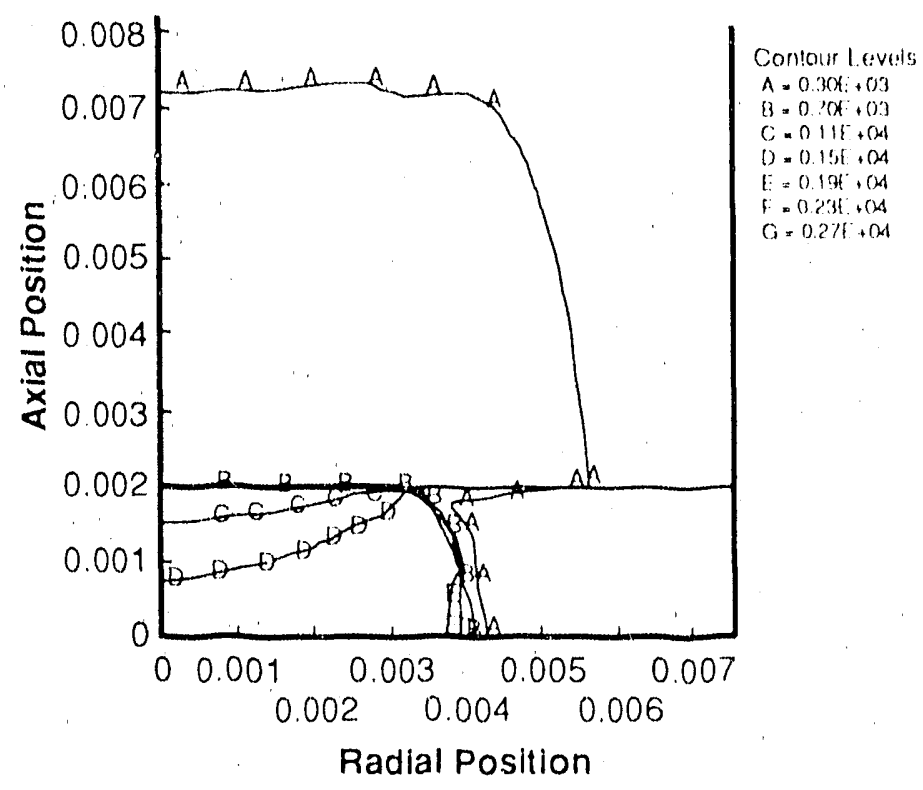

Fig. EM-5. Temperature contour plot at time $1=0.85 \mu$ s that was generated with TOPALCHI:M using simple. Arrhenius parameters to produce a propagating burn iront. Shown is one quarter of the radially symmetric $\mathrm{CH}_{3} \mathrm{NO}_{2}$ and diamond problem. The thickness is $20 \mu \mathrm{m}$ (radius $7.5 \mu m$, emulating the experimental arrangement. The zone size is one $\mu \mathrm{m}$, the igrition temperature $1.5(x) \mathrm{K}$, the logarithm of the pre-exponential factor 32 , and the activation energy $2.1 \times 10^{4} \mathrm{~K}$. The thermal conductivity of the diamend is high enough to produce "pre-heating" helore the burn front and a significant reduction in provluct comperature behind the front. The hotlest part of the burn zone is subsequently in the center of the sample.

The most recent experimental effort has been in the temporal and spectral resolution of light emitted during the laser-ignited burn of nitromethane in the DAC. The light emilled from the entire sample cross section is dispersed with a low-resolution spectrometer, the visible spectrum is imaged on the slits of a streak camera, and the temporally streaked image is saved digitally with a vidicon. Preliminary low-pressure data show no spectral features identifiable with known/suspected intermediate or product species. In this low. pressure regime $(<20$ GPa), dark product is produced, and the corresponding spectral information suggests a convolution of temperatures. The data can then be coupled to the tirne-dependent temperature contours generated in the previous modeling effort with TOPAZCHEM. Spectral emittance is calculated at each time step using Planck's equation. A simple model assumes that: 1) all chemiluminescence is emitted from the outermost latyer of reacting nitromethane and 2) emittance is unity for reacted material (black carbonaceous deposit for low-pressure ignition) and near zero for starting matterial (polycrystalline clear). 
It is expected that the spectral data resulting from laser-ignition of $\mathrm{CH}_{3} \mathrm{NO}_{2}$ under pressures $>20 \mathrm{GPa}$ and producing clear product will be very different than the preliminary data seen at low pressure producing black product. New data should provide information concerning the reaction pathway branching seen as a function of pressure. 


\section{Characterization of Solid-State Microstructures in High Explosives by Synchrotron X-ray Tomography}

W. C. Tao

C. E. Clements

\section{Overview}

It has been suggested that the microstructural discontinuities in energetic materials serve as sites for local hydrodynamic heating and result in the formation of "hot spots"; it has also been suggested that the rates of coalescence, dissipation, and propagation of these thermal sites are the primary factors determining the initiation sensiti vity of condensed energetic formulations. The objectives of this research are (1) to characterize nondestructively the type and distribution of microstructural defects in high-explosive single crystals and composite formulation and (2) to examine their respective influences on hotspot generation and propagation.

\section{Progress}

We have successfully applied non-invasive techniques to characterizing the detailed microstructures in HMX single crystals, in a composite formulation consisting of fuel (RDX, NG/TA), oxidizer $\left(\mathrm{NaNO}_{3}\right)$, and in metallic additives (aluminum) using a conventional $x$-ray source coupled with the analytical software and data accuisition hardware developed for 3D microtomography (1()- $\mu \mathrm{m}$ spatial resolution). No microstructural features were observed in the HMX single crystal with tomography, which leads us to conclude that no de fects larger than $10 \mu \mathrm{m}$ were present. Higher spatial resolution can be achieved in future studies by using either synchrotron radiation or the new microfocus $x$-ray source with appropriate $x$-ray filters to remove unwanted radiation.

The composite formulation examined was supposedly nonporous with $5-\mu \mathrm{m}$ aluminum dispersed evenly throughout the matrix. From our tomography study, we found the aluminum to be inhomogeneously dispersed in clusters approximately $50 \mu \mathrm{m}$ in size. Some porosity, nominally $5 \%$, was also observed. To further test our experimental capability, we designed a phantom matrix using the $x$-ray absorption coefficients for HMX, with a complex integration of defect structures (pores, aluminum, orthogonal microcracks, density gradients), and subjected this phantom for 3D tomography analysis. Using a well characterized synchrotron beam profile and the radiometric deconvolution technicues of our analytical sof ware, we were able to reproduce the image of the phantom with mimimal loss in structural resolution.

The next research phase involves studying the correlation between microstructural defects and hot-spot formation. The experimental method employed in this phase of the research involves ultraf ast microphotography. Coupled with both streak and frame cameras, ultrafast microphotography allows us to examine a single erystal under shock loading with spatial and temporal resolutions of $1 \mu \mathrm{m}$ and $1 \mathrm{~ns}$, respectively. Using the laser microphotography facility in cooperation with A. Frank from B Division, we have been able to observe the passage of a shexk wave, generated by a microstapper against the 
surface of the crystal, through the defect mapped region. The optical emission from the collapse of the voids within the defect region as the stress wave passes is measured under cross polarization. These results are to be presented in the SPIE Conference at San Diego in July 1990 .

\title{
New Approaches to HE-Initiation Chemistry
}

\author{
C. Stevens I. Stephens
}

\section{Overview}

We are exploring a new approach to the understanding of the initial reaction steps in the shock-induced chemistry of condensed-phase explosive molecules. The need to obtain a clear understanding of the first chemical events, let alone a step-by-step description of the path to detonation, has presented a particularly difficult challenge and has largely resisted penetration. New approaches using sub-picosecond lasers for initiation and interrogation have been proposed and implemented. However, spectral congestion and generai opacity problems due to low concentrations of intermediate species have all combined to limit the quality of the information obtained or obtainable.

In order to circumvent the problems associated with rnonitoring chemical pathways inside condensed media, we are exploring an approach that allows us to diagnose the chemistry by vapor phase mass spectrometry and, simultaneously, to exercise control of shock-wave amplitude and adjust time-of-reaction from sub-picosecond to microseconds.

\section{Progress}

The general approach involves a suitable substrate (capable of propagating highintensity shock waves) that is located in a high-vacuum chamber. The substrate is cooled to cryogenic temperatures $(10$ to $20 \mathrm{~K}$ ) and coated with a condensed layer of a rare gas. This is followed by a molecular-beam-deposited layer of explosive molecules. This layer will vary from sub-monolayer thickness to many layers. The explosive layer is then followed by an additional layer of rare gas. The shock wave passes through the substrate and initial rare-gas layer into the HE layer, compressing the explosives. After the shock wave has passed through the second rare-gas layer to the vacuum interface, the resulting rarefaction wave vaporizes the rare gas and explosives into the vacuum and (ultimately) into a mass spectrometer. The thickness of the outer rare-gas layer thus determines the amount of time the explosives are kept snder pressure.

We investigated several potential technologies for producing short-duration stress pulses including lasers, electric or foil explosion guns, and magnetic foil accelerators. We have chosen to adapt an existing magnetic foil accelerator to meet our requirements. It is necessary to achieve 10-(jPa in the explosive layer in order to ensure that substantial chemistry occurs. In order to calculate the pressures achievable in various materials, we have developed a software package for the Macintosh computer utilizing Hugoniot data to propagate shock waves through material composites. 
A significant problem became obvious early on in the propagation analys::: Blastic: precursor waves traveling faster than the main shock wave compress and release the HE layers before the desired amplitude wave arrives at the surface. For high-intensity shock experiments, this has forced the consideration of substrates having either very high elast:c limits (>10 GPa) or very low elastic limits such that the desired shock waves in the 1()-GPa range override them. Finally, we are constrained to consider materials that have a reasonable shock-impedance match with the condensed rare-gas/HE/rare-gas composite to provide good shock transmission. Suitable materials meeting these constraints are alkali halide salts for high elastic precursor amplitudes and tough plastics such as polycarbonates for easily overridden precursors. The optimum alkali halide substrates are $\mathrm{KCl}$ and $\mathrm{KBr}$, with shock transmission into condensed argon calculated to be $82 \%$ and $71 \%$, respectively.

We have conducted some preliminary experiments using the existing magnetic accelerator to drive copper flyer plates onto $\mathrm{KBr}$ and polycarbonate substrates. Our interest here is in the spall properties of these materials. As expected, the KBr disintegrated into small particles at shock pressures near $5 \mathrm{GPa}$, whereas polycarbonate resisted spall at these pressures. The $\mathrm{KBr}$ fragments carried little of the forward momentum from the shock and were captured by a thin paper tissue. A collimated metal nole structure should allow the passage of molecular species while capturing most of the substrate debis. The ultimate spall limit for polycarbonate will be ascertained with a modified magnetic accelerator.

Another series of experiments has examined the limits of magnetic field acceleration of thin copper foils. By cooling the copper flyer to cryogenir temperatures, we improve conductivity by more than two orders of magnitude. The heat capacity also drops, but by a much smaller factor than does the resistivity, which results in a net improvement in currentcarrying capacity of a factor of 50. The limit then becomes the ability of the foil to maintain flatness while under magnetic field compression during flight.

Some amount of time was spent in the development of a Moire fringe velocimeter to provide a simple, portable velocity-measuring device to free us from the complex and troublesome existing VISAR system. Electrical noise contamination has so far prevented good measurement of flyer velocities. However, higher (but unknown) velocity acceleration experiments were conducted in the $1 \mathrm{~km} / \mathrm{s}$ to $1.5 \mathrm{~km} / \mathrm{s}$ range by decreasing the copper flyer width by a factor of 2 , thereby increasing the magnetic field strength by as much as 4 . The thicker flyer foil (same cross-sectional area) was slightly crumpled but did maintain reasonable flatness. For generation of precisely planar shocks, we may need tougher metal flyer foils. With operation at cryogenic temperature, the conductivities of a number of tough metals are sufficiently high for this purpose.

Experiments using an indirect-drive copper flyer will allow repetitive shocks using the same flyer. This capability will enable us to perform a large number of preliminary experiments without opening the vacuum system to replace the flyer. Several designs are being tested to deternine which is the most durable. 


\section{References}

En-1. M. S. Pevzner, T. N. Kulibabina, N. A. Povarova, and L. V. Kilina, Khim. (ieterotsiklich. Soedin, 929)(1979), Engl.

EN1.2. L. I. Bagal, M. S. Pevzner, A. P. Figorov, and V. A. Samarento, Khim. Geterotsiklich. Soedin 6, 928 (1970).

EM-3. L. Grehn and U. Ragnarsson, Angew. Chem. Imt. Ead. Engl. 24, 510 (1985).

ENI.4. E. J. Browne, Aust. J. Chem. 22, 2251 (1969).

EN-5, T. Witkowski, and R. K. Robins, J. Org. Chem. 35, 26.35 (197()).

EN-6. W. L. Jorgensen and J. M. Briggs, Molec. Phys. 63, 547 (1988).

\section{Publications}

D. F. Calef and A. L. Nichols III, "Structure and Thermodynamics of Asymmetric Molecules: Application to Linear 'Triatomic Dipolar Molecules," accepted for publication in Molecular Physics.

\section{Presentations}

A. R. Mitchell, P. F. Pagoria, and C. L. Coon, "Synthesis, Characterization and Scale-up of 2-(oxo)-1,3,5-trinitro-1,3,5-triazacyclohexane (K-6)," presented at Energetic Oxidizers Workshop, Naval Weapon Center, China Lake, Calif, Dec. 11, 1989.

R. Mitchell, P. F. Pagoria, and C. I. Coon, "Synthesis, Scale-up and Characterization of" K-6," presented all Technology Coordination Group lll Review, Naval Weapon Center, Chima Lake, Calif, Mar. 6, 1990).

A. 1. Nichols III and D. F. Calef, "The Effect of Molecular Solvation on Bond Breaking." presented at the March 19y) Mecting of the American Physical Society.

S. I'. Rice and M. F. Foltz, "I ligh Pressure Burn Rate Studies in a Diamond Anvil Cell," presented at lligh Energy Density Matterials Contractors Meeding, Long Beach, Calif, Feb, 26-28, 190(). 


\section{TRITIUM}
P. C. Souers
G. W'. Collins
J. L. Maienschein
E. R. Mapoles

\section{Nuclear Spin Polarization}

\section{Deuteron Magnetic Resonance}

The deuteron's longitudinal relaxation time, $\mathrm{T}_{1 \mathrm{D}}$, in solid D-T (actually $25 \%, \mathrm{D}_{2}-5() \%$ DT-25\% $\mathrm{T}_{2}$ ) was measured at nuclear magnetic resonance (NMR) frequencies of 5.8 to 7.0 $\mathrm{MHz}$. The data are shown for a sample at $5 \mathrm{~K}$ in Fig. T-1 as a function of the percent of $\mathrm{J}=1 \mathrm{D}_{2}$ and compared with $\mathrm{D}$ in HD data taken by Mano and Honig |Ref. T-1). There is a large discrepancy, which indicates the presence of a new mechanism lowering the relaxation time of the deuteron.

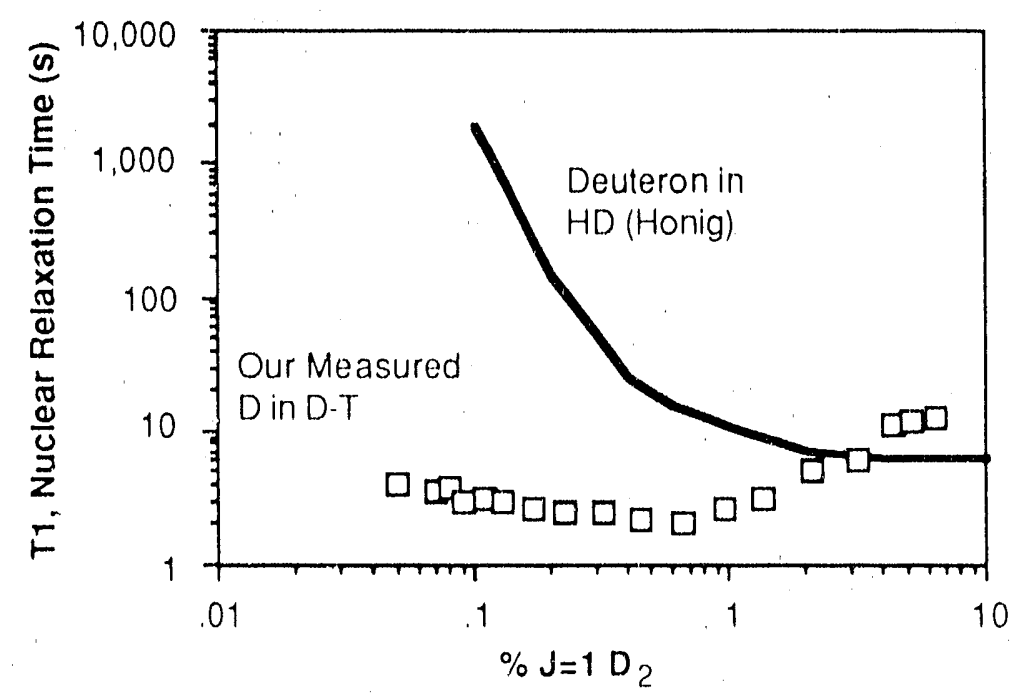

Fig. T.1. Longitudinal nuclear relaxation lime for the deuteron in solid D) T at $5 \mathrm{~K}$ (syuares) and in $\mathrm{HL}$ )

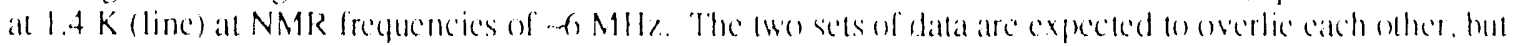

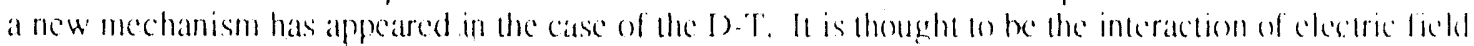

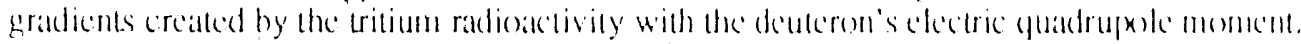

The conventional caluse of nuclear relaxation in solid hydrogen is the electric quadrupole $(\mathrm{F} Q Q \mathrm{Q})$ mechanism. This is a short circuit of nuclear magnetic energy mongeh the molecular rotation. For D in D.'T, we would have expected the laQ(e) relation:

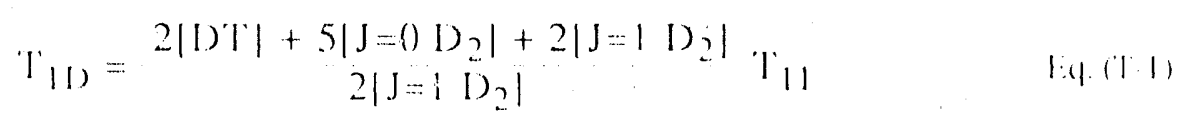


where the quantities in brackets are mol fractions and $\mathrm{T}_{11}$ is an inherent relaxation time. Also, $J$ is the molecular rotational quantum number. Equation ( $\mathrm{T}-1$ ) works for both protons and tritons in HD and D-T. By wating for the $J=1 D_{2}$ to be catalyzed away to about $0.1 \%, \mathrm{Eq}$. ( $\mathrm{T}-1$ ) would predict a $\mathrm{T}_{1 \mathrm{D}}$ of 20 to $30 \mathrm{~s}$. Instead, we obtain about $2 \mathrm{~s}$ at the lowest $J=1$ concentrations. Thus, Ec. (T-1) fails for the deuteron in solid D-T.

The likely new mechanism is the interaction of the first derivative of an electric ficld with the nuclear quadrupole moment of the deuteron. The electric field is probably caused by defects created by the tritium radioactivity. This interaction is strong enough to widen the deuteron's NMR halfwidth from $1(0)$ to $10(0) \mathrm{Hz}$. Using a (distance - $^{-3}$ dependence, one cin estimate an electric field gradient of up to $10^{9} \mathrm{~V} / \mathrm{m}$ across the deuteron. A mixture of field gradient strengths results in a single deuteron resonance with no separate peaks.

"This unexpected new source of relaxation is anfortunate for nuclear spin relaxation, for which long nuclear relaxation times are required. We had earlier expected a long deuteron time because of the small magnetic monent of the nucleus; however, this mechanism is electrical in nature. Our theoretician at Washington University predicts that $T_{11}$ will be proportional to the square of the NMR frequency. We plan to rerun with a superconducting magnet in check this prediction. If true, we could be forced to do the polarization at a magnetic field higher than the 3.3.5-T field previously planned.

\section{Optical View of Therma! Spiking}

We have previously described the thermal spike found in solid D-T and $\mathrm{T}_{2}$ below about $3 \mathrm{~K}$. We know from electron-spin resonance that hundreds to a thousand parts per million of hydrogen atoms are created by the tritium radioactivity. Something (e.g., a sudden small temperature rise) causes the atoms to recombine cooperatively in a spectacular event that causes the cryostat cell to rise $5 \mathrm{~K}$ in temperature. The atoms have vanished as a result.

We have now seen visual optical evidence of the atomic recombination, as shown for a solid D-T sample at $2.4 \mathrm{~K}$ in Fig. T-2. The millisecond speed of the event is apparent. The D-T was on the walls of a transparent, hollow sapphire ball. The sample was given at least ten minutes to build up a high atom density. The cell was then pulsed with an electrically driven heat pulse to start the thermal spike. A photodiode with filters was used to detect the light. The sample in Fig. T-2 showed $<10 \%$ of the light intensity below $710 \mathrm{~nm}$ and $5(1 \%$ above $780 \mathrm{~nm}$. An obvious ruby peak at $694 \mathrm{~nm}$ caught our attention early on but turns out to be of little importance in the final analysis. The caluse of the fluorescence is unknown, but we may speculate that it is related to the known "F-center" resonance in solid hydrogen at about $18(X) \mathrm{nm} \mid \mathrm{Ref}$. T-2|. We estimate that $\sim 0.1 \%$ of the total recombination energy is appearing in the emitted light.

The sample cell was also studied at higher temperatures. The light intensity drops by a factor of $\sim 10()$ as we heat from 2.4 to $4.0 \mathrm{~K}$. The period of the light spike increases by the same amount so that the area under the light output curve is constant. The atom density is known to be several hundred ppm in this temperature range. At $7 \mathrm{~K}$, the light intensity 
dramatically drops and bottoms at a low value of about $10 \mathrm{~K}$. This corresponds to the decrease in atom concentration seen in electron-spin resonance.

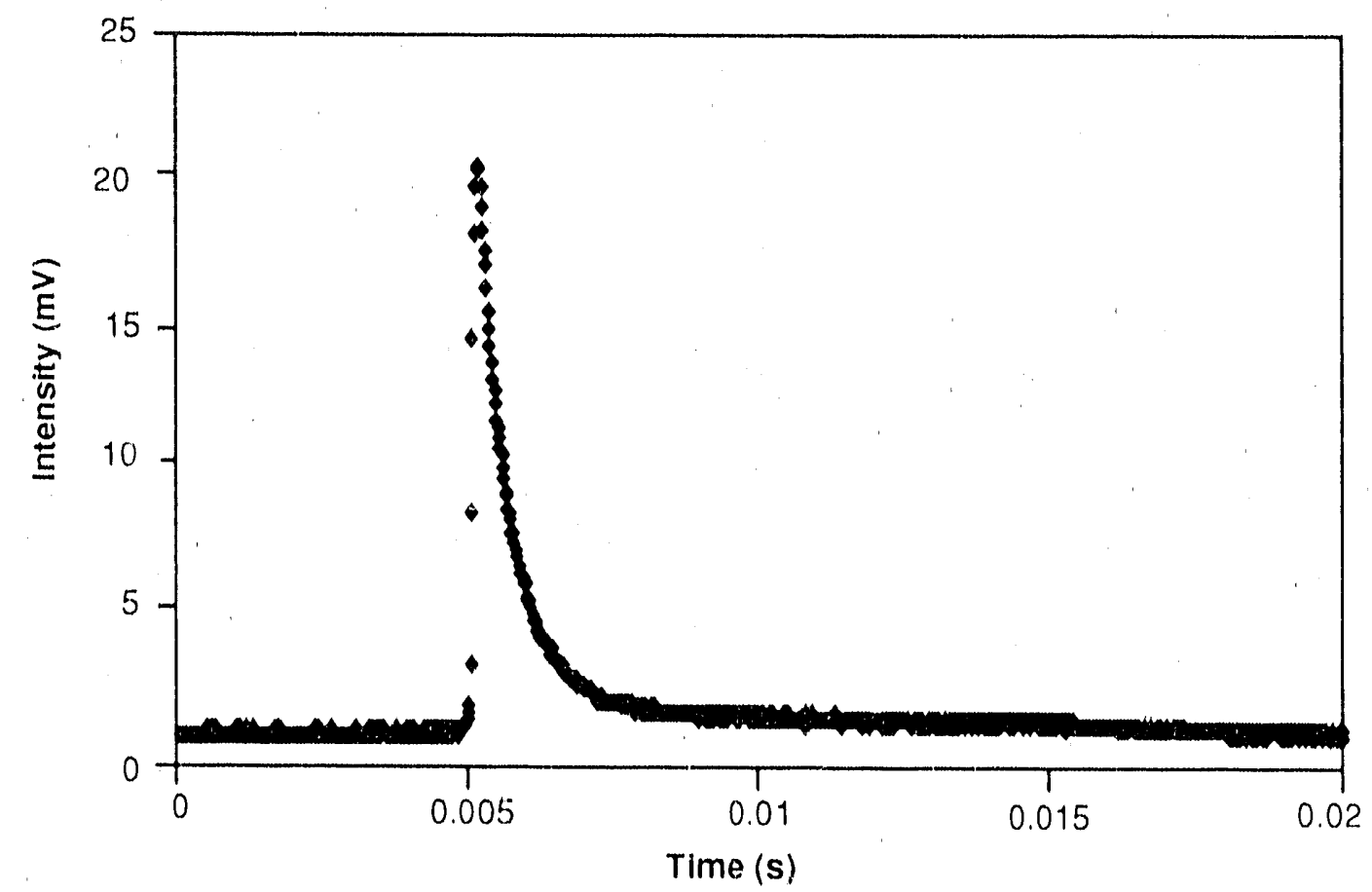

Fig. T-2. Intensity of light emitted from solid D-T' at $2.4 \mathrm{~K}$ as a result of atomic recombination. More than hall the light is in the infrared at wavelengths longer than $780 \mathrm{~nm}$.

We also noted that the thermal spikes physically moved the D-T sample around the inside of the sapphire cell. This provides the exciting possibility of a low-temperature way to uniformly layer solid D-T on the inside of a laser fusion target. This technique, called "beta layering" by the target makers, has previously only worked for the solid just below the triple point.

\section{Tritium in Mercury}

As a part of the ongoing environmental activities, we measured the tritium in $6(x) \mathrm{kg}$ (2.5 years' worth) of mercury used in Sprengel pumps in the LLNL tritium facility. The slag and the remaining filtered mercury were counted following dissolution into nitric acid. A second method of redissolving the tritium into glycol was also used as a check. The filtered mercury was found to possess a low activity of 2 to $16 \mu \mathrm{Ci} / \mathrm{kg}$, which confirms that hydrogen is not very soluble in mercury. The residue was much higher at 0.2 to $5 \mathrm{Ci} / \mathrm{kg}$. It was composed of about $1 / 3$ mercurous oxide and $2 / 3$ elemental mercury. 


\section{Search for Cold Fusion*}

We reproduced the Frascati experiments, which reported bursts of neutrons from comperature-cycled palladium and titanium with a deuterium overpressure. We ran HiD and D-T as well as $D_{2}$, up to 50 atmospheres, with temperature cycling, hetween room comperature and $77 \mathrm{~K}$. Pilot $\mathrm{U}$ scintillation counters in coincidence were used, along with a LeCroy digital oscilloscope capable of $2.5 \mu \mathrm{s} / \mathrm{channel}$. After much redesign, our equipment could detect bursts of up to $10(1) \mu s$ with $5(0$ or more neutrons. Many false "neutron" signals were seen, from liguid nitrogen spilled on one counter to unexpected cosmic-ray bursts coming from lead bricks used early in the work. Many types of metal samples were used, and they were cyeled in every conceivable waly.

As the result of 1.50$)$ hours of ohservation, no cold-fusion neutrons were seen, either in bursts at the time of temperature cycling or in steridy state. The complete study has been accepted for publication in The Phssical Review.

\section{References}

T'- 1. H. Mano, Proton and Deuteron Spin Relavation in Solid Hydrogen-Denteride at Temperatures hetween 0.4 and $4.2 \mathrm{~K}$, Ph.D. thesis, Syracuse University (University Microfilms, Ann Arbor, MI 48106, 1978). A. Honig was the thesis supervisor.

T-2. P. C. Soucrs, Hydrogen Properties for Fusion Energy (University of California Press, Berkeley, 1986), p. 289.

\section{Publications}

B. Balke, L. Cox, (). Fackler, M. Mugge, P. C. Souers, R. T. Tsugawa, and R. M. White, "Limits on Neutron Emission from "Cold Fusion' in Metal Hydrides,"

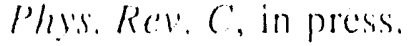

P. IE. Barry, J. S. Bowers, R. G. Garza, P. C. Souers, J. S. Cantrell, and T. Beiter, "Reaction of Lill and Bel I2," I. Nucl. Mater., in press.

G. W. Collins, P. C. Souers, E. M. Fearon, E. R. Mapoles, R. 'T. 'T'sugawa, and J. R. Cianes, "Themal Conductivity of Condensed D-T' and T2," Physs. Rev. I3 41, $1816(190)(1)$.

(i. W. Collins, B. M. Fearon, J. L. Malenschein, E. R. Mapoles, R. T. Tsugawa, P. C. Soncrs, and J. R. Caines, "lriggered Energy Releases in Solid Hydrogen

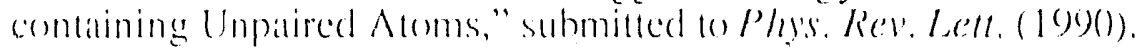

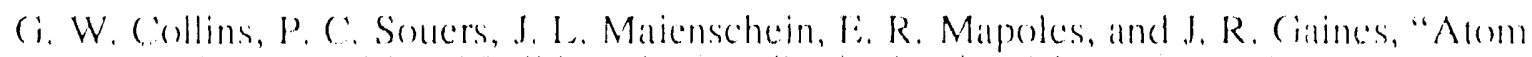

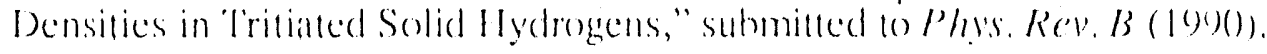

J. L. Maicnschein, P. L. Barry, L. Mc Murphy, and J. Bowers, "Syndhesis and Propertices of a low Densily, Iligh Porosity L ithium Hydride Beryllium Hydride linam," Mater. Sici. ling... in press.

\footnotetext{
"With B. Balke, L. Con, O. Farkler, M. Mugser, and R. White of Physics.
} 
E. R. Mapoles, F. Magnotta, G. W. Collins, and P. C. Souers, "Optical Activity in Tritiated Solid Hydrogen," Phys. Rev. B, in press.

P. C. Souers, C. L. Folkers, T. McCreary, R. O. Lindahl, G. D. Snider, F. Vanderhoofven, and R. T. Tsugawa, "Swelling of Tritiated Lithium Hydride Powder," J. Nucl. Mater, in press.

P. C. Souers, E. M. Fearon, J. D. Sater, E. R. Mapoles, J. R. Gaines, and P. A. Fedders, "NMR of D-T Adsorbed onto Silica Aerogel," submitted to J. Vac. Sci. Techincl. A (1990).

R. T. Tsugawa, J. S. Bowers, J. A. Emig, R. S. Hafner, J. L., Maienschein, and A. S. Nicolosi, "Determination of Tritium in Mercury from Sprengel Pumps," J. Nucl. Mater., in press. 


\title{
HIGH-TRANSITION-TEMPERATURE SUPERCONDUCTIVITY*
}

\author{
M. Fluss (Thrus! Area Leader)
}

\section{Overview}

The LLNL effort in high-temperature superconductivity is focused on fundamental questions concerning:

- The nature of the nigh-transition-temperature (high- ${ }^{-} \mathrm{T}_{\mathrm{c}}$ ) superconducting materials.

- The synthesis and characterization of high-quality single crystals, and experimental and theretical studies of their electronic structure.

- The role of magnetism, phonons, and plasmons.

This year, we nave added efforts more closely related to the application (technology) of high- $\mathrm{T}_{\mathrm{c}}$ materials that have developed from our fundamental research. Accomplishments for this period are highlighted by:

- Incorporation of advanced crystal-growing and synthesis capabilities.

- Our successful entry into studies of core-exc1tations with x-ray photoelectron spectroscopy (XPS) at LLNL, with conduction electron studies with photoemission spectroscopy (PES) at the Wisconsin ALADDIN synchrotron.

- Development of a theory linking positron lifetime results to electron properties of high- $\mathrm{T}_{\mathrm{c}}$ superconductors, which may lead to precise measurements of the temperature dependence of the superconducting gap.

- Continued progress in developing processing technologies that may lead to useful electronic device applications.

The thrust has contributed toward growth and improvement in the materials science capabilities at LLNL. Our low-temperature-physics laboratory is used by alloy and laser programs at LLNL, and the new $x$-ray diffraction facilities and ion-beam (RBS) end station will also contribute to the benefit of more programs than just the high- $T_{c}$ area. The laser ablation facility, in addition to providing high-quality thin-film samples of high- $\mathrm{T}_{\mathrm{c}}$ materials, is also being used to engineer substrates for the physical imaging of DNA and other organic molecules. Our increasing capabilities in photoelectron spectroscopy using synchrotron light is a direct consequence of the initiative generated from the needs of our electron-structure studies of the high- $\mathrm{T}_{\mathrm{c}}$ materials.

The program has assisted in attracting new career scientists in synchrotron radiation, surface science, and solid-state chemistry. Six graduate students are currently working towards their degrees under the auspices of this effort; two others have obtained their doctorates. Six post-docs have worked, or are now working, under this program; one of them has become a permanent career hire at LLNL, and one has taken a career position at

\footnotetext{
${ }^{*}$ Supported also by Departmental Institutional Research and Development.
} 
22

UCID-20622-9()-1

ORNL. Additionally, we continue to utilize this project to further university, sister lab, and industrial collaborations.

\section{Materials Synthesis and Transport Properties}
J.Z. Liu*
R. Shelton
B. Olsen

\section{Objectives}

Our major objectives are to produce high-quality single crystals and films of technologically and experimentally interesting variants of the high- $\mathrm{T}_{\mathrm{c}}$ materials. Both of these objectives have been realized, although our thin-film equipment is currently undergoing major improvements and is expected to be back on-line in early May of 1990.

\section{Accomplishments}

Our most noteworthy accomplishment during the past six months has been the development of the ability to remove twin defects ijy uniaxial compression applied to the high-temperature superconductor $\mathrm{YBa}_{2} \mathrm{Cu}_{3} \mathrm{O}_{7}$, in which twins are formed when samples are cooled from high temperatures to room temperature. A before-and-after example, accomplished on a high-quality $\mathrm{YBa}_{2} \mathrm{Cu}_{3} \mathrm{O}_{7}$ crystal, is shown in Fig. HT-1. The twins are visualized through the use of polarized light and are clearly seen to be removed in the process developed by us. This capability of removing twin defects is a key to further studies of the physics and chemistry of this compound.

Our $\mathrm{YBa}_{2} \mathrm{Cu}_{3} \mathrm{O}_{7}$ single crystals have smooth, highly reflective surfaces and fimensions as large as $4 .\left(0 \times 4.0 \times 0.1 \mathrm{~mm}^{3}\right.$, although the one shown in Fig. HT-1 is $1.5 \times 1.5 \times 0.1 \mathrm{~mm}^{3}$. Magnetization measurements indicate a transition temperature of $93 \mathrm{~K}$ with a transition width $<1 \mathrm{~K}$, representing a very high-quality sample. The Meissner effect and magnetic critical current density were measured on the same crystals before and after the detwinning.

Future work will include Pr-doped, oxygen-doped, and Br-doped variants of these crystals on which known effects from variations in the magnetic monient and charge, respectively, will be studied. In addition, a new study has been initiated with S. Moss, University of Houston, in which high-resolution x-ray studies will be performed on these materials above and below the critical temperature to search for structural and dynamical changes in the atomic configuration that may be associated with the high- $\mathrm{T}_{\mathrm{c}}$ mechanism.

\section{Electronic Structure Studies}

The electronic structure of the high- $\mathrm{T}_{\mathrm{c}}$ superconductors that physically is responsible for superconductivity (e.g., the doped carrier hole states) is still not understood. Experiments and theory aimed at obtaining an understanding of the electronic structure properties of the $n$-type and p-type high- $\mathrm{T}_{\mathrm{c}}$ materials are the objectives of this activity.

\footnotetext{
*University of California--Davis.
} 
Experimentally, we use positron annihilation, XPS, and photoemission. Our theoretical studies are exploring possibilities related to the existence of the unusual quasi-particles "anyons" and the theoretical integration of the conflicting properties of localization (molecular character) and itinerancy (metallic character), both of which are exhibited in these materials.

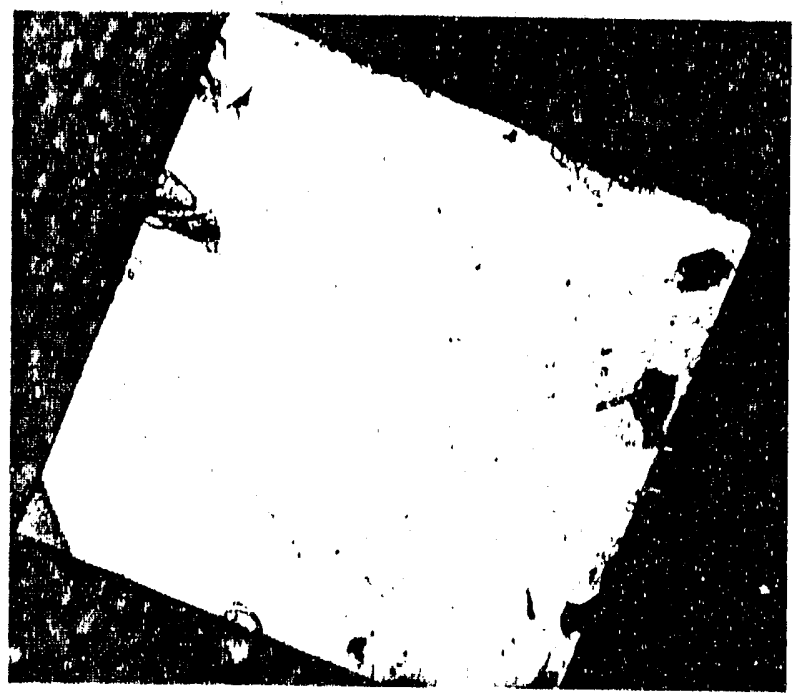

(a)

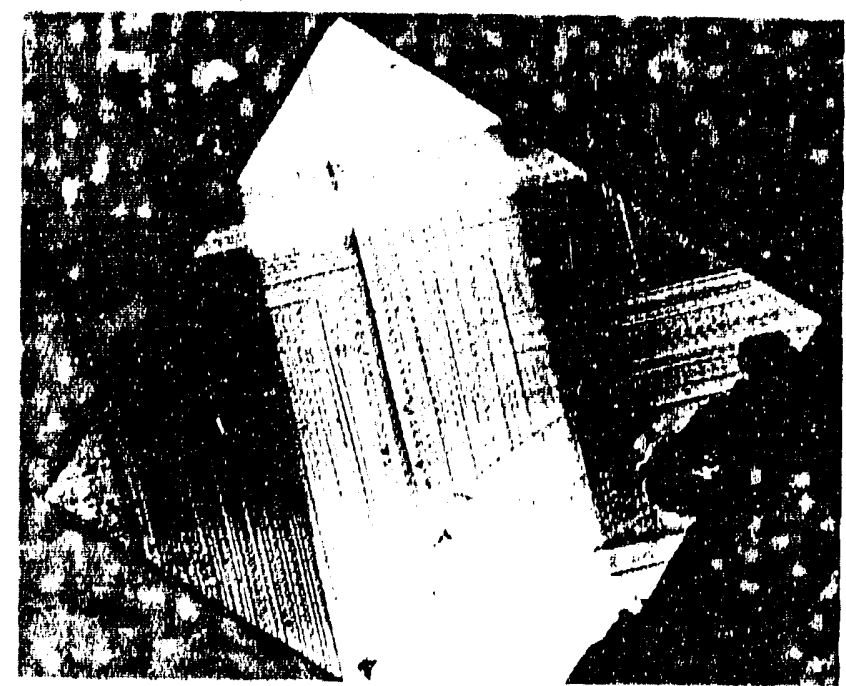

(b)

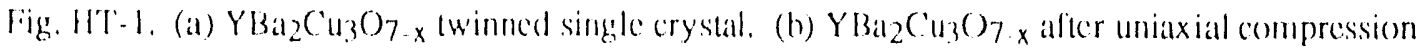
showing complete absence of ewinned planes. Our results show that, all low temperature, the twin boundaries are not the primary pinning eenters responsible for the high critical current densily observed in the copper-oxygen plane for thin-lilm configurations of this material. However, additional work carriced ont in collaboration with ANL oil the magnetizatien hysteresis of the salle crystal in the twinned and untwinned states reveals that pinning due to twinning planes contributes a substantial. anisolropic fraction of the observed critical currents. Removal of the twin planes alway's results in the reduction of the magnetization hysteresis; i.e., the twin planes are active pinning centers and not pathes of cassy flux motion. 


\section{Core and Valence Band XPS and UPS Spectra of $\mathrm{YBa}_{2} \mathrm{Cu}_{3} \mathrm{O}_{7-\mathrm{x}}$}

C. Colmenares

C. Evans

\author{
I. Z. Liu \\ R. L. Smith
}

P. A. Sterne:

\section{Objectives}

We have undertaken a study of the chemistry of the near-surface region of high- $\mathrm{T}_{\mathrm{c}}$. superconductors because of its importance to many physical probe techniques and its technological applications in electronics and high-frequency devices. Our short-term objective is to determine whether or not $\mathrm{YBa}_{2} \mathrm{Cu}_{3} \mathrm{O}_{7-x}(1-2-3)$ materials lose oxygen under vacuum at $300 \mathrm{~K}$, particularly with exposure to a photon flux, because recent work by Fowler et al. [Ref. HT-1] has shown that good quality single crystals cleaved in ultrahigh vacuum (UHV) at $3(0) \mathrm{K}$ do not lose oxygen. This is in marked contradiction to a rather large number of published papers, which purport that it is necessary to cool 1-2-3 specimens to $20 \mathrm{~K}$ to avoid oxygen loss.

We also want to determine the effect that oxygen stoichiometry has on the core and valence band spectra of $\mathrm{YBa}_{2} \mathrm{Cu}_{3} \mathrm{O}_{7-\mathrm{x}}$ and other superconductive materials. In the longer term, we will study the reaction of $\mathrm{O}_{2}, \mathrm{CO}_{2}$, and $\mathrm{H}_{2} \mathrm{O}$ with $\mathrm{YBa}_{2} \mathrm{Cu}_{3} \mathrm{O}_{7-x}$ as a function of exposure to better characterize the effect of air exposure on clean surfaces and its impact on technological applications. We will use $x$-ray and ultraviolet photoelectron spectroscopies (XPS and UPS, respectively) and high-resolution electron energy loss spectroscopy (HREELS) to carry out these measurements.

\section{Accomplishments}

Small $\left(2 \times 2 \mathrm{~mm}^{2}\right)$ single crystals of $\mathrm{YBa}_{2} \mathrm{Cu}_{3} \mathrm{O}_{6.7}$ and $\mathrm{YBa}_{2} \mathrm{Cu}_{3} \mathrm{O}_{6.9}$, with sharp superconducting transitions from 80 to $92 \mathrm{~K}$ (DT from $1 \mathrm{~K}$ to $15 \mathrm{~K}$ ) were studied using XPS with Mg Ka (1253.6 eV) radiation, and UPS with He I (21.2 eV) and He II (40.8 eV) radiations |Fig. HT-2|. The crystals were cleaved at $3(x) \mathrm{K}$ in UHV of $\sim 1 \times 10^{-1()}$ torr to produce clean surfaces, but air-cleaved surfaces were also used to study the effect of air contamination. The oxygen partial pressure in the vacuum chamber was monitored with a residual-gas analyzer (RGA), which was operated at very high sensitivity to detect possible oxygen loss of cleaved samples. We did not detect any measurable oxygen loss when cleaving 1-2-3 single crystals under UIVV at $30(0) \mathrm{K}$ or during prolonged storage (1 10 2 weeks) under these conditions. The partial pressure of oxygen measured with the RGA was $\sim .3 \times 10^{-13}$ torr at a total pressure of $1 \times 10^{-10}$ torr for vacuum-cleaved crystals; we feel this is part of the residual gases that contribute to the base pressure of the system. Y, Ba, $\mathrm{Cu}$, and $\mathrm{O}$ with traces of $\mathrm{C}$ were the only elements detected. The core levels for these elements, obtained by XPS, agree with those of Fowler et al. RRef. HT-11. In measurements laken in $\sim 1$ hour, no change was measurable in the above core levels. However, $x$-ray exposures longer than three hours resulted in complete reduction of $\mathrm{Cu}^{+2} \mathrm{to} \mathrm{Cu}^{+}\left(\mathrm{Cu}_{2}(\mathrm{O})\right.$ or Cu metal; it is also possible that the "green phase" of orthorhombic $\mathrm{Y}_{2} \mathrm{BaCuO}_{5}$ may have 


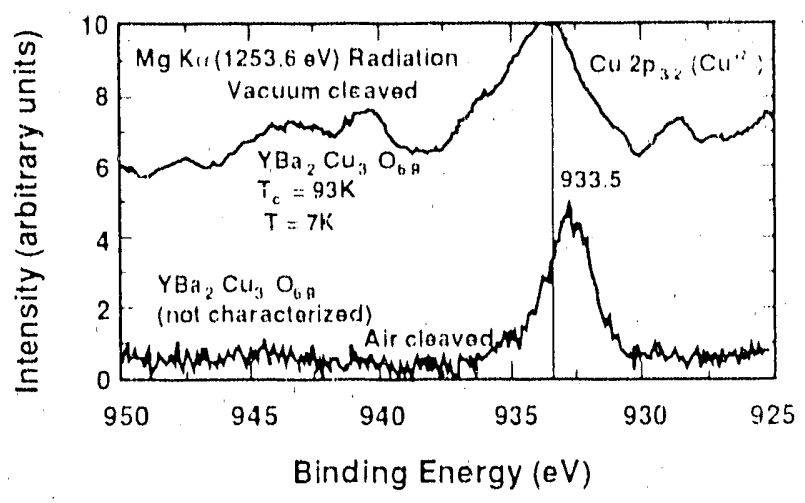

Fig. HT-2 The Cu $2 p_{3 / 2}$ level for valcum- and air-cleaved single crystals of $\mathrm{Y} \mathrm{Ba}_{2} \mathrm{Cu}_{3} \mathrm{O}_{6,9}$.

been formed |Red:HT-2|. This will be pursued further. There was no change on the $Y$ and Ba spectra. Crystals cleaved under altrahigh vacuum conditions have a relatively broad Cu 2p.3/2 (9.3.3.5 eV) core peak and a sillellite on the high-binding-energy side whose area is $\sim$ ).46 of the main peak (Fig. 11T-2), which agrees with the data of Fowler et al. This spectrum is practically identical to that of a sample of CuO. For crystals cleaved in air, the Cu 2p 3/2 peak is narrower and shifts to a lower binding energy (932.5 eV), as shown in Fig. 11T-3, which indicates a change in oxidation state. From these data and the x-raygenerated Auger peak at $-3,35 \mathrm{eV}$ ( $\mathrm{L}_{3} \mathrm{VV}$ transition), we have concluded that this peak consists of $\mathrm{CuO}$ and $\mathrm{Cu}_{2} \mathrm{O}$ or $\mathrm{Cu}$ metal. The $\mathrm{O}$ is kevel of the vacuum-cleaved superconductor shown in Fig. HT-3 is clearly at $528 \mathrm{eV}$, in agreement with Fowler's data. Exposure of the sample to air gets rid of this peak, and a very broad peak appears that can be deconvoluted into four components. These probably correspond to $\mathrm{Y}, \mathrm{Ba}$, and $\mathrm{Cu}$ oxides, hydroxides, and carbonates.

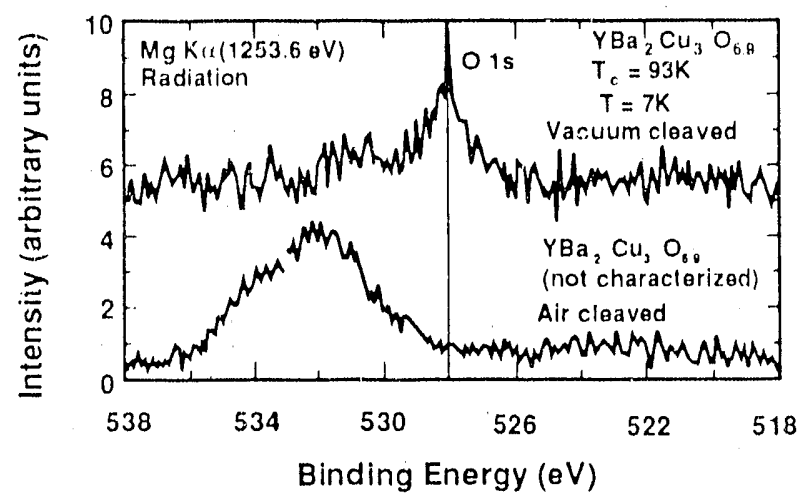

Fig. HT-3. The O 1 s level for vacuum- and air-cleaved single crystals of $\mathrm{YBa}_{2} \mathrm{Cu}_{3} \mathrm{O}_{0.9}$.

\section{Future Milestones}

We will perform the final XPS and UPS measurements on the core levels and valence band spectra of $\mathrm{Y}^{\prime} \mathrm{Ba}_{2} \mathrm{Cu}_{3} \mathrm{O}_{7-x}$ during the rest of $\mathrm{FY} 9()$. We will need larger crystals than 
the ones used so far to improve the signal-to-noise ratio of our measurements. $A$ theoretical effort to formally model these core-state measurements has been undertaken by $P$. Sterne in the theory group. We will also initiate experiments in which clean surfaces are exposed to $\mathrm{O}_{2}$. In FY91, we plan to expose clean surfaces to $\mathrm{CO}_{2}$ and $\mathrm{H}_{2} \mathrm{O}$ and to initiate the HREELS studies to assess completely the effect of exposing clean surfaces to air.

\section{Fermi Surface and Valence Band Mapping in $\mathrm{YBa}_{2} \mathrm{Cu}_{3} \mathrm{O}_{7}$}
I.C. Tobin
J. Z. Liu $^{*}$
F. Solal
C. C. Olsen ${ }^{* *}$
P. Sierne
J. O'Brien
R. Howell

\section{Objectives}

Photoelectron spectroscopy provides two major avenues of investigating high- $T_{\mathrm{c}}$ superconductors (HTSC): (1) higher-energy chemical measurements with XPS and (2) electronic-structure determination at lower energies. To complement the in-house effort using XPS and UPS, a synchrotron-radiation-based, ultrahigh-resolution band-mapping and gap-measurement program has been started. Angla-resolved photoelectron spectroscopy has historically been used to map the valence electronic structure of singlecrystal metal and semiconductor samples, both in terms of the three-dimensional structure and of the two-dimensional structure of layered materials, surfaces, and whathin films of adsorbates. These measurements are made within the one-electron model. For superconductors, the situation is complicated by the underlying collective nature of superconductivity. It should be noted that it remains a point of serious debate whether the one-electron model, which is the traditional framework of photoemission band mapping, has any validity for HTSC materials in which collective eleciron effects are obviously of tremendous importance. Despite this formalistic issue, it has been shown by Olson et al. [Ref. HT-3] that it is possible to use high-resolution, synchrotron-based, angle-resolved photoelectron spectroscopy to observe the presence of a superconductor gap in $\mathrm{Bi}_{2} \mathrm{Sr}_{2} \mathrm{CaCu}_{2} \mathrm{O}_{8}$. Additionally, Fermi surfaces (bands crossing the Fermi energy) can actually be mapped within the Brillnuin zone, within the one-electron picture. These measurements provide a powerful and stringent test of state-of-the-art theoretical calculations. Empirically, it can be said that the momentum-resolving measurements of the superconducting gap in $\mathrm{Bi}_{2} \mathrm{Sr}_{2} \mathrm{CaCu}_{2} \mathrm{O}_{8}$ by Olson et al. [Rcf. HT-3] clearly indicate the. usefulness of such measurements. Moreover, even if the one-electron picture fails, it is important to compare our experimental data with the theoretical results of electronicstructure calculations in order to ascertain which states are involved in superconducting and which remain essentially normal. For example, in $\mathrm{YBa}_{2} \mathrm{Cu}_{3} \mathrm{O}_{7-(1,}$, the question remains

\footnotetext{
* University of California-Davis.

**A Ames Laboratory.
} 
whether it is the one-dimensional "chain" or the two-dimensional "plane" state that is involved in superconducting. With such issues in mind, we have begun a band-mapping and gap-measurement program of HTSC materials, starting with untwinned $\mathrm{YBa}_{2} \mathrm{Cu}_{3} \mathrm{O} \%$. 


\section{Accomplishments}

A high-resolution photoemission study of $\mathrm{YBa}_{2} \mathrm{Cu}_{3} \mathrm{O}_{6.9}$ has been carried out, in collaboration with $C$. G. Olson of Ames Laboratory. We have obtained untwinned single crystals of $\mathrm{YBa}_{2} \mathrm{Cu}_{3} \mathrm{O}_{6.9}$ from J. Z. Liu and performed high-resolution (30) MeV, $2^{\circ}$ ) photoemission experiments with C. Olson at the University of Wisconsin Synchrotron Radiation Center. We have mapped the valence bands of $\mathrm{YBa}_{2} \mathrm{Cu}_{3} \mathrm{O}_{6,9}$ along the highsymmetry directions such as $\mathrm{G}-\mathrm{X}, \mathrm{G}-\mathrm{Y}$ and $\mathrm{G}-\mathrm{S}$, including measurements of the polarization dependences of the cross sections. (Because $\mathrm{YBa}_{2} \mathrm{Cu}_{3} \mathrm{O}_{6.9}$ is a layered material, it can be thought of as a two-dimensional structure.) Our most promising datia at present are from around the $Y$ point of the two-dimensional Erillouin zone. As can be seen in Fig. HT-4, two peaks are near the Fermi energy; one dees not disperse, but the other moves from a deeper binding energy and crosses the Fermi surface as the exit angle and parallel momentum are changed.

\section{Future Milestones}

Further experimental work and analysis are in progress. Some possibilities include pursuing the effects of temperature variations, oxygen-concentration changes, and doping with $\mathrm{Pr}$, which seems to cause magnetic quenching of the superconductivity, thus allowing us to turn the high- $\mathrm{T}_{\mathrm{C}}$ state on and off as an experimental variable. The present observations are quite preliminary but represent a new capability for LLNL. Future experiments are planned for Wisconsin and SSRL (Stanford Synchrotron Radiation Laboratory) using a range of high-quality single crystals and incorporating in situ XPS capabilities to monitor changes in surface chemistry or composition.

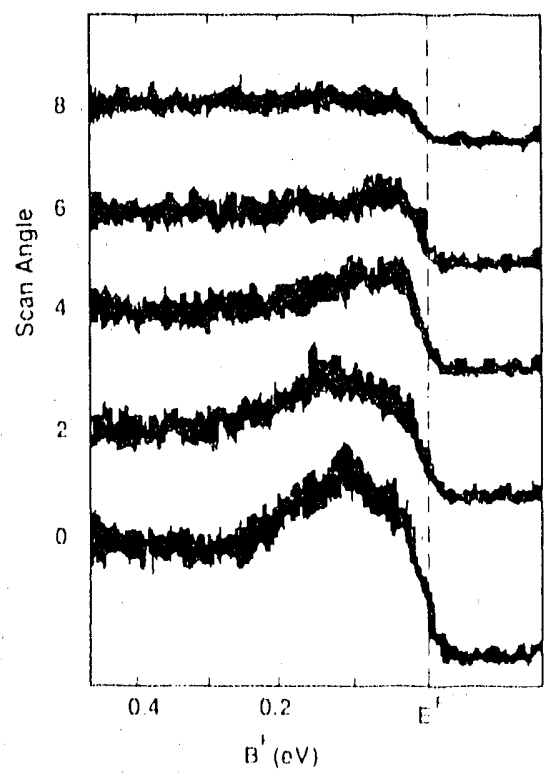

Fig. HT-4. Photoemission spectrum of $\mathrm{YBa}_{2} \mathrm{C}_{3} \mathrm{O}_{6,9}$, showing a potential fermi-surface crossing. 


\section{Positron Studies}

R. Howell
M.J. Fluss
J.Z. Lin

\section{Objectives}

We have measured, and are continuing to measure, the real-space monentum density for the electronic structure in superconducting oxides using the technique of positronanninilation angular correlation. Experiments have been undertaken in supereonductors and related oxides with the goal of correlating these results with calculations of the electronic structure and other measurements such as photoemission. In the past, we have used a molecular model to gain understanding about the positron results; a major concern is the nature of the positron wave function. Because this is an all-electron technicue, similar to that of Compton scattering, many details of the behavior of the bonding electrons have been determined. This year, we are performing high-precision measurements on samples of untwinned $\mathrm{YBa}_{2} \mathrm{Cu}_{3} \mathrm{O}_{7}$ and $\mathrm{Laa}_{1.85} \mathrm{Sr}_{(.15} \mathrm{Cu}_{2} \mathrm{O}_{4}$. The $\mathrm{La}_{1.85} \mathrm{Sr}_{(0.15} \mathrm{Cu}_{2} \mathrm{O}_{4}$ samples were obtained as part of a collaboration with $K$. Kitazawa. To achicve these milestones, we and our collaborators at the University of Texas have separately completed upgrades on our experimental apparatus. We are currenlly starting our measurements. Our $\mathrm{YBa}_{2} \mathrm{Cu}_{3} \mathrm{O}_{7}$ and the $\mathrm{Lat}_{1.85} \mathrm{Sr}_{(0.15} \mathrm{Cu}_{2} \mathrm{O}_{4}$ mealsurements are nearly complete.

A second long-term goal is to explore the source of deviations in the electron-positron overlap introduced by the superconducting transition by measuring the positron lifetimes as a function of temperature. Milestones in this program include the measurement of new superconducting compounds including the n-type materials and p-type materials modified by substitution. The work on positron annihilation, in collaboration with J. Kaiser at UTA, has now reached a stage where we have a fair degree of confidence in the results for the positron-lifetime calculations. This has been achieved by calculating bulk lifetimes for a large nu:nber of elemental metals and particle defects. Application to the $\mathrm{Ba}_{1-\mathrm{x}} \mathrm{K}_{\mathrm{x}} \mathrm{BiO}_{3}$ system initially looked unfavorable, since the calculated lifetimes were considerably lower than the measured lifetimes. It now appears, however, that the experiments were seeing the lifetime of trapping states, not the bulk lifetime. Calculations of vacancies on the metal and oxygen sites all lead to increases in the calculated lifetimes, supporting this picture.

\section{Accomplishments}

In the data taken for electron-momenturn density to this time, there has been no clear identification of a Fermi surface in the momentum distributions measured by positron annihilation that have been taken here at LLNL, and confirmed by the Geneva group. Features typical of a Fermi surface have been reported in electron-energy measurements of

\footnotetext{
* University of Texas.

** University of California-Davis.

tUniversity of Tokyo.
} 
$\mathrm{Y} \mathrm{Ba}_{2} \mathrm{Cu}_{3} \mathrm{O}_{7}$ and $\mathrm{Bi}_{2} \mathrm{Sr}_{2} \mathrm{CaCu}_{2} \mathrm{O}_{8}$ by photoemission and also observed in our own measurements. The next goal for the momentum-density measurements is to reconcile these measurements and identify the physical significance of the momentum broadening in the momentum-space measurements. The possibility for a reconstruction of the 3D surface remains open.

We have measured temperature dependence of the positron lifetime in $\mathrm{Ba}_{-x} \mathrm{~K}_{x} \mathrm{BiO}_{3}$, $\mathrm{Nd}_{2-x} \mathrm{Ce}_{x} \mathrm{CuO}_{4-1}$, and $\mathrm{Y}_{1-x} \mathrm{Pr}_{x} \mathrm{Bi}_{2} \mathrm{Cu}_{3} \mathrm{O}_{7}$ materials and compared the results with calculations in the linear muffin-tin orbital (LMTO) formalism. These measurements and calculations may help us to relate the shanges in positron lifetime to the condition of the superconducting oxide and possibly to the superconducting mechanism. Such results may also serve as tests of the nature of the shielding of the positron, the positron's wave function, and the nature of the pairing mechanism that leads to the boson state.

A new analytical description of the effect of BCS pairing on temperature dependence of the positron lifetime has been developed by Kresin |Rer. HT-4|. This theory is based on screening effects originally proposed for real-space pairing by Chakraborty |Ref. HT-5|. As a consequence of Kresin's work, we should be able to deduce (from precision measurements of the temperature dependence of the positron lifetime below $\mathrm{T}_{\mathrm{C}}$ ) the temperature dependence of the superconductor gap.

\section{Future Milestones}

The angular-correlation measurements are well underway on very-high-quality crystals. The comparison of the $\mathrm{La}_{1.85} \mathrm{Sr}_{(.15} \mathrm{Cu}_{2} \mathrm{O}_{4}$ and $\mathrm{YBa}_{2} \mathrm{Cu}_{3} \mathrm{O}_{7}$ materials, with each other and with different doping conditions, will lead to a better understanding of the intermediate metallic state of these materials. The future goal of the lifetime studies is to establish the systematics of positron lifetimes in several superconducting oxides, including $\mathrm{YBa}_{2} \mathrm{Cu}_{3} \mathrm{O}_{7}$. in which sample variations make interpretation difficult. The role of defects in these measurements must be defined, and precision measurements of $\mathrm{L}_{41} 1.85 .5 \mathrm{Sr}_{(1.15} \mathrm{Cu}_{2} \mathrm{O}_{4}$ will be started to determine the temperature dependence of the gap. Recent work, in collaboration with T. Gonis a"d E. Sowa, suggests a convenient way of extending the LMTO to a fullpotential method without an enormous increase in computer time. Such a method would provide a much better basis for calculation of spectra for comparison with experiment as well as allowing the calculation of structural-energy differences (e.g. the orthorhombic distortion in 214 or the monoclinic distortion in $\mathrm{BaBiO}_{3}$ ). A future goal of this work is 10 develop such a method and apply it to both structural and spectral calculations. Once that has been completed, measurements designed to test specific models of the temperature dependence of the lifetime will be performed. The lifetime studies are an important adjunct of the momentum studies because they provide some indication of the defect properties of the sample and hence indicate if the positron is indeed in a delocalized state as required for interpretation of the momentum density studies. 


\title{
Model Hamiltonian
}

\author{
J.B. Grant \\ A.K. McMahun
}

\section{Objectives}

The question of identification of the states cocupied by the doped carrier holes, which should be a simple question of electronic structure, remains unanswered after three years of intense research on the high- $T_{c}$ cuprates by the international scientific community. The answer will discriminate between the "anyon" school of Anderson, Lalughlin, Wilcek, and others who require the doped holes to occupy ps states, the "d-excitation" school of Weber, Cox, and others who require $p_{\pi}$ states, and lingering theoretical suggestions that these holes may be in $\mathrm{p}_{z}$ states on the apical oxygens. Experiments so far cannot distinguish between $p_{x}$ and $p_{\pi}$ states and, although most rule out $p_{\%}$, this conclusion is contested by some groups.

The reason such simple questions of electronic structure have gone unanswered is that electrons or holes in the high- $T_{c}$ cuprates are both itinerant (as in common metals) and strongly interactit ob (als in localized atomic and molecular systems). This challenging combination falls between the existing theories, which stress one of these limits at the expense of the other. It is our goal to develop a quantitative theory of electronic structure for this new class of materials, because we believe the high- $T_{c}$ puzzle will not be solved until such fundamental materials questions are answered.

Our strategy in dealing with itinerant yet strongly interacting electrons or holes is to throw out extraneous degrecs of freedom, retaining in more manageable model Bamiltonians only those low-energy excitations that might be relevant to superconductivity. While this strategy is sibared in part by many groups, such models are usually based on intuition. We, however, have developed a modification of our existing local-density functional method, which generates quantitative and material-specific parameters defining, such model Hamilonians. Solution of these models is now the major component of our effort. In order to demonstrate the quantitative abilities of this combined approach, our near-term goal has been to calculate the insulating gaps, superexchange frepuencies, and doped-carrier states in the isostructural compounds $\mathrm{L} \mathrm{a}_{2} \mathrm{CuO}_{4}, \mathrm{Lal}_{2} \mathrm{NiO}_{4}, \mathrm{~K}_{2} \mathrm{CuF}_{4}$, and $\mathrm{K}_{2} \mathrm{NiF}_{4}$. Since only the first compound has been doped to high- $\mathrm{T}_{c}$ superconductivity, this comparison may also allow us to identify features necessary for the high- $\mathrm{T}_{\mathrm{c}}$ phenomenom.

\section{Accomplishments}

Our earlier effort |Ref. HT. (f) to calculate model Hamiltonian parameters was strictly valid only for the fairly localized Cu(3d) states in the cuprates, although estimates were made for the more extended $O(2 p)$ states; approximate solution of the model yielded a number of guantities in reasonable agreement with experiment |Ref. HT-71. Using numerical Wannier Sunctions, we have now generalized this approach to states of arbitrary localization, providing even-handed treatment of boht Cu(.3d) and $O(2 p)$ states. The problem of generating model Hamilonians is now largely solved. 
We first carried out exact solutions of the model Hamiltonians for small clusters (e.g., 1 to 4 formula units) of $\mathrm{La}_{2} \mathrm{CuO}_{4}, \mathrm{La}_{2} \mathrm{NiO}_{4}$, and $\mathrm{K}_{2} \mathrm{CuF}_{4} \mid \mathrm{Rec}$. $\mathrm{HT}$-8|. Although relative comparison of the calculated insulating gaps appeared promising, variation in these results with cluster size was disturbing and serves as a reminder of the itinetrancy of the important states, which requires bulk-like treatment.

We then initiated what is proving to be a very successful series of approximate solutions using Hartree-Fock (HF) plus limited configuration intetaction (Cl) for essentially bulk systems ( 16 to 64 formula units, periodically reproduced through all space). We find that the HF solutions alone already track the large relative vartiations in insulating gap to within 20\%, and the order of magnitude vartations in superexchunge frepuency to within 5()$\%$, among the four compounds. These results show the insulating exchange-cotrelation gaps of the parent cuprates to be predominantly of exchange and not correlation character as is generally assumed. However, the $\mathrm{Cl}$ is needed to bring the observed $b_{1}$ symmetry-ionization state within range, and so correlation is still important. The HF results also rule out $\mathrm{p}_{\pi}$ states for the doped holes. Although more extensive $\mathrm{Cl}$ will be required to discriminate between $p_{s}$ and the apical oxygen $p_{\%}$ states, the improving guantitative agreement with experiment that we are finding for the insulating galps and superexchange frequencies should provide the credibility to make our results definitive.

\section{Future Milestones}

Our first milestone is to complete $\mathrm{HF}+$ limited $\mathrm{Cl}$ calculations for bulk $\mathrm{Lin}_{2} \mathrm{CuO}_{4}$, $\mathrm{L}_{2} \mathrm{NiO}_{4}, \mathrm{~K}_{2} \mathrm{CuF}_{4}$, and $\mathrm{K}_{2} \mathrm{NiF}_{4}$, emphasizing quantitative comparison with experiment in regard to insulating gap, superexchange frequency, symmetry of the doped carrier states, and wave vector of these states. Angle-resolved photoemission measurements, possibly by LLNL personnel, could provide much of the missing data. We anticipate close guantitative agrement with experiment, which should provide the credithility that will allow these theoretical results to play a major role in discriminating among conflicting high- ${ }^{T}{ }^{\circ}$, theories.

Second, we see the seeds in our $\mathrm{Cl}$ calculations of the doping-indueed loss of magnetism in the cuprates. Given the occurrence of high- $T$, superconductivity at doping levels just beyond loss of the lexal moment and the prominent role played by magnetic Bluctuations in the "anyon" high- Tc models, we plan to calculate the magnetic order parameter (staggered magnetization) as a function of doping. We believe both this and the previous milestone can be obtained within the remaining halli-year.

It should be noted that hard experiment-theory comparisons in regatrd to those doped. Mott-insulator-like characteristics, which many intuitively believe to underlie the high-' $T$ '. phenomenon, are sorely missing. We believe we are developing theoretical terols to rectify this situaticn and to provide the kind of experiment-theory ileration reguired to cut through some of the materials problems surrounding the cuprates. Perhaps we can then fexcus more clearly on the underlying caise of the phenomenon. 


\section{Magnefism, Phonons, and Plasmons}

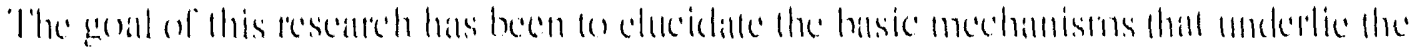

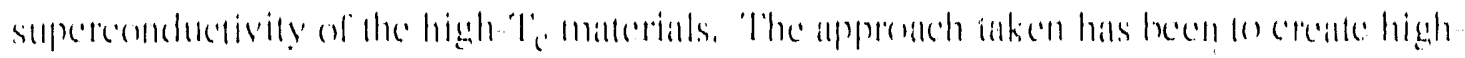

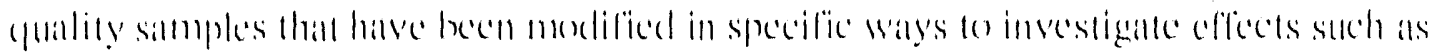

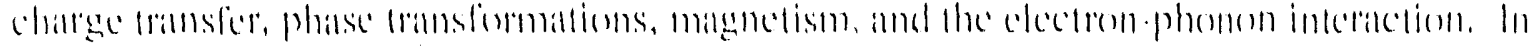

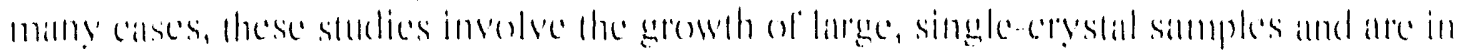

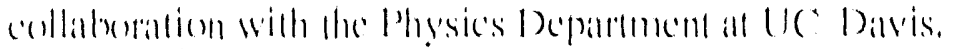

\section{Plasmon Coupling in Layered Materials}

('inlminures

S. T. Bosison

$1 \% \operatorname{sinsin} \mid 11111.1$

\section{()hjective}

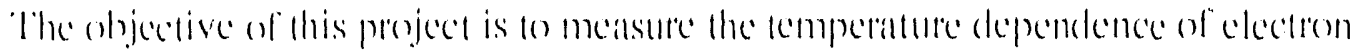

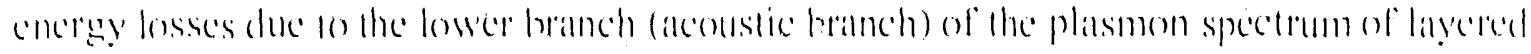

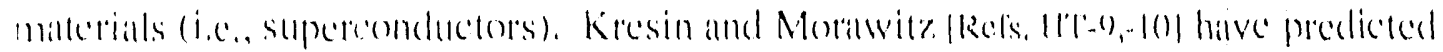

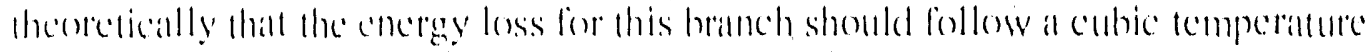
arenendence, A verification of this prediction would support the view that a phonenplasmon interation is the mechanism for the high-le of layered copper oxide superconductors.

\section{Acromplishments}

We have refurbished a IRRERISS system. 'The instrument is equipped with a sample manipulator capable of handing several samples and with a heating calpability of up to

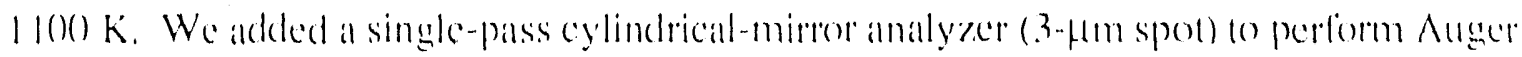
chectron spectroscopy ( $A$ ISS) and a double-pass cylindrical-mirror analyzer for XeS and

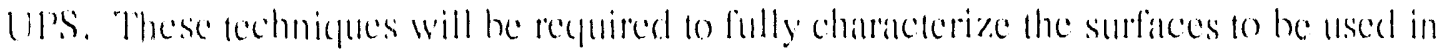
IIREELISS. Additionally, we have included a very stable power supply for the IIRLALLS; it is now being checked.

\section{Fiture Milestones}

The entire system will be moved from building 2.35 to huilding los, reinstalled, and operational by June 190(). By the end of fiY()(), we will meatsure energy losses for graphite, coppere oxides, and severial superconductors. 


\section{Phonon and Magnetism Studies}
II. R. Riudousky
l. L. Lint
N. Phillips:
R. Shellonin
K. Mr: (urly $^{* *}$

\section{Objective}

The goal of this research is to elucidate the basic mechanisms that underlice the superconductivity of this class of materials. The approuch taken has been to create highyuality simmples that have been modified in specific: ways to investigate effects such ats. charge transfer, phase transformations, magnetism and the electron phonon interation. In many cases, these studies involve the growth of large, single-crystal samples and ane in collaboration with the Physics Department at UC Davis.

\section{acoumplishments}

$\mathrm{YBa}_{2} \mathrm{C}_{3} \mathrm{O}_{7}$ has becen studied extensively by Raman spectroscopy, but with "single" crystals contaning high densities of twins that interehange the a and b directions. Along the b direction are the oxygen atoms that form the Cu(1) o(1) "chaths." There are and equivalent oxygen altoms atong the a direction, henee, there are no (u(1) o(1) chaths in this dircetion.

In collaboration with Sandia Natiomal Laboratory, a complete mapping of all the phonon mextes has now been completed using the delwinned erystals. Previously unreported features are seen in the spectra obtained with the incident laser beam propagating along the Cu(2) O(2)\&(3) planes. In particular, the degree of anti-resentance (penetration of the Raman line below the background) of the i $16 \mathrm{~cm}^{-1}$ phomon (a Bat altom vibration along the caxis) is much greater for polarization along the (u(1) $O(1)$ chatus than it is for polarization perpendicular to the Cu(l)-()(1) chains. Significantly, no antiresonant behavior is observed for this Ba vibration in the spectra with light polarized allong the axis despite intense scattering from an electronic continumm.

This anti-resonance is important because it is a characteristic signature of the interatetion of a discrete phonon with the electronic continumm. In traditional superconductors, it is the the electron-phonon interaction that underlies the pairing of the electrons and, therefore, the supereonductivity. 'This type of Raman information, which can relate the strenghth of the electron-phonon information to the important crystal directons, is crucial to our attempts at understanding the role the electrom-phonen interaction still plays in the high- $l_{\text {e }}$ oxide superconductors.

Heat capacity experiments have been performed on a series of $\mathrm{Y}_{1-x} \mathrm{Pr}_{x} \mathrm{Bal}_{2}\left(\mathrm{C}_{3} \mathrm{O}\right)_{7}$ materials in collaboration with the Chemistry Department at UC Berkeley and the Phy'sies Department at UC-Davis. This system is currently of high interest becillse Pr is the only

\footnotetext{
* Lawrence Berkeley Laboratory and University of California Berkeley.

** Sandia National Laboratories Livermore.

University of California Davis.
} 
rare earth that, when substituted for $Y$, causes tiamful effects on the supercondacting properties. There hats been considerable controversy over the valence of the Pre ion (3 or 4) and the very large values of the electronic specific-heal coefficients reported by some workers on this system. The hent-capacity measurements we made have sedtled this second controversy.

High-precision measurements (0,1\%) were performed on four sumples, with (), 10, 20, 3(), and $40 \%$ Pr substiluted for $Y$. These measurements were made al very low temperalures (().310 12.5 K) and high fields (0 10 $7 \mathrm{~T}$ ), which allowed observation of a strong Pr hyperfine interaction, as well as previously unobserved magnetic ordering in the $30 \%$ Pr sample. When these contributions to the heat capacity are laken into alecenunt, the values of the specilice-heall coeflicient are reduced by a fuctor of four. 'The a mplete analysis of these heat capacity data and the ir applicalion to the general problem of understanding the destruction of $\mathrm{T}_{\mathrm{c}}$ in the $\mathrm{Y}_{1-x} \mathrm{Pr}_{x} \mathrm{Ba}_{2} \mathrm{Cu}_{3} \mathrm{O}_{7}$ system will be competed over the nex! several months. On a longer time scale, we plan to continue this type of mealsurement using a new high-temperature callorimeter $(4.2$ to $4(0) \mathrm{K})$, optimized for small single crystal samples, which is being constructed in collaboration with the Physics Department al UC Davis and should be operational this fiscal year.

\section{Future Milestones}

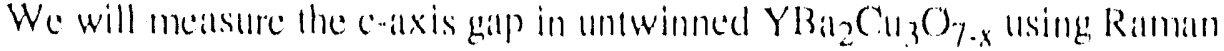

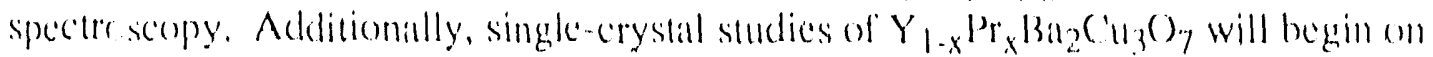
completion of symthesis of these simples.

\section{Technological R\&D (Doping and Circuits)}

\section{Doping of YBC()}

R. cilas.s

In order to study the role of charge transfer, we have suceessfully substituted Br into

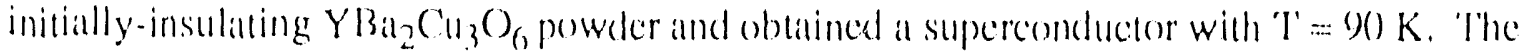
bromination prexess is significantly different from oxygenation in that it cant be carried out all low lemperattures (260) ${ }^{\circ}()^{\circ}$ and reguires times of only a lew minutes. We have also demonstrated that the bromination process is effective in improving the properties of oxygen-deficeient thin lilms, which is important for potential electronics applicattions. Our present objective is to extend this work to as-manufactured high-l'e devices in such a way that this process can be used as a final doping procedure, thus protecting existing components from high-temperature deterioration. Additionally, we plan more detated studies of the structural and eleceren properties of this new material. 


\section{Patterning for Circuits and Magnets}

$$
\text { Fi. Millitsky } \quad \text { ri, Magnolla* }
$$

\section{()bjectives}

We are studying various ways in which high-depth-of-field laser patterning and hybrid waferscale processing can be adapted to high-T, thin films in order to engineer stute-of - theart devices that exploit the useful properties of these new materials |Refs. IIT-11,-12,-13,-14|. We are concentrating on technologies that will benefit from the high-' $T_{\text {(.). high critical }}$ current densities, high critical fields, and high conductivities of thin films of these materials while avoiding technologies that are hindered by their extremely short coherence lenghths or inferior bulk properties. The three devices we are currently studying are:

- Transmission lines suitable for $>1$-Gllz bandwidth system interconnection of a hybrid wafer scale supercomputer with $<2.5$-mm pitch.

- High-speed interconnects for ultrafast devices $(\sim 1)(1)$ Gllz) such as should be attainable from vacum microelectronics |Ret. HT'-1.5|.

" Migh-field mangets using ' $\mathrm{T}_{\mathrm{c}}$ superconducting films.

\section{Accomplishments}

We are developing a process for depositing and etching thin films of high-'l', superconductors and various ceramics. We are currently acepuiring statte-of-the-int films from Conductus Inc. and are working with them collaboralively to chancterize these films during various stages of processing. We need to chandaterize transmission lines fabricalced using varrions technologies to verify calculations and to choose optimal structures for intrachip and interchip interconnecrs. We are cumently using a variely of eyuipment and expertise from O-Division for perforning laser-etching substrate bevelling, substrate polishing, film deposition, and film etching. We have been refining the methex developed at L.LNL for dry patterning thin films of high-temperatture superconductor ceramies suitable for creating three-demensional structures with $\mu m$-scale features. We are developing a process for bevelling and polishing various coramies, such as lanthamum aluminate $\left(I_{\text {aAAO }}\right)$ and yturia-stabilized zircomia.

\section{Finture Milestones}

The thrust of our near-term endeavor involves duplicating our laser-palterning reginen on well-chanacterized, high ligure-of-meril, high-Te films on in-house bevelled and polished ceramic to determing the effect of stach processing on the final system parameters.

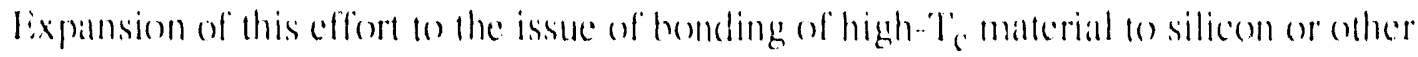
semicondector devices will be driven by comresponding reseatreh inten the physical and

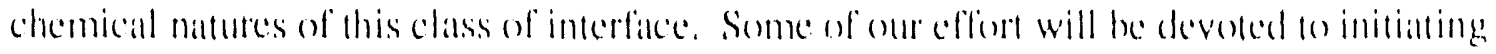
such studices.

\footnotetext{
* Conductus Inc.
} 


\section{Referencers}

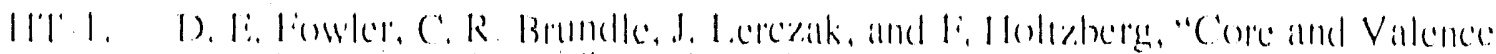

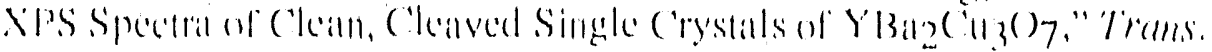

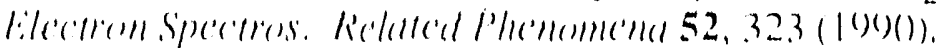

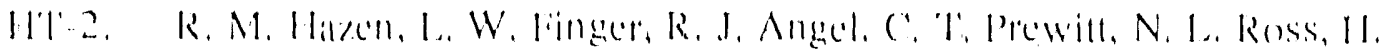

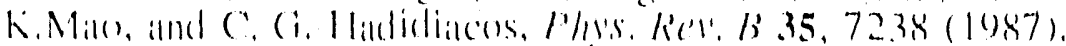

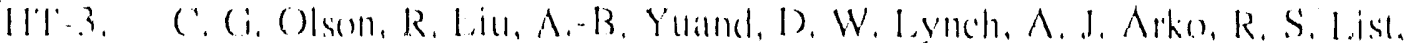

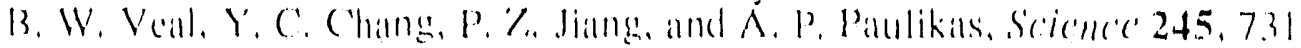
(1) (1)).

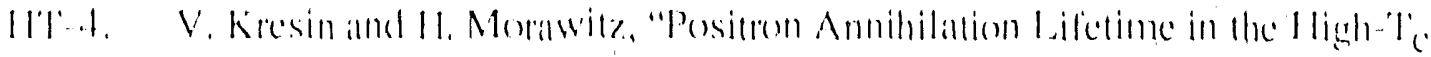

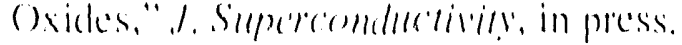

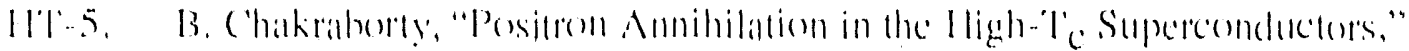

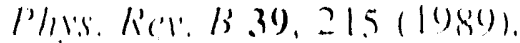

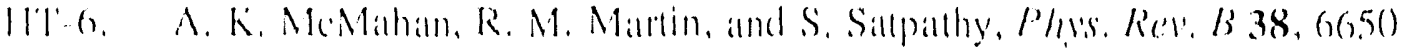
(1) 1 (1)

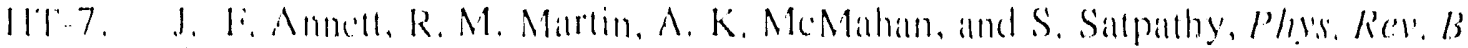
$4(1)(198))$.

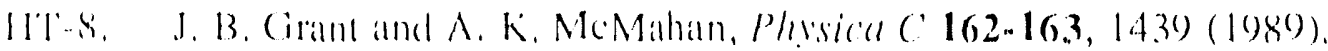

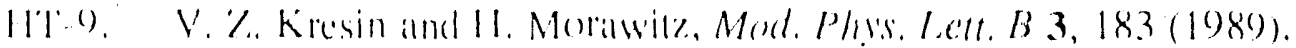

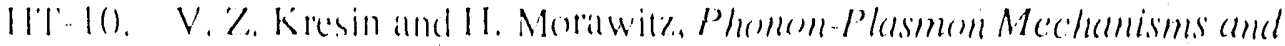

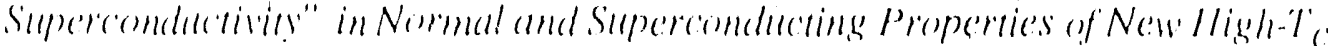
Orides (Noval l'ress, New York, log)()), in press.

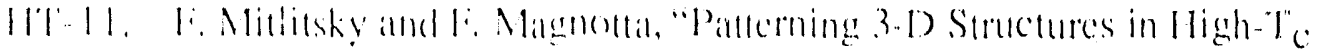

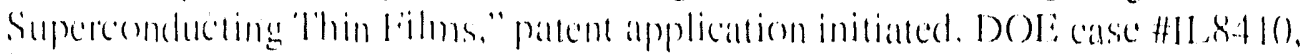
Nov. 1989).

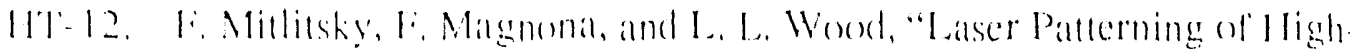

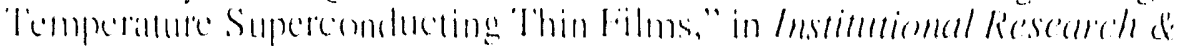

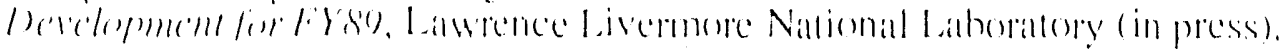

II' 1.3. (). K. Kw(nn, B. W. Lannley. R. R. W. Pease and M. R. Bealstey,

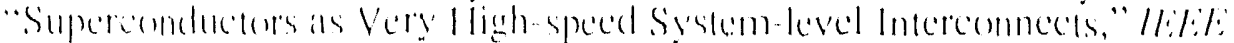

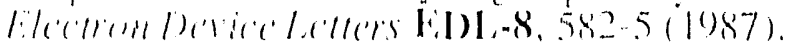

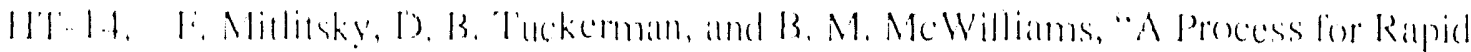

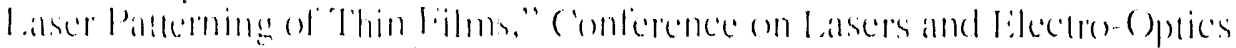

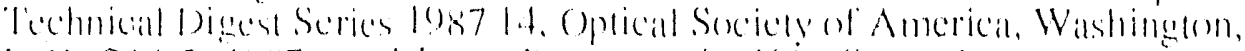

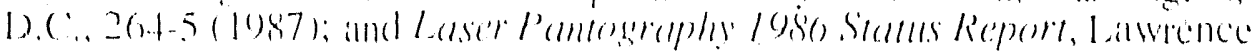

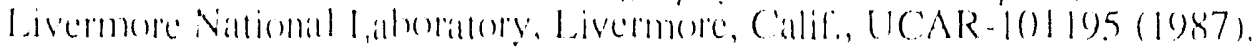


II'T-1,5. F. Millitsky, J, C. Whitchead, A. F. Bernhardt, and B. M. MCWilliams, "Pabrication of Giate Araty Interconnect Structures Using Directo-write Deposition Processess," Springer Proce. Phys. 1.3. The Physiss" and Fabrication of Microstructures and Microdevices . 5, Fds. M. J. Kelley and C. Weisbach (Springer-Verlag, Dilsseldorf, 1986).

\section{Publications}

J. F. Annett, R. M. Mattin, A. K. McMahan, and S. Satpathy, "The Electronic Hamiltonian and Antiferro Magnetic Interactions in La $\mathrm{La}_{2} \mathrm{CuO}_{4}$," Phess. Rev. $B$ 40, 262()$(1989)$.

M. Balroch, "Y-Ba-Cu-O Supereonducting Films Produced by Long-Pulse Lalser Vaporization," Appl. Phys' Lett. 55, 197 (1989).

A. I. Fetter, C. B. Hanna, and R. B. Latughlin, "The Relationship Between High 'Temperature Supercond ctors and the Fractional Quantum Hall Effect," Phass. Rev. B 39, 9679 (1989).

T. J. Folkerts, R. N. Shelton, and H: B. Radousky, "Preparation and Characterization of" Single Phase $13 a_{1} \mathrm{~K}_{x} \mathrm{BiO}_{3}, "$ Phisica $\mathrm{C} 162-164,55()$ (1989); also presented at MelrSC-11, Stanford University, Stanford, Callif, Jul. 23-28, 1989.

J. B. Cirant and A. K. Mc Mahan, "Comparison of the Electronic Structure of $\mathrm{Lat}_{2} \mathrm{CuO}_{4}$, $\mathrm{Lal}_{2} \mathrm{NiO}_{4}$ and $\mathrm{K}_{2} \mathrm{CuF}_{4}, "$ Physica $\mathrm{C}$ 162-164, 1439 (1989): also presented all $\mathrm{M}^{2}$ IITSC-11, Stanford University, Stanford, Calif, Jul. 23228, 1989).

A. Conis, E. C. Sowa, and P. A. Sterne, "Exact Treatment of Poisson's Equation in Solids With Space-Filling Cells," submitted to Phys. Rev. Lett.

C. B. Hanna, R. B. Latughlin, and A. L. Fetter, "Quantum Mechanics of the fratctionalStatistics Gas: Particle-Hole Interaction," submitted to Physs. Rev.

R. H. Howell, H. B. Raldousky, A. L. Wachs, M. J. Fluss, P. E. A. Turchi, Y. C. Jcin, C. S. Sundar, C. W. Chu, R. N. Shelton, and D. G. Hinks, "Systemattes in Positron Annihilation Lifetime Analysis of High "T. Superconducting Transitions,"

Phivica C 162-164, 1.377 (1989); also presented at M2IITSC- II, Stantord Uriversity, Stanford, Calif, Jul. 23-28, 1989.

Y. C. Jean, H. Nakanishi, M. J. Fluss, A. L, Wachs, P. L. A. Turchi, R. H. Howell, Z. Z. Wang, R. L. Meng, P. H. Hor, Z. J. Huang, and C. W. Chu, "A Comparison of the Tempe ature Dependence of Electron Positron Momentum Density Charateristics in Ti(2223), Y(123) and La(214) Superconductors," I. Physs. C, in press.

Y. C. Jean, C. S. Sundar, A. Bharathi, D. C. Hinks, B. Dabrowsti, Y. Zheng, A. W. Mitchell, J. C. IIo, R. II. Howell, A. L..Wachs, P. E. A. Turchi, M. J. Iluss, R. I.. Meng, P. H. Ilor, 'Z J. Huang, and C. W. Chu, "The Electronic propertics of lligh T'. Superconducters Probed by Positron Annihilation," Physice C 162-164, 1.370 (1989); also presented at M2ITTSC-11, Stanford University, Stanford, Calif., Jul. $23-28,1989$. 
Y. C. Jean, C. S. Sundar, A. Bharathi, J. Kyle, H. Nakanishi, P. K. Tseng, P. H. Hor, R. L. Meng, Z. J. Huang, C. W. Chu, Z. Z. Wang, P. E. A. Turchi, R. H. Howell, A. L. Wachs, and M. J. Fluss, "Local Charge Density Change and Superconductivity: A Positron Study," Phys. Rev. Lett. 64, 1593 (190()).

V. Kalmeyer and R. B. Latughlin, "Theory of the Quantum Spin Licquid," Phys. Rev. B 39, $11879(1989)$.

V. Kresin and H. Morawitz, "Positron Annihilation Lifetime in the Migh-T. Oxides," I. Struct. Chem., in press.

R. B. Lalughlin, "Random Phase Approximation in the Fractional Statistic Gas," Annals of" Physics 191, $163(1989)$.

R. B. Latughlin and Z. Zou, "Charged Excitations of the Chiral Spin Liquid," submitted to Phis. Rev.

H. M. I edbetter, S. A. Kim, C. E. Violet, and J. D. Thompson, "Low-Temperature Elastir constants of Polycrystalline $\mathrm{La}_{2} \mathrm{CuO}_{4}$ and $\mathrm{Lal}_{1.85} \mathrm{Sr}_{(0.15} \mathrm{CuO}_{4}$," Physics $\mathrm{C}$ 162-164, 460) (1989); also presented at M²HTSC-Il, Stanford University, Stanford, Calif., Jul. 23-28, 1989.

J. Z. Liu, M. D. Lan, P. Klavins, and R. N. Shelton, "Meissner Effect and Magnetic Critical Current Density in Detwinned $\mathrm{YB}^{\mathrm{B}_{2}} \mathrm{Cu}_{3} \mathrm{O}_{7-\mathrm{x}}$ Single Crystals," Phys Lett. $144,26.5(1990)$.

K. F. Mc Carty, J. Z. Liu, R. N. Shelton, and H. B. Radousky, "The Raman-Active Phonons of a Twin-Free $\mathrm{YBa}_{2} \mathrm{Cu}_{3} \mathrm{O}$ Crystal: A Complete Polarization Analysis," Phys. Rev. B, in press.

K. F. McCarty, H. B. Radousky, D. G. Hinks, Y. Zheng, A. W. Mitchell, T. J. Folkerts, and R. N. Shelon, "Electron-Phonon Coupling in Superconducting Bato. $\mathrm{K}_{0.4} \mathrm{BiO}_{3}$ : A Raman-Scattering Study," Phys. Rev. B Rapid Comm. 40, 2662 (1989).

C. I. Merzbacher, and N. W. Winter, "Calculation of the ${ }^{17}$ O NMR Spectra for" YBal2 $\mathrm{Cu}_{3} \mathrm{O}_{7}, "$ submitted to Phys. Re'v.

13. L. Olsen, R. E. Russo, P. Berdahl, R. P. Reade, and J. M. McMillan, "Fabrication and Characterization of Y-Bat-Cu-O Thin-Films on Stainless-Steel Substrates," submitted for the Procecedings of the TMS Conference, Anaheim, Callif., Feb. 18...22, 1990.

K. C. Ot, R. M. Aikin, L. Bernardez, A. Connor, Z. Fisk, M. J. Fluss, E. Carcia, M. Golublatt, W. B. Mutchinson, G. Il. Kwei, C. J. Malggiore, J. A. Martin, R. Meisenheimer, M. Nastasi, E. J. Peterson, E. J. Tesmer, J. D. Thompson, T. L. Walker, J. O. Willis, and P. J. Yvon, "Oxygen Isotope Effects in Yurium Barium Copper Oxides," Phisi. Rev. B, 39, 428.3 (19)89).

J. L. Peng, P. Klavins, R. N. Shelton, H. B. Radousky, P. A. Hahn, and L. Bernardez, "Upper Critical Fiekd and Normal State Properties of Single Phate

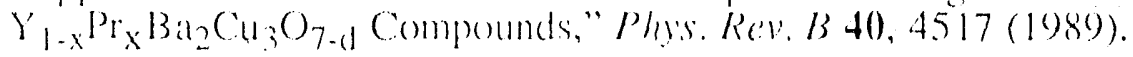

J. L. Peng, P. Klavins, R. N. She!ton, II. B. Radousky, P. A. Hahn, L. Bernardez, and M. Costantino, "Preparation, Chanaterization and Supereonducting Properties of

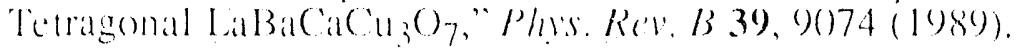

J. I. Peng, R. N. Shelon, and II. R. Radousty, "Kondo laffect and Supereondactivity in

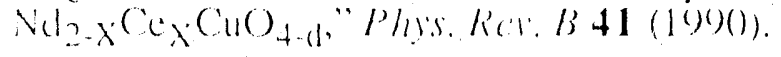


J. L. Peng, R. N. Shelton, and H. B. Radousky, "Preparation of and Magnetic Scattering in $\mathrm{Nd}_{2-\mathrm{x}} \mathrm{Ce}_{\mathrm{x}} \mathrm{CuO}_{4-\mathrm{d}}$," Solid State Commun. 71, 479 (1989).

J. L. Peng, R. N. Shelton, and H. B. Radousky, "Superconductivity and Magnetic: Scattering in $\mathrm{Nd}_{2-\mathrm{x}} \mathrm{Ce}_{\mathrm{x}} \mathrm{CuO}_{4-\mathrm{d}}$," Physics C 162-164, 89 (1989); also presented at M²HTSC-II, Stanford University, Stanford, Calif., Jul. 23-28, 1989.

H. B. Radousky, R. S. Glass, P. A. Hahn, M.. J. Fluss, R. G. Meisenheimer, B. P. Bonner, C. I. Merzbacher, E. M. Larson, K. D. McKeegan, J. C. O’Brien, J. L. Peng, R. N. Shelton, and K. F. McCarty, "Metallization and Superconducting Properties of $\mathrm{YBa}_{2} \mathrm{Cu}_{3} \mathrm{O}_{6.2} \mathrm{Br}_{y}$," Phys. Rev. B., in press.

H. B. Radousky, P. Hahn, J. L. Peng, and R. N. Shelton, "Magnetic Pair Breaking in the $\mathrm{Y}_{1-\mathrm{x}} \mathrm{Pr}_{\mathrm{x}} \mathrm{Ba}_{2} \mathrm{Cu}_{3} \mathrm{O}_{6.95}$ System," Physics $\mathrm{C}$ 162-164, 1363 (1989); also presented at $\mathrm{M}^{2}$ HTSC-II, Stanford University, Stanford, Calif., Jul. 23-28, 1989.

H. B. Radousky, K. F. McCarty, J. L. Peng, and R. N Shelton, "Preparation and Raman Analysis of Single Phase $\mathrm{Y}_{1-\mathrm{x}} \mathrm{Pr}_{\mathrm{x}} \mathrm{Ba}_{2} \mathrm{Cu}_{3} \mathrm{O}_{7}$," Pnys. Rev. B, Rapid Comm. 39, 12383 (1989).

P. Sterne, "First-Principles Study of Phase Stability and Kinetics of Oxygen ordering in $\mathrm{YBa}_{2} \mathrm{Cu}_{3} \mathrm{O}_{7-\mathrm{y}}$," submitted for the Proceedings of the ICMC'90) Topical Conf.-High Temperature Superconductors-Materials Aspects, Garmisch-Partenkirchen, West Germany', May 9-11, 1990.

P. A. Sterne and L. T. Wille, "First Principles Calculation of Oxygen ordering in $\mathrm{YBa}_{2} \mathrm{Cu}_{3} \mathrm{O}_{7-y}$," submitted for the Proceedings of the MRS Spring Meeting-Atomic Scale Calculations of Structure in Materials, San Francisco, Calif., Apr. 15-20, 1990.

P. A. Sterne and L. T. Wille, "Oxygen Vacancy Ordering in $\mathrm{YBa}_{2} \mathrm{Cu}_{3} \mathrm{O}_{7-y}$," Physics $C$ 162-164, 223 (1989); also presented at M²HTSC-II, Stanford University, Stanford, Calif., Jul. 23-28, 1989.

C. Sundar, A. Bharathi, Y. C. Jean, D. G. Hinks, B. Dabrowksi, Y. Zheng, A. W. Mitchell, J. C. Ho, R. H. Howell, A. L. Wachs, P. E. A. Turchi, M. J. Fluss, R. L. Meng, P. H. Hor, Z. J. Huang, and C. W. Chu, "The Electronic Properties of High T $\mathrm{C}$ Superconductors Probed by Positron Amihilation," Phavica $C$ 162-164, 1379 (1989); also presented at M²HTSC-II, Stanford University, Stanford, Calif., Jul. 23-28, 1989.

R. J. Tench, M. Balooch, A. L. Connor, L. Bernardez, B. Olson, F. Wooten, W. J. Siekhaus, and D. R. Olander, "SiC Film Deposited by Pulsed Excimer Latser. Ablation," submitted for the Proceedings of the MRS Spring Meeting, San Franciseo, Calif., Apr. 15-20, 1990.

P. E. A. Turchi, A. L. Wachs, K. H. Wetzler, R. H. Howell, M. J. Fluss, J. H. Kaiser, and R. N. West, "Electron Momentum Density Studies in High-Tc Materials by Positron Annihilation Spectroscopy: Theory and Experiment,"J. Phys.: Condens. Matter 2, $1635(199())$.

C. E. Violet, R. G. Bedford, P. A. Hahn, N. W. Winter, and Z. Mei, "Local Oxygen

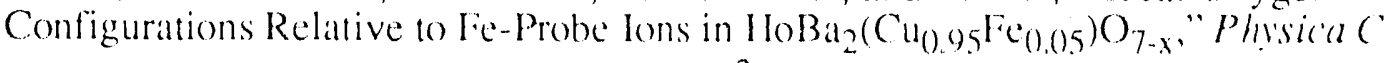
162-164, 1291 (1989); also presented at M²HTSC-II, Stanford University, Stanford, Calif., Jul. 2328, 1989. 
A. L. Wachs, P. E. A. Turchi, R. H. Howell, Y. C. Jean, M. J. Fluss, J. H. Kaiser, R. N. West, K. L. Merkle, and A. Revcolevschi, "Positron Annihilation Studies of. the Electronic Structure of NiO," Phys. Rev. B 40, 1 (1989).

A. L. Wachs, R. N. West, J. H. Kaiser, P. E. A. Turchi, S. Rayner, H. Haghighi, R. H. Howell, Y. C. Jean, M. J. Fluss, K. L. Merkle, A. Revcolevschi, and Z. Z. Wang, "Electron-Positron Momentum Distribution Measurements of High- $\mathrm{T}_{\mathrm{c}}$ Superconductors and Related Systems," Physica C 162-164, 1375 (1989); also presented at M2HTSC-II, Stanford University, Stanford, Calif, Jul. 23-28, 1989.

S. T. Weir, W. J. Nellis, E. A. Early, C. L. Seaman, and M. B. Maple, "Effects of Shock-Induced Defects on Flux Pinning in $\mathrm{YBa}_{2} \mathrm{Cu}_{3} \mathrm{O}_{7}, "$ Physics $\mathrm{C}$ 162-164, 1263 (1989); also presented at M ${ }^{2}$ HTSC-II, Stanford University, Stanford, Calif., Jul. $23-28,1989$.

S. T. Weir, W. J. Nellis, P. C. McCandless, W. F. Brocious, C. L. Seaman, E. A. Early, and M. B. Maple, "Crystallographically-Oriented Superconducting $\mathrm{Bi}_{2} \mathrm{Sr}_{2} \mathrm{CaCu}_{2} \mathrm{O}_{8}$ by Shock Compaction of Pre-Aligned Powder," submitted to App. Phys. Lett.

U. Welp, W. Kwok, G. W. Crabtree, K. G. Vandervoort, and J. Z. Liu, "Magnetization Hysteresis and Flux Pinning in Twinned and Untwinned $\mathrm{YBa}_{2} \mathrm{Cu}_{3} \mathrm{O}_{7-\mathrm{d}}$ Single Crystals," Appl. Phys. Lett., in press.

N. W. Winter, and C. E. Violet, "Theoretical Study of Copper Nuclear Quadrupole Resonance in $\mathrm{YBa}_{2} \mathrm{Cu}_{3} \mathrm{O}_{7-\mathrm{x}}$," submitted to Phys. Rev.

N. W. Winter, and C. E. Violet, "Calculation of the Nuclear Quadrupole Resonance Spectra of $\mathrm{YBa}_{2} \mathrm{Cu}_{3} \mathrm{O}_{7-x}$," Physica C 162-164, 261 (1989): also presented at $M^{2}$ HTSC-II, Stanford University, Stanford, Calif., Jul. 23-28, 1989.

\section{Abstracts}

R. H. Howell, J. C. O’Brien, P. Sterne, H. B. Radousky, P. E. A. Turchi, M. J. Fluss, J. L. Peng, J. J. Folkerts, R. N. Shelton, and D. G. Hinks, "Positron Annihilation Lifetime Analysis of Superconducting Oxides," Bull. Amer. Phys. Soc. 35 (199()).

Y. C. Jean, C. S. Sundar, A. Bharathi, L. Y. Hao, R. H. Howell, P. E. A. Turchi, M. J. Fluss, P. H. Hor, R. L. Meng, Z. J. Huang, and C. W. Chu, "Local Electron and Positron Densities in High T $\mathrm{c}$ Superconductors," Bull. Amer. Phys. Soc. 35 (1990).

J. Z. Liu, M. D. Lan, P. Klavins, and R. N. Shelton, "Study on Magnetic Critical Current Density in Detwinned $\mathrm{YBa}_{2} \mathrm{Cu}_{3} \mathrm{O}_{7-x}$ Single Crystals," Bull. Amer. Phys. Soc. 35 (1990).

F. A. Sterne, and J. H. Kaiser, "First Principles Calculation of Positron Lifetimes in Metals," Bull. Amer. Phys. Soc. 35 (199()).

P. Sterne, "Theoretical Study of Oxygen ordering in $\mathrm{YBa}_{2} \mathrm{Cu}_{3} \mathrm{O}_{7-y}$," Bull. Amer. Phys. Soc. 35 (1990).

L. T. Wille and P. A. Sterne, "Theoretical Study of Oxygen Ordering in $\mathrm{YBa}_{2} \mathrm{Cu}_{3} \mathrm{O}_{7-y}$," Bull. Amer. Phys. Soc, 35 (1990).

\section{Invited Lectures}

W. J. Nellis, "Tutorial on Shock Compression of Solids," presented at American Physical Society, Committee on Applications of Physics, Anaheim, Calif. Mar. 11, 1990 Bull. Amer. Phys. Soc. 35 (1990). 


\section{Invited Presentations}

M. J. Fluss, H. B. Radousky, R. S. Glass, F. Mitlitsky, and J. Z. Liu, "Building the Technical Foundation for Processing Strategies of the High-7 . Superconductors," presented at Superconductivity Applic. Conf., SC Global 9(), Long Beach, Calif., Jan. $17-19,1990$.

R. H. Howell, A. L. Wachs, P. E. A. Turchi, Y. C. Jean, M. J. Fluss, R. N. West, J. H. Kaiser, S. Rayner, H. Haghighi, and Z. Z. Wang, "Electron Momentum Measurements of $\mathrm{YBa}_{2} \mathrm{Cu}_{3} \mathrm{O}_{7}$," presented at 9th International Symposium on Superconductivity, Tskuba, Ibaraki, Japan, Nov. 14-17, 1989. 


\title{
INTERFACES, ADHESION, AND BONDING
}

\author{
W. E. King (Thrust Area Leader)
}

Overview

The Interface, Adhesion, and Bonding Thrust Area is investigating the influence of impurities, flaws, and inclusions on adhesion and bonding at internal interfaces. The influence of interfaces on materials properties is controlled by mechanisms that are operative over the range of length scales from atomic to macroscopic. Detailed determination of the operative mechanisms requires theory validated by comparable experiments. Theoretically, we have developed a unicue capability for calculating the electronic structure at interfaces, where symmetry is reduced compared with the bulk. Specifically, the method, called the real-space multiple-scattering theory (RSMST), can treat interfaces and include the effect of atomic relaxation at the interface. Currently, it is not possible to predict atomic relaxations using the RSMST (because of the large computational resources that would be required); therefore, we have coupled this method with the semi-empirical cmbedded atom method (EAM), which uses modified two-body potentials with molecular dynamics, molecular statics, or Monte Cario techniques to determine atomic rearrangements. These methods are at present limited to metallic systems; however, the extension of one or both methods to metal/ceramic interfaces appears to be possible.

Our experimental effort will produce results that are directly comparable with theoretical calculations. Consequently, our initial investigations will treat the planar metal/netal interfaces and metal/ceramic interfaces (in anticipation of improvements in the theory) of well-defined misorientations relative to the perfect crystal. To span the entire range of length scales described above, we will require macroscopic bicrystals a few millimeters thick, with interfacial areas on the order of a square centincter. To obtain such bicrystals, we plan to employ the diffusion-bonding approach recently demonstrated at the MaxPlanck-Institut, Institut für Werkstoffwissenschaft, Stuttgart, W. Germany (MPI). Initially, bicrystals will be obtained through a collaboration with MPl. In parallel with this research project (and in collaboration with Sandia National Laboratories-Livermore), an ultrahigh-vacuum diffusion-bonding machine is being developed for installation at LLNI.

\section{Technical Activities and Results}

\section{Electronic-Structure Calculations at Metal Grain Boundaries}

$$
\text { E. Sowa A. Gonis }
$$

We have developed a first-principles methed, the RSMSI defined above, for calculating the electronic structure of systems with extended defects, e.g., surfaces and interfaces IRefs. IA-1, IA-2I. This method relies on certain invariance properties of systems, namely, the periodic repetition of a basic unit along a given direction (e.g., the repetition of 
atomic planes to produce a surface). These properties allow us to reduce a semi-infinite system to one of finite spatial extent and to calculate the electronic: structure of extended defects. Motivated by the desire to gain insight into bonding mechanisms at metallic interfaces, we have applied the method to selected grain boundaries in Cu $|R e f| A-3 \mid$. .

Our RSMST code has been demonstrated to work on twist and tilt grain houndaries in $\mathrm{Cu}$, including boundaries based on high-Miller-index planes. Although this code is nonself-consistent and cannot determine total energies, we have used it to determine the effect on the local electronic density-of-states (DOS) of boundary relaxations predicted by the semi-empirical EAM. Four different methods of expressing mathematically the invariance properties of semi-infinite systems have been implemented and are being evaluated for optimal convergence rates and computational efficiency. The most efficient version will he: used to implement charge self-consistency and total-energy capabilities.

We also have a fully self-consistent total-energy code |Ref. IA-4]. This code is a hybrid that uses the RSMST method described previously to handle the direction perpendicular to the interface and conventional methods for the directions parallel to the interfice. In contrast to the pure RSMST code, it is limited to interfaces with translational invariance parallel to the interface plane. Although it will not be able to treat incoherent interfaces and interfaces with isolated impurities, it will serve as a valuable check on the more gencril code.

\section{Influence of Impurities on Grain-Boundary Diffusion}

W. E. King

L. Bernurdez
I. II. Park, ANL

A. (I)Int)

We have begun to investigate the atomic transport of cations and anions in $\mathrm{Cr}_{2} \mathrm{O}_{3}$ and $\mathrm{Cr}_{2} \mathrm{O}_{3}$ doped with ceria. The experiment is novel in that we have simultaneously diffused both cation and anion tracers on the same sample. Powders of $\mathrm{Cr}_{2} \mathrm{O}_{3}$ and $\mathrm{Cr}_{2} \mathrm{O}_{3}$ with valrious amounts of cerra doping have heen prepared. Compicted green pellets have heen sintered at the oxygen partial pressure corresponding to the $\mathrm{Cr}_{-}-\mathrm{Cr}_{2} \mathrm{O}_{3}$ cejuilibrium at 155()$^{\circ} \mathrm{C}$. After sintering, the samples were coated with a thin layer of ${ }^{51} \mathrm{Cr}_{2} \mathrm{O}_{3}$ powder. The samples were diffusion annealed at the oxygen partial pressure corresponding to the $\mathrm{Cr}^{-} \mathrm{Cr}_{2} \mathrm{O}_{3}$ eepuilibrium at $1100{ }^{\circ} \mathrm{C}$ for 8 hours. The oxygen partial pressure was estithlished using a mixture of $\mathrm{Cr}$ and $\mathrm{Cr}_{2}{ }^{18} \mathrm{O}_{3}$. Penetration of ${ }^{50} \mathrm{Cr}$ and ${ }^{18} \mathrm{O}$ ) was mealsured using secondary-ion mass spectrometry (SIMS).

Preliminary results are shown in Iïg. IA-1. The diffusion conefficient of the grain boundary is proportional to the slope of this curve. A steep slope in the long tail of these curves indicates a lower diffusion coefficient than would al shatlow slope. The se preliminary results indicate that () diffuses more mapidly on Cr grain boundaries thain (r. This agrees with previous results hut now with conventional wistom. Further experiments

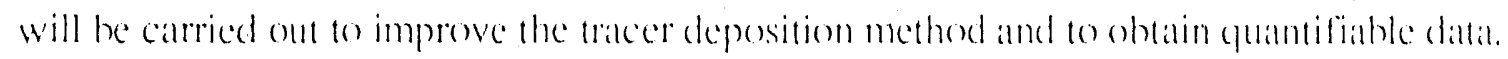




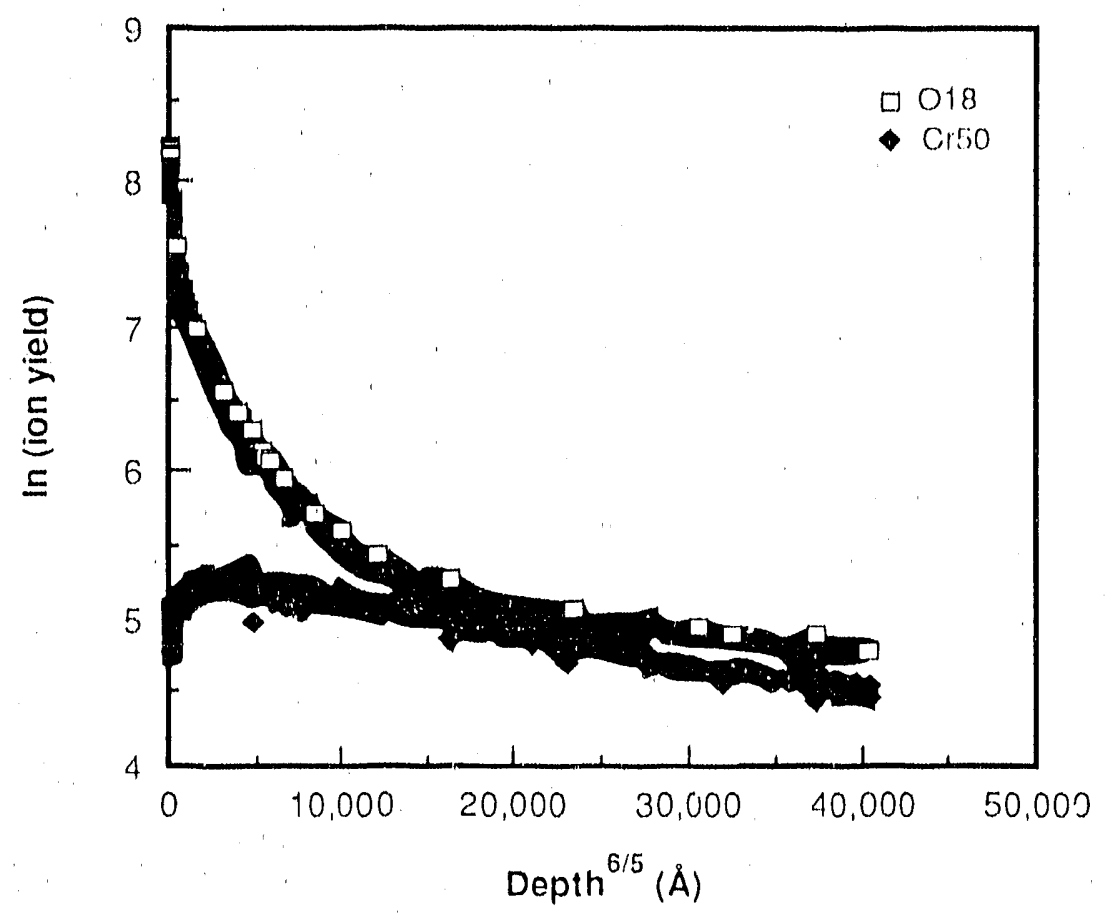

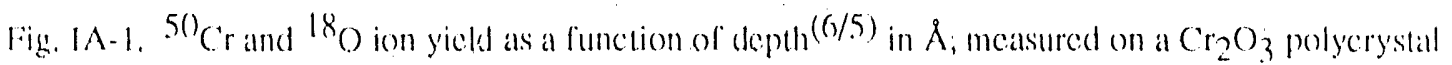
that had heen dilfusion annealed all lit() ${ }^{\circ} \mathrm{C}$ for 8 hours.

\section{Trace Impurity Analysis of Metal Single Crystals}

Introduction. A key to the success of the work proposed by the thrust area is the ability to prepare well-characterized interfaces of known crystallography and purity. Results of a recent round-robin investigation of the impurities present in a common piece of $\mathrm{Nb}$ indicated the need for further investigation |Ref. $|\mathrm{A}-5|$.

Determination of Significant Impurities in Nb. Previous work to quantify the trace impurity levels in $\mathrm{Nb}$ single crystals indicalted that routine quantification for a wide range of elements may not be practical and that specific impurities that are expected to be deleterious to the planned experiments should be targeted for analysis. I was determined that the target impurities are those expected to segregate to the grain boundary during the diffusion -bonding process. To identify these impurities, a surface segregation study using Auger electron spectroscopy (AES) was carried out on the surface of a Nb single crystal at a variety of temperatures between $25^{\circ} \mathrm{C}$ and $6(0){ }^{\circ} \mathrm{C}$.

A Perkin-Elmer 6() Multiprobe was used for the analyses. Before heating, the sample surface was sputter cleaned and subseguently chanacterized. The sample was then heated to $500{ }^{\circ} \mathrm{C}$. After 40 min at temperature, the carbon concentration had increased $1066 \%$ and clearly showed a mixture of two states, one of which was a carbide (as identified by its (istinctive peak shape). Onygen and sulfur were also present. The area was sputtered to 
remove surface contamination and lo see which contaminants might migrate to the surfice, and at what rate. Dalta were acepuired ats a function of time. Alter 12 min all temperature, Iwo carbon species, including a carbide, were again observed. The plot in IFig. IA - 2 shows the change in concentrations with time. At temperatures $>57()^{\circ} \mathrm{C}$, the ciabon concentration decreased, until at $6(x){ }^{\circ} \mathrm{C}$ no carbon was detectable.

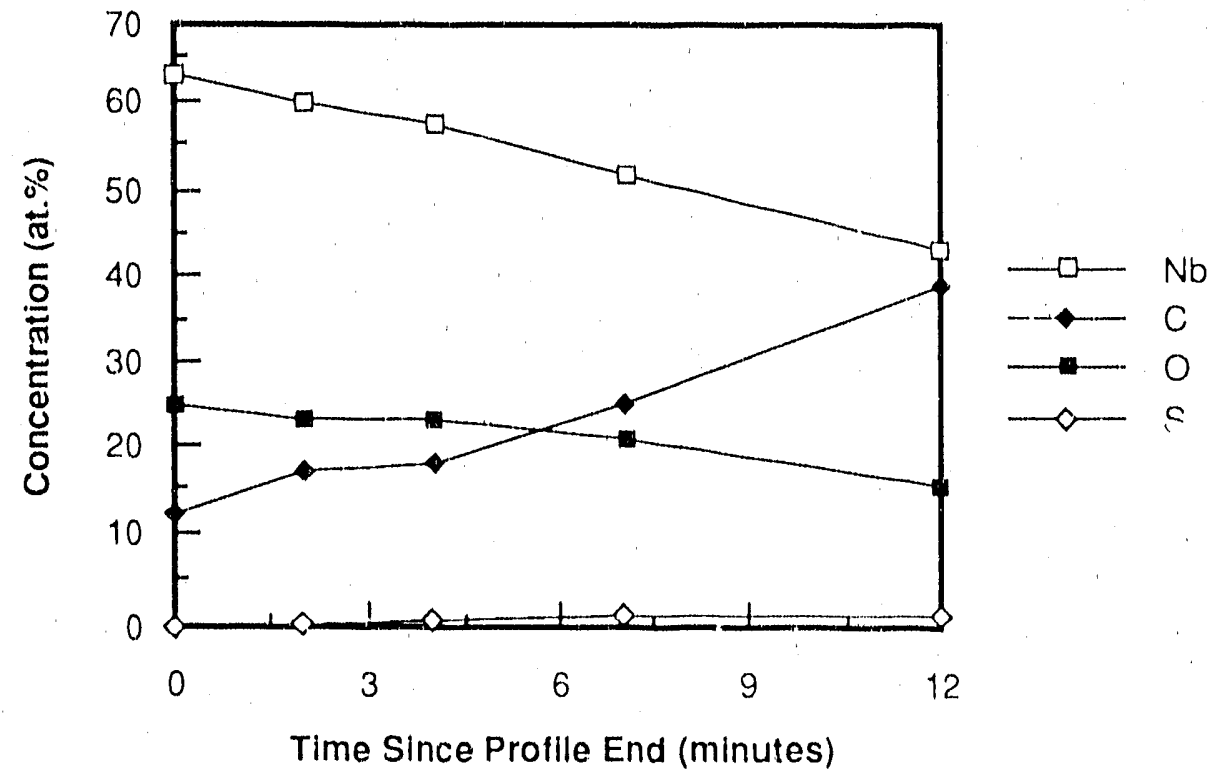

Fi', IA-2. Time evolution of the surface composition of a $\mathrm{Nb}$ single crystal anncaled at $5(x){ }^{\circ} \mathrm{C}$, studir 1 using AES.

Sulfur, niobium, carbon, and oxygen were the only elements detected on the sample at any point in the analysis. The disappearance of $\mathrm{C}$ from the surface of $\mathrm{Nb}$ was further investigated by surveying the surface concentration as a function of time and temperature. Figure IA-3 shows the AES spectra from this investigation. It was observed that during a 15-min anneal at 5()$)^{\circ} \mathrm{C}, \mathrm{C}, \mathrm{S}$, and $\mathrm{O}$ concentrations all increased as previously observed. The temperature was increased by $\sim 1()\left({ }^{\circ} \mathrm{C}\right.$, and the $\mathrm{C}$ peak was observed to disappear after only 4.5 min. During the next $2.5 \mathrm{~min}$, the O peak was observed to decrease slightly in magnitude and split. This could be due to either to surface segregation of oxygen or to oxidation of the surface by residual gas in the vacuum system. The C peak was not observed to reappear upon cooling. 


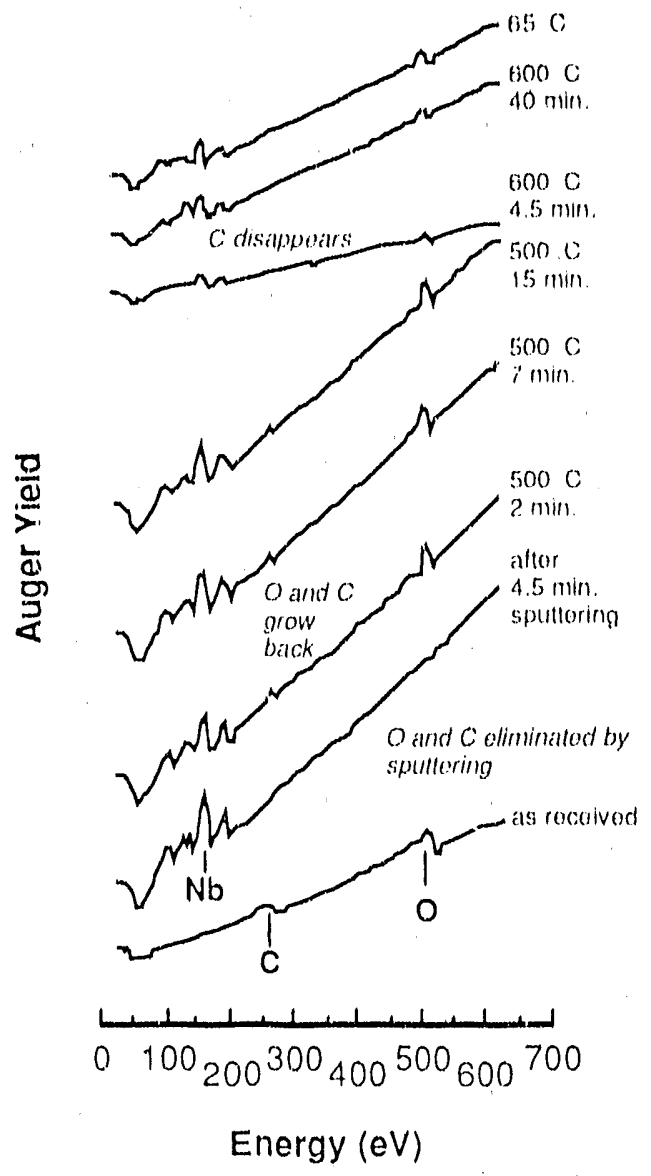

Fig. IA-3. AES spectra demonstrating the temperature and time dependence of the surface concentration of a $\mathrm{Nb}$ single crystal; seculence progresses from bottom to top.

On the basis of this result, we conclude that the bulk impurities $C, O$, and $S$ should be minimized in the Nb single crystals obtained from Ames National Laboratory. Further experiments will be carried ent to determine if it is possible to locally purify the nearsurtace region of the sample by a combination of thermal eycling and sputtering. In addition, the appropriate heat treatment to minimize $C$ will be determined.

Round-Robin Impurity Analysis, In this work, standard samples have been procured for a round-robin investigation. Standard simpling technigues have been employed on divide the simples for the round-robin investigation. A selected assortment of unidentified standard simples including samples from different standards and multiple samples from the same standard, have been sent to the participating analytical haboratories.

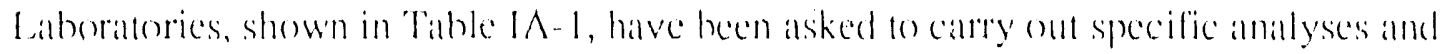

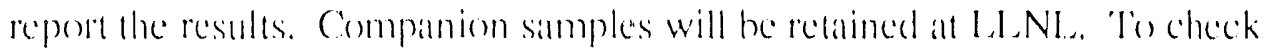
reproducibility, a second series of samples will be circulated aller completion of the lirst round. A third round will include standard samples and samples thall will he used in our experimental program. On the basis of the compiled results firm all thee series of tests, est methods and laboratorices will he selected for analytical work in this thrust arcal. 


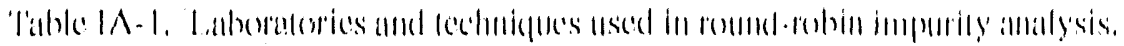

\begin{tabular}{|c|c|c|}
\hline laborutory & 'l'clinlylur & lilumberlls \\
\hline Allies & Varemun lusion & $11,(1, \mathrm{~N}$ \\
\hline Ames & Combustion & $(1$ \\
\hline Ames & 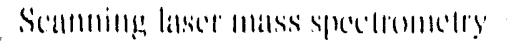 & All \\
\hline lixulel corp. & 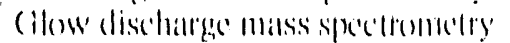 & AII \\
\hline I.I.NI & Combustion, ignilionn & $H,(1,(), N, S$ \\
\hline I.I.NI & ICPNIS & 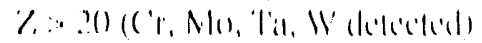 \\
\hline
\end{tabular}

\section{Preparalion of Ultra-blat Nb single crystals for Diffusion Bonding}
13. Hill:hs
II. Wir'll
11. I: Kin!

In the future, the intertaces used for the experimental pertion of this proghtam will he

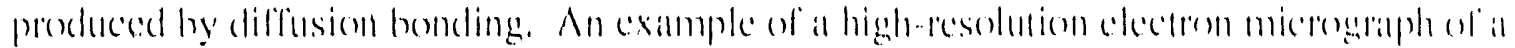
Nh grain boundary that was produced by diffusion bonding is shown in ligh. WA.t. 'The'

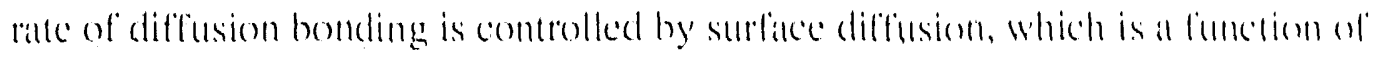

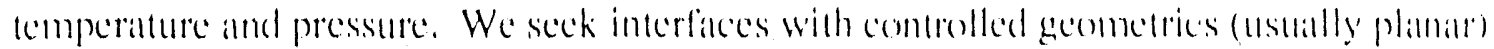

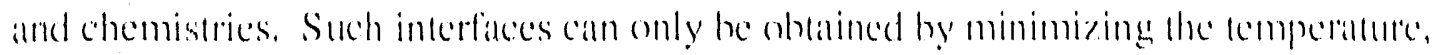

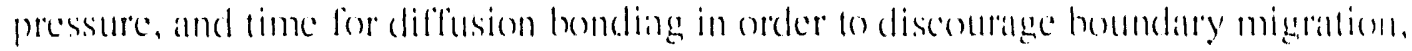

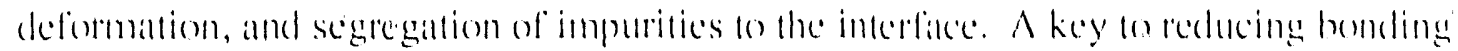
emperature, pressure, and time is the minimization of the volume of millerials thall must he

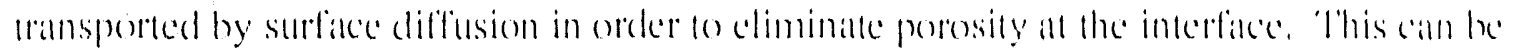

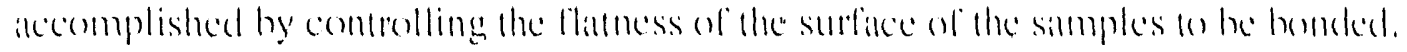

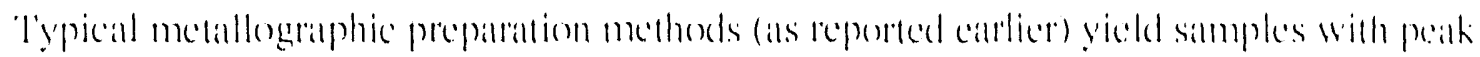

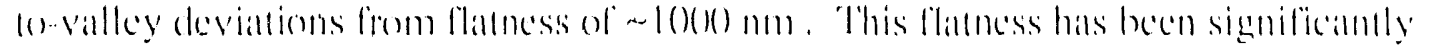

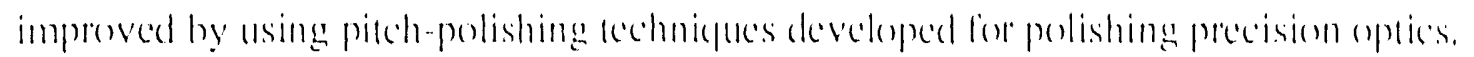

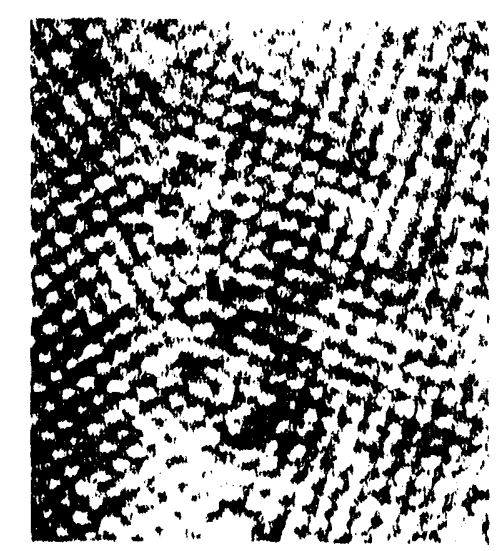

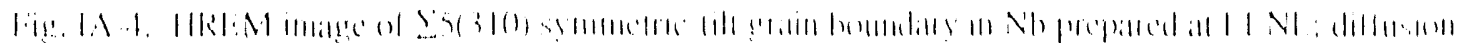

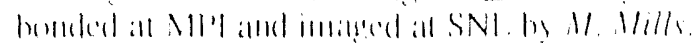




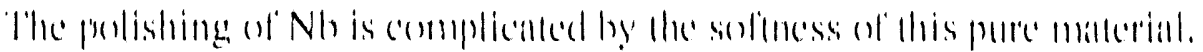

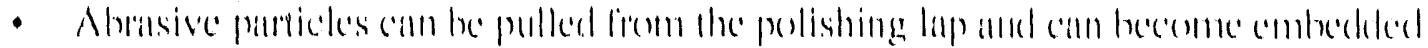

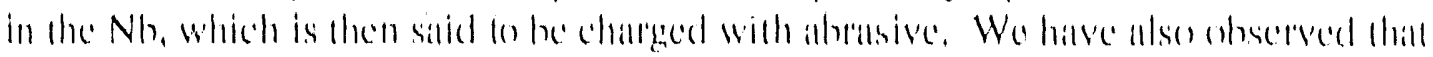

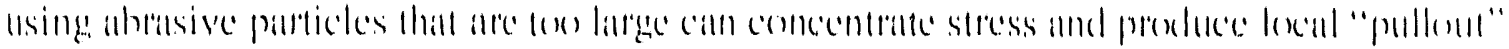

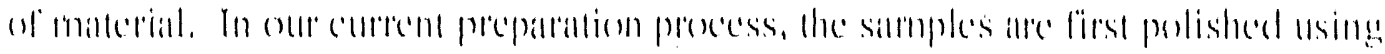

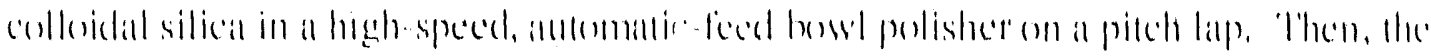

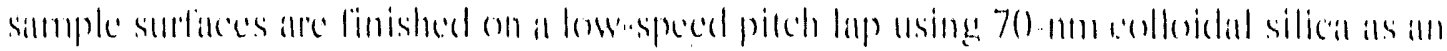

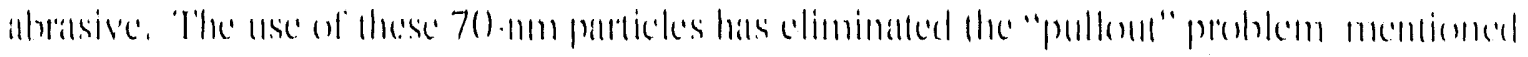

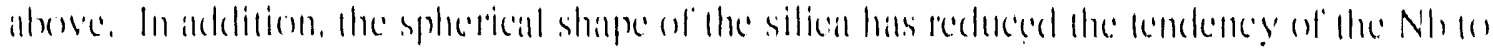

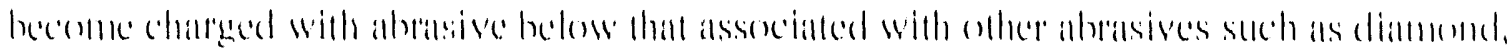

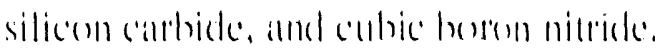

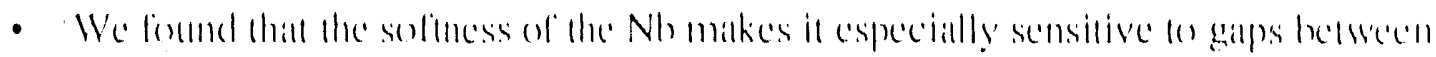

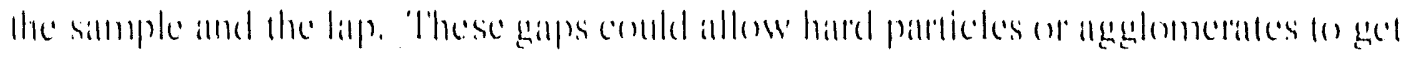

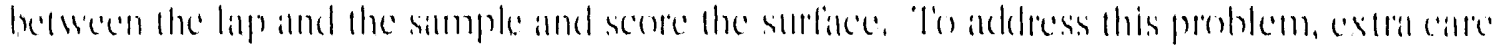

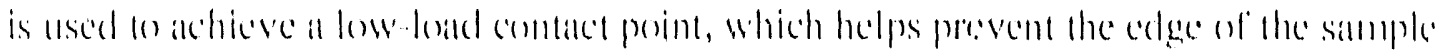
liom being lifted during the polishing process.

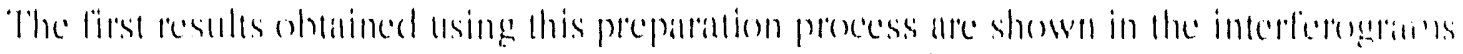

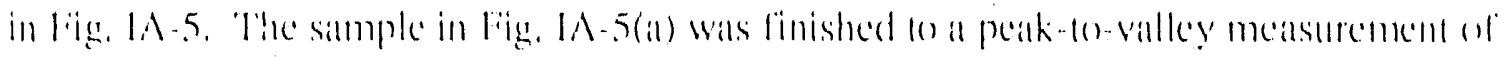

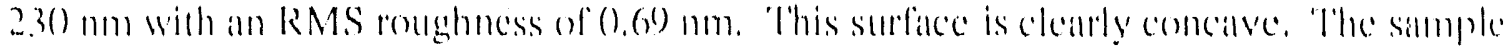
in lïg. IA -5(h) was substantially heller, having a peak-10-valley measurement of 82 mm and

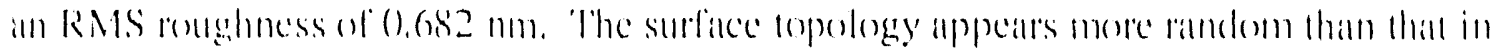

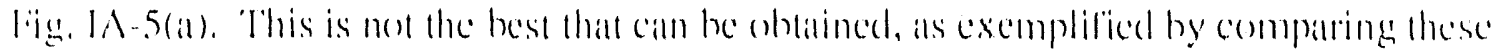

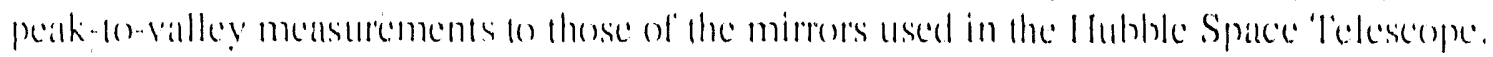

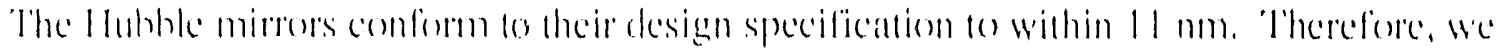

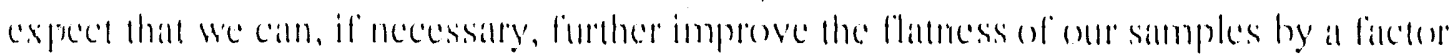
(1) $\sim 10$.

(ii)

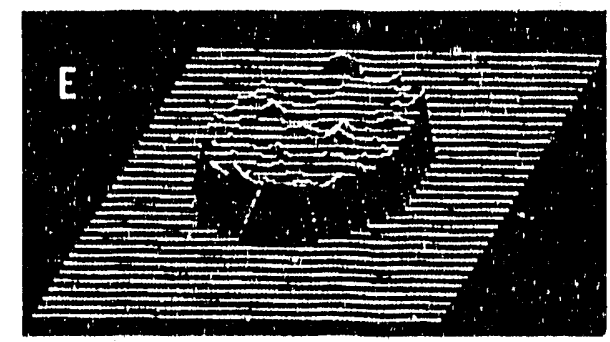

(b)

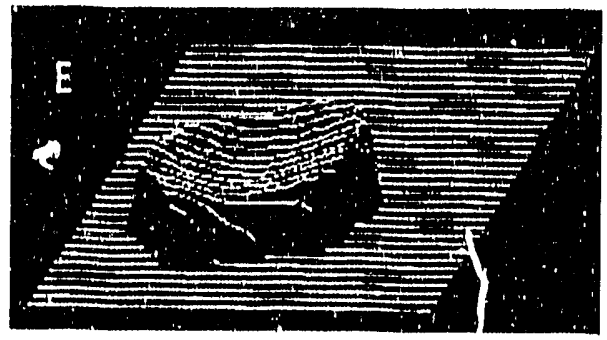

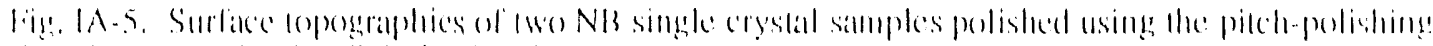

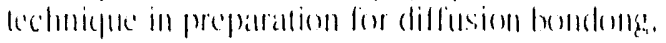




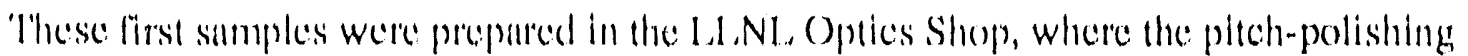

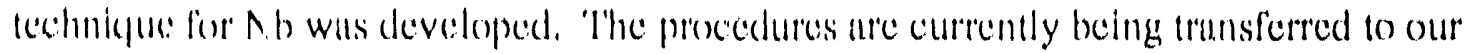
labotatory so that that they may be used routincly to prepare diffusion-bonded sumples.

\section{Roferences}

IA-1, X, G, Zhang and $\wedge$. Gonis, "A New, Real Space, Multiple Ssattering Theory Method for the Determintation of Electronic Structure," Phys. Rev. Lett. 62 , $11611164(1980)$

IA-2. X. (i. Zhang, A. Conis und J. M. MacLatren, "Real-Space Multiple-Scattering Theory and the Electronic Structure of Systems with Full! or Reduced Symmetry," Phy: Rev, B 40, 3(69) 3710 (1989)).

IA 3: L. C. Sowa, A. Gonis, X, -G. Zhang, anc S, M. Foiles, "Electronic Structure of Gritin Boundaries," Phys. Rev. B 40, 999.3.9996 (1989).

IA-4. J. M. Maclaren, X,-Ci. Zhung, A. Gonis, and S. Crampin, "Multiple-Scattering, Solutions to the Schröklinger Equation for Semi-infinite Layered Materials," Phys. Re'v. B 40, 995.599)58 (1989).

1A.5. W. Li. King, Interfaces, Adhesion, and Bonding, Lalwrence Livermore Nattional laboratery, Livermore, Calif., UC(I)-20622-89-1 (1989).

\section{Publications}

W. Li. King, Interfieces, Adhesion, and Bomding, Lalwrence Livermore National laboratory, Livermore, Calif, U(CID)-2()622-.19-2 (19)()).

W. L. King and J. H. Park, "Effect of Y on Cation and Anion Diffusion in Chromia,"

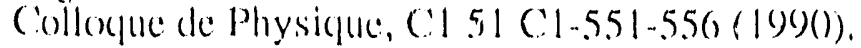

J. M. Maclaren, X.-G. Zhang, A. Conis, and S. Crampin, "Multiple-Scattering Solutions to the Schrödinger Liguation for Semi-infinite Layered Materials," Phys, Rev. B $4(0,9955.9958(1989)$.

E. C., Sowa, A. Gonis, X. -G. Zhang, and S. M. Foiles, "Electronic Structure of Grain Boundaries," Phys, Rev. B 40, 999) 3-9996 (1989).

E. C. Sowa, A. Gonis, and X. (i. Zhang, "First-Principles Calculations of the Electronic: Structure of Cirain Boundaries," presented all lntermatomal Congress on Intergranular and Interphatse Boundaries in Materials: 11389, Ecole des Mines de Paris, i. ance, 1989.

X.-G. Zhang, A. Conis, and J. M. Macharen, "Real-Space Multiple-S'antering Theory and the Electronic Structure of Systems with full or Reduced Symmetry, "Phy's. Rev. $B 40,36(94.3710(1989)$. 


\section{Presentations}

L. C. Sowa, "lilectronic Structure Calculations at Metal Grain Boundaries," Max Planck Instilut fïr Metullforschung, Institut für Werkstoffwissenschaft, Sept. 12, 1989.

B. C.. Sowil, A. Conis, X, - G. Zhang, and S. M. Foiles, "The Electronic Structure of S.5 Grain Boundaries in Cu," prescented at Materials Resentuh Society, Boston, Maine, Nov. 27-Dec: 2, 1989.

E, C. Sowa, A. Gonis, and X.-G. Zhang, "Electronic Structure Calculations of Cirain Boundaries in Cu," presented at March 199() Meeting of the American Physical Socicly, Anaheim, Calii, March 12 16, 190().

E. C. Sowa, A. Gonis, and X,-G. Zhang, "Electronic Structure Calculations of 25 Gran Boundaries in Cu," presented at 1990 Spring Mecting of the Materials Research Socicty, San Francisco, Callf, April 16-20, 1990, 392. 


\title{
FUNDAMENTAL ASPECTS OF METAL PROCESSING
}

\author{
J. N. Kass (Acting Thrust Area Le'ader)
}

\section{Overview}

This year, important new tasks in multilayer science and phase-diagram studies were added. Described here is the progress during the first half of FY9() for each of the task areas. Expectations for the second half of FY9() are briefly discussed.

\section{Large-Strain Deformation of Metals and Alloy}

\author{
M. E. Kassiner
}

G. A. Henshall

\section{Ductility of Aluminum Polycrystals}

As discussed in the final FY89 progress report for this subtask, we are determining the variation of the torsional ductility of aluminum with temperature and strain mate. New, more accurate, data have been obtained using a rheometrics torsion device; these data have been incorporated into a new publication, which rationalizes the extended ductility on a furdamental basis.

\section{Large-Strain Deformation of Al-Mg Alloys}

Significant controversy exists about the origin of the microstructure of Al-Mg alloys when they are deformed to large strains at elevated temperatures. In particular, a dramatic: increase in high-angle boundaries has been reported with large-strain deformation. This has been attributed to classic dynamic recrystallization that accompanies the decrease in stacking-fault energy with $\mathrm{Mg}$ additions. We believe that our earlier "basseline" aluminum results, which proposed the new geometric-dynamic-recrystallization concept, may be relevant with this group of alloys. A review of this subject was recently submitted for publication. Transmission electron microscopy was performed on test specinens that had been torsion tested and then quenched. The results on a 6 at. \% $\mathrm{Mg}$ alloy at $425^{\circ} \mathrm{C}$ and a strain rate of $10^{-3} \mathrm{~s}^{-1}$ dispute the discontinuous-dynamic-recrystallization concept for these alloys in favor of a geometric-dynamic-recrystallization model. Further tests at other strain rates and $\mathrm{Mg}$ compositions are currently being performed.

In a $F Y 9()$ article that has been written and accepted for publication, we discuss our understanding of thermomechanical processing of $\mathrm{Al}-\mathrm{Mg}$ alloys in relation to the production of superplastic microstructures. 


\section{Steady-State Flow in Al at Ambient Temperature}

Substantial experimental and theoretical controversy exists as to whether or not a true mechanical steady state exists with large-strain deformation at ambient temperatures. Furthermore, there is controversy as to the origin of the Stage IV hardening that occurs, apparently, in all metals with low-temperature, large-strain deformation. The controversy has been somewhat intensified by our silver results reported this fiscal year. Our objective is to conciusively determine whether a genuine mechanical steady state can exist at low temperatures and to correlate the details of the dislocation microstructure with Stages III and IV. Careful activation-energy measurements would help determine the steady-statedeformation mechanism if steady state is confirmed.

Several ambient-temperature torsion tests on pure Al have been performed with ambiguous results. Currently, specially processed (severely plastically deformed at LN temperature; followed by annealing to produce a fine grain size), high-purity Al will be compression tested (machined, deformed, machined again, etc., to minimize barrelling) instead of torsion tested to achieve the necessary large plastic strains.

\section{Time-Dependent Failure of Silver Interlayer Welds}

$$
\text { R. S. Rosen M. E. Kassner }
$$

This effort has been principally concerned with the rate-controlling mechanisms for time-dependent failure of diffusion-welded-silver interlayers fabricated by planarmagnetron (PM) sputtering electrodeposition, as well as with how processes other than diffusion welding (such as brazing) exhibit time-dependent failure. To test the generality of these results, 150 - $\mu \mathrm{m}$-thick interlayer brazes made with pure silver (using titanium-hydride flux and annealed type 304 SS and maraging steel base metals) were tested to determine if creep rupture occurs.

Figure MP-1 shows that creep rupture is observed in the brazed-silver joints when both plastic and elastic base metals are used. At high stresses, rupture times for brazed interlayers are shorter than those for diffusion-welded-silver interlayers that have been deposited by PM sputtering. This result is consistent with the lower ultimate tensile strengths of brazed-silver interlayers compared to those of diffusion-welded-silver interlayers deposited by physical vapor deposition. Aiso, the data for brazed-silver interlayers have higher (apparent) creep-rupture-applied stress exponents than those for interlayers prepared by PM sputtering. Certainly, these new data, together with earlier observations using other processes, suggest that mechanically induced creep rupture may be a general phenomenon in silver interlayer joints and, probably, also in joints using other interlayer materials.

Limited studies during the second half of FY90 will include the mechanical behavior of gold interlayers and our new precipitation-hardened $\mathrm{Ag}-13.5$ at.\% $\mathrm{Al}$ alloy interlayer. 


\title{
Failures of Metals at High Strain Rates
}

\author{
W. II. Gourdin
}

During the first half of this fiscal year, problems associated with the High-Explosives Application Facility (HEAF) and an unexpected cutoff in matching funds from the Office of Munitions resulted in limitations in the number of experiments that could be performed. Emphasis was placed on analysis and documentation of work completed or nearly so.

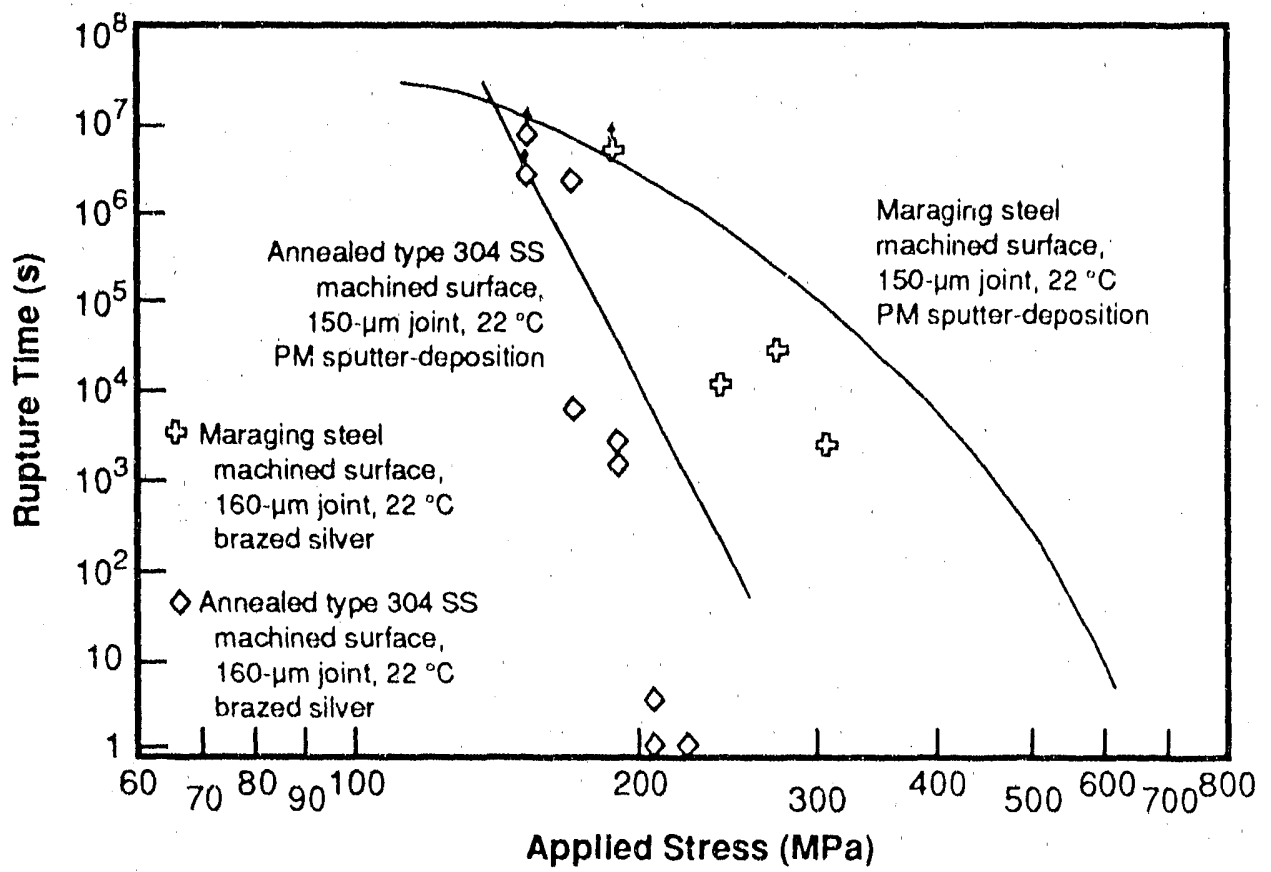

Fig. MP-1. Stress vs. time to-rupture plots of silver-interlayer welds.

A series of experiments was completed on electrodeposited, fine-grained, bright acid copper (UBAC), a material characterized by grain boundaries pinned by impurities. Flow stresses and elongations decline significantly at temperatures of $4(X){ }^{\circ} \mathrm{C}$, but failure remains ductile. This contrasts with the recent suggestion that embrittlement at low rates accounts for the poor performance of UBAC as a shaped-charge liner. Our data suggest that other factors account for low elongations as temperature increases.

In collaboration with J. Dini, we also tested copper electrodeposited in a cyanide solution. The results revealed poor performance. This will be checked against a test on an actual liner if it can be successfully fabricated.

We began experiments with new lots of powder metallurgy, arc-cast, and electronbeam-melted tantalum. The flow stress is high ( $(0.6 \mathrm{GPa})$, but otherwise this material shows the same absence of work-hardening and low elongation at failure that characterize the other tantalum materials we have studied.

An analysis of oxygen-free electronic (OFE) copper data is being performed within the context of the mechanical threshold stress (MTS) model. We find that the overall stress 
changes with grain size but that the rate of change of the stress with strain (the hardening) does not (at a fixed strain rate). This indicates that the grain size effect must be included in the "athermal" rather than in the "thermal" component of the stress. Analysis showed that the MTS model provides an excellent description of both lower rate data and ring data.

The observation that hardening rate is independent of grain size implies that the stain at which plastically unstable deformation begins decreases with decreasing grain size. We observe, however, that the total elongation at failure increases with decreasing grain size. This suggests that the rate of growth of the necks is important. This will be pursued in the second half of FY 90 .

\section{Modeling Non-Steady-State Rapid-Solidification Processes}

A rapid-solidification model has been developed to describe the formation of ultrafine particles that occur in rapidly solidified, dilute, hyper-entectic alloys. In the Al-Be system, ultrafine Be particles $(<10 \mathrm{~nm})$ form in Al-rich alloys containing approximately $5 \mathrm{wt} \% \mathrm{Be}$ when the alloys are solidified at rates $>0.1 \mathrm{~m} / \mathrm{s}$. These particles have a random crystallographic orientation and a unique modulated appearance that forms in "waves" parallel to the advancing solidification front, which indicates that the Be particles periodically nucleate and grow from the liquid phase during non-steady-state solidification conditions. This solidification mechanism has been observed in other alloy systems and is of interest because of the potential technological advantages that ultrafine microstructures offer over the rod/lamellar microstructures that form in conventionally solidified alloys.

The rapid-solidification model was used to determine which of two possible nucleation mechanisms is responsible for the formation of the ultrafine microstructures. One mechanism is the homogeneous nucleation of stable, hexagonal close-packed (HCP) Be particles. The model indicates insufficient solute enrichment in the liquid phase to overcome the relatively high liquid/solid (L/S) interfacial energy of these particles. The second possible mechanism is the homogeneous nucleation of metastable liquid-Be droplets. Preliminary estimates of the liquid/licjuid (L/L) interfacial energy were used to investigate the possibility of liquid-phase separation. Under these conditions, the model indicates sufficient solute enrichment in the liquid phase to overcome the $L / L$ interfacial energy, allowing homogeneous nucleation to be achieved by means of a licjuid-phase separation mechanism. These results are of interest because they indicate that the ultrafine microstructures only develop in those systems where the liquid-phase miscibility gap is accessible through rapid-solidification conditions. During the remainder of FY9(), a theoretical basis for calculating the $\mathrm{L} / \mathrm{L}$. surface tension will be incorporated into the model. This will complete the initial modeling effort. Application of the model to other binaryalloy systems with phase diagram characteristics similar to those of $\mathrm{Al}-\mathrm{Be}$ (Cu-Cr and Sn-Al) will also be initiated.

\footnotetext{
* Harvard University.
} 


\title{
Incorporation of Advanced Material Models in FEM Codes
}

\author{
G. A. Ilenshall \\ G. L. Gondrecu*
}

LLNL finite-element codes were applied to the stress analysis of the solid-state bonds described above. For base metals that deform plastically, it was found that the plastic strain in the interlayer produced by a given applied stress is significantly larger than for a similar weld between elastic base metals. As the thickness of the interlayer decreases for given diameter of component section, the principal stresses decrease and the stress distribution becomes more uniform. Moreover, the sensitivity of the stress state to changes in thickness also decreases. Finally, using the creep law implemented as part of this task, we found that creep of the base metal can induce creep of the interlayer even if the interlayer material alone does not creep. The creep rate of the interlayer is controlled by the creep rate of the base material. These results explain several experimental observations that could not be understood without the code improvements described above.

Implementation of the "MATMOD" constitutive equations into NIKE 3D was completed. It was found that a numerical integration routine more robust than "NONSS" is necessary for the use of MATMOD in problems of practical size.

\section{Recrystallization Studies}

\author{
C. W. Price
}

The primary objective of this task is to develop computer models to simulate grain growth, formalize grain-impingement geometry, simulate recrystallization kinetics, and isolate limitations of existing kinetic models. Another important objective is to develop improved atomistic models based on computer simulations and experimental observations.

Two papers were presented at Recrystallization ' 9() in Wollongong, Australia. These papers were based on the simplified computer simulation (SCS) model. A unique finding of the SCSs is that conformance of the interfacial migration geometry to the axial-symmetry constraint has a much greater affect on kinetic behavior than does the specific geometric shape of either the interface or the recrystallized grains. The axial-symmetry constraint is a novel concept that is finally beginning to reveal how important metallurgical parameters (such as deformation geometry and the initial grain size) should be incorporated into the kinetic models.

\footnotetext{
*Nuclear Explosives Engineering Division (NEED).
} 


\title{
High-Performance Nano-Engineered Multilayers
}

\author{
T. Burbere \\ N. Nyily'n
}

This newly funded task has the objective of exploring the mechanical and chemical behavior of nano-engineered multilayer materials. Using magnetron sputtering, we fabricated free-standing foils that were several tens of mm thick and consisted of thousands of layer pairs to provide a direct evaluation of properties.

Three sets of experiments were performed. The lirst was intended to produce hightensile-strength materials. Crystalline copper/3()4 stainless steel multilayers were made with moderate $(2 \%)$ mismatch across interfaces between the latyers. Bulk ultimate lensile strengthe for copper and stainless steel are 35 and $8(0)$ ksi, respectively. In marked contrast, we measured multilayer strengths exceeding that for ultahigh-strength maraging stects. No significant change in elastic modulus was observed. Several factors may contribule to this remathable strength, including the small flaw sizes chanacteristic of multiayers, the presence of closely spaced layer interfaces, and the interatomic forces across a coherent interface. Figure MP-2 is a HREM photo of a coherent interfice between Pt and Cr. "The berding of the atomic planes is quite evident.

The second set of experiments involves multilayers of high purity $\mathrm{Cu}$ and an amorphous Cu, $/ 2$ alloy. Foils with 35- and 5-nm Cu revealed 15()-ksi strength with about $8 \%$ deformation and greater than $90 \%$ reduction in area. This is an excellent combination of strenghth and ductility.

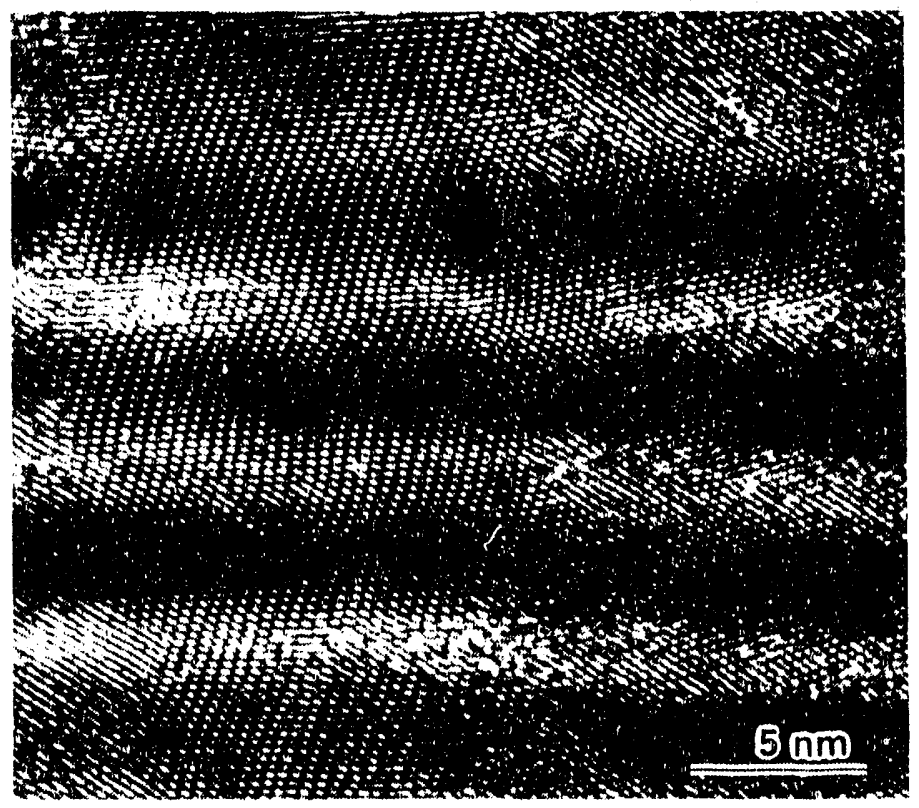

Fig. MP-2. HREM photo of Pl. Cr multilayer showing bending of allomic planes.

The linal set of experiments was intended to assess smoothness of a Mo/Si multilayer. Smoothness is very important for possible wear-resistant applications. Measurements 
using a $/ Y G(G) 5.5(0)$ interferometer revealed root mean sepuare roughness of less than (1. 1 mm and peak-10-peak of a few mm.

The work in this task has now been completed. I lowever, we intend to seek supplementary funding to more fully explore the theory, propertics, and potential applications of the se materials.

\section{Correlation of Electronic Structure with Processing of Advanced Substitutional Alloys}
A. li. Iankowski
P. E. A. Turshi

The primatry objective of this work is to examine the origins of phase stahility in alloys, with special emphases on the oceurrence of structural mansformations in substitutional alloys cexhibiting complex crystalline structures and on the possibility of processing recently predicted, ordered configurations in A15-based alloys.

So latr, theotetical studies have indued detailed examinations of the ground-state

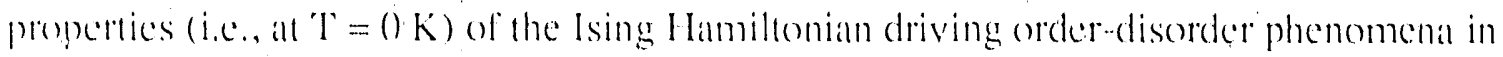
A15-based alloys and of the thermodymamie properties of two new ordered states at the composition $\triangle_{5} B_{3}$ and $\triangle_{7} B$, besides the well-known configurallon $A_{3} B$ based on the $A 1.5$ crestalline structure al ' $\mathrm{I}^{\prime}=0 \mathrm{~K}$. Phase diagram calculations allowed us to define the demain of stability, in temperature and conentration, of these new ordered stattes. We also charified the peculiarities of ordering mechanisms in complex structures. Finally, we calculaled diffaction palterns and short-range-order, diffuse-scattering intensities (as (ntatined with $x$-rays or neutrons) to facilitate comparison with future experimental imsestigations.

A few systems were selected in order to confirm the theoretical findings: "li-Pd and V. (ial. Thin film deposition has been used for the direed synthesis of crystalline deposits of

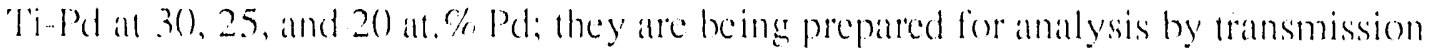
clectron microscopy ('IEM). Thin-film deposits with more than 3.3 alt. \% Pd are amorphous. 'Thin films of Ga-V have been sputtered from a hot-pressed alloy target. At 20 and 3.5 all. $\%$ (ia, the deposits are microcrystalline-amorphous, whereas 30 at. $\%$ (ia crystallites in an amorphous matrix appear to be an off-stoichiometric $A_{3} B$ structure. Delailed erystal structure determination is in progress. In addition to the program objectives, a composition-continuous series of molybdenum-oxide films has heen made using reatetive spuntering. Crystalline structures have heen produced in addition to those described in correct phase diagrams and in the literature.

\section{Applications of Synchrotron Radiation 'Techniques to the Study of Thin-Film Growth and Multilayered Structures}

$$
\text { T. II. liarluer, , Ir. }
$$

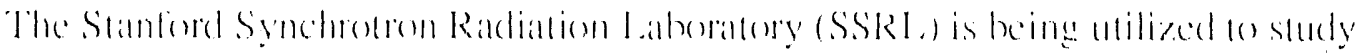

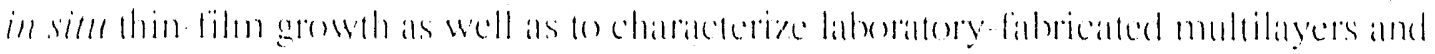


ulauhin fihms. The experiments were just recently completed, and results for in situ. growth are presented.

A thin-film, sputter-deposition system allowing sequential or co-deposition of two materials that could be installed in the beamline 1()-2 hatch was designed and constructed. This was designed to operate all grazing $x$-raly incidence, wilh deposition rate control for the species of interest at (0.05 to 1 .() momolayers/s. Fast, solid-state detectors were used to dever the fluoresene from the substrate material or the depositing adatom so that exiended $x$-ray ahsorption finc structure (EX $\mathrm{El}$ S ) spectra could be gathered in vacum.

For the fïst time, in situ EX $A$ IS measurements during vacuum-sputter deposition of thin films have been pertormed. Substrates used were superpolished, fused-silica substrates coated with $5($ ) $11 \mathrm{~m}$ of tungsten followed immediately by 70 monolayers of (iu. Cu deposition was interrupted after each of the first 20 monolayers in order to allow BXANS spectra to be ohtaned. The QEXAFS (quick-scanning EXAFS) technicyue was li. do obtain spectra within 21 s, minimizing contamination of the exposed surface of the copper film. The samples were illuminated at grazing incidence close to the critical angle.

We compared the evolution of the structure of these Cu films with results similarly obtained on the structure of Cu in W/Cu multilayers as a function of Cu thickness, and also with the structure of separately prepared, single Cu overlayers on W covered with a merective Clayer.

These results demonstrate a capability for doing surface structural measurements on a timescalc of seconds for sub-monolayer coverages. In the present case, this allows tis to follow the evolution of spulter-grown films under clean, uncontaminated conditions. In the gencral sense, however, it implies a capability for studying surface structures as a function of theckness, time, or chemical conditions.

A sofi $x$-ray fluoresecence I:XA is technigue that greatly simplifies this experimental procedure was demonstrated. Datta on a wide range of elements at their $K$ - and L-absorption edges were aleguired. These results indicate that QREXAFS studies are also possible at edges of 1()()$-e V$ threshold or higher using the new detector system and stalc-of-. the-art, soft $x$-ray synchrotron sources. These sources include our beamline 8-2 SGM source and the beamline 1()-1 S(iM to be installed as a wiggler side station during the next nine months.

In summary, the experimental results obtained demonstrate that thin-film growth maly be studied dynamically from its earliest stages at photon energies of 10$) \mathrm{eV}$ to $40 \mathrm{keV}$. This conabes the charaterization of interfaces as they are formed in a systematic mamer that will allow an in-depth understanding of the nature of interfaces to be developed from both structural and electronic-structure perspectives.

\section{Publications}

J. W. Dini and W. H. Courdin, "IEvaluation of electroformed Copper for Shaped Charge Liners," Plating and Surfuce Pinishing, in press.

J. W. Ehmer, S. M. Allen, and T. W. Eagatr, "Microstructural Development During Rapid Solidification of Statinless Steel Alloys," Metall. Trams. A 20A, 2117 (1989)). 
J. W. Elmer and T. W. Eagar, "The Influence of Cooling Rate on the Ferrite Content of Stainless Steel Alloys," in Recent Trends in Welding Science and Technology, Eds. S. A. David and J. M. Vitek (American Society for Metals, Metals Park, 199()), pp. $165-170$.

G. A. Henshall, M. E. Kassner, and R S. Rosen, "Ambient-Temperature Creep Failure of Silver-Aided Diffusion Bonds Between Steel," in Diffusion Bonding, Ed. R. Pearce (Cranfield, U.K. 1990), in press; also Lawrence Livermore National Laboratory, Livermore, Calif., (UCRL-101690), 1990).

G. A. Henshall, R. S. Rosen, M. E. Kassner, and R. G. Whirley, "Tensile Deformation Behavior of Interlayer Bonds Between Elastic and Plastic Base Metals Determined Using Finite-Element Analysis," submitted to Weld.J. UCRL-1()2280, (199()).

G. A. Henshall, R. S. Rosen, M. E. Kassner, and R. G. Whirley, "Finite-Element Analysis of Interlayer Welds Loaded in Tension," Lawrence Livermore National Laboratory, Livermore, Calif., UCRL-1(2280)(199()), submitted to Weld. J.

A. F. Jankowski, M. A. Wall, and P. E. A. Turchi, "Crystallization of Amorphous Ti-Pd," to be published in J. Less Common Met.

M. E. Kassner, "A Case for Taylor Hardening in Aluminum and Type 3()4 Stainless Steel at Elevated Temperature," J. Mater. Sci. 25, 1990).

M. E. Kassner, "The Rate-Dependence and Microstructure of High-Purity Silver Deformed to Large Stains between (0.16 and 0.3() T,$"$ Metall. Trans. 20A, 2()()1 (1989).

M. E. Kassner, "Large-Strain Deformation of Aluminum Single Crystals at Elevated Temperature as a Test of the Geometric-Dynamic-Recrystallization Concept," Metall. Trans. 20A, 2182 (1989).

M. E. Kassner, P. H. Adler, M. G. Adamson, and D. E. Peterson, "The Al-U (Aluminum-Uranium) System," Bull. Alloy' Phase Diag. 11, 82 (1990).

M. E. Kassner, N. G. Nguyen, G. A. Henshall, and H. J. McQueen, "Effects of Temperature and Strain-Rate on the Extended Ductility of Aluminum," submitted to Mater. Sci. Eng.

M. E. Kassner and N. Q. Nguyen, "The Effects of Temperature and Strain-Rate on the Elevated Temperature Ductility of Aluminum in Torsion," to be published in Advanced Aluminum and Magnesium Alloys (ASM Int., Brussels, 1990).

M. E. Kassner, N. Q. Nguyen, G. A. Henshall, and H. J. McQueen, "The Effects of Temperature and Strain Rate on Extended Ductility of Aluminum," to be published in Hot Deformation of Aluminum Alloys, Ed. T. G. Langdon (TMS-AIME, Warrendale, 199()$)$.

M. E. Kassner and D. E. Peterson, "The Al-Th (Aluminum-'Thorium) System," Bull. Alloy Phase Diag. 10, 466 (1989).

M. E. Kassner and D. E. Peterson," 'The Al-Pu (Aluminum-Plutonium) System," Bull. Alloy Phase Diag. 10, 459 (1989).

M. E. Kassner, R. S. Rosen, G. A. Henshall, and W. E. King, "Delayed Failure of Silver-Aided Diffusion Welds Between Steel," in Proce'edings of the 2 nd International Conference on Brazing, High-Temperature Brazing and Diffusion Welding (DVS-Verlag, Düsseldorf, 1989), p. 47. 
M. E. Kassner, R. S. Rosen, G. A. Henshall, and K. D. Challenger, "l'ime-1)ependent lailure of Silver-Interlayer Diffusion Bonds Between Non-Deforming Bane Metals," in Creep and Frasture of Enginesering Materials and Struntures, Vals. B. Wilshire and R. W. Evans (Inst. Melials, London, 1990), p. 179.

M. L. Kassuer, R. S. Rosen, and G. A. Henshall, "Delayed Mechancial Failure of Silver. Interlayer Diffusion Bonds," submitted to Metall. Trans. (UCRL,-1()2283, 10()()).

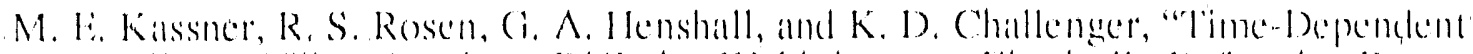

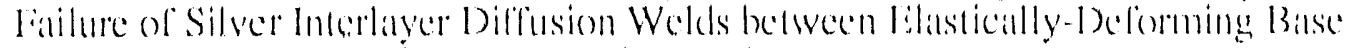

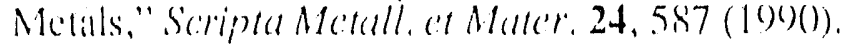

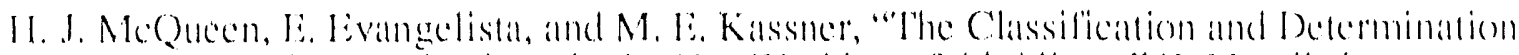
of Restonative Mechanisms in the I Iot-Working of Al-Alloy's." K. Mcterll, in press.

11. J. MaQueen and M. E. Kassner, "Behavior of Al-Mg Alloys in Hot Working and

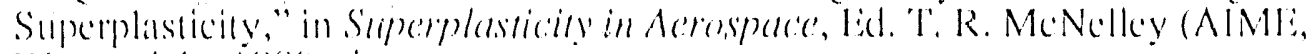
Warrendile, fo() $)$, in press.

(.. W. Price, "Comments on the Extent of Simultaneous Recovery During Recrystallizallon and lts liffect on Recrystallization Kinclics," Seripta Metall. 23, 127.3 (19889).

(. W. Price, "Lse of Johnson-Mchl-Avmami Kinetics in Recrystallization of Metals and

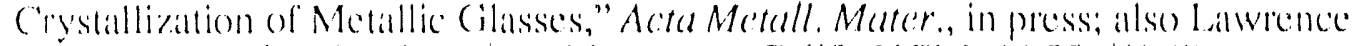
L.rermote National Laboratory, Livermore, Callif., UCRL,-9) $5.5(1(1989)$.

C. IV. Price, "The Concept of 'A xial-Symmetry Constraint' and les Significance in

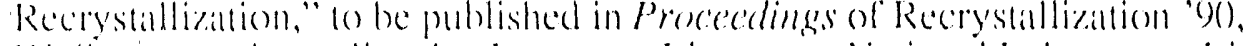
Wollongong, Australiat: also Latwrence Livermore National L aboratory, Livermore,

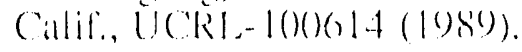

C. W. Price, "Use of Computer Simulations to Analyze Limitations of Kinctic Medels for" Recrystallizaltion," o be published in Proceededings of Recrystallizalton "()), Wollongeng. Amstralia; also Latwence Livermore National Laboratory, Livermore, Calil., L(KL-10()61.5(1980).

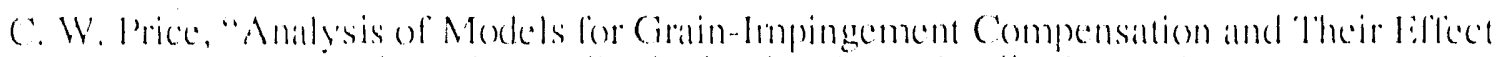

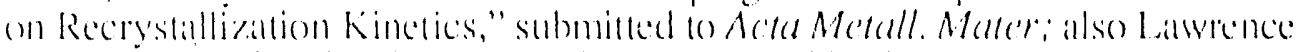

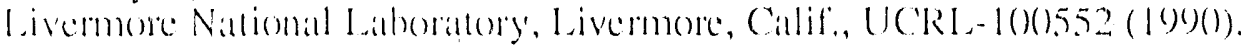

R. S. Rosen, "lime-Dependent Failure of Silver Interlayer Welds," Ph.l). Dissertanton,

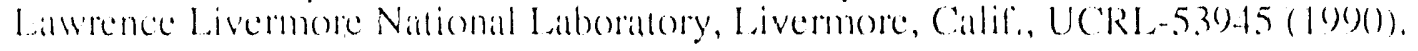

R. S. Rosen, S. Beitscher, and M. E. Kassner, "Stress Corrosion Cracking of U raniumSilver Intertakes in Silver-Aided Diffusion Wekds," in Environment-Indenced Cracking of Metals, Eds. R. P. Ciangloff and M. B. Ives (NACLE, Ilouston, Ig(g)), p. $4.9 \%$

M. L. Rosen and M. E. Kassiner, "Diffusion Welding of Silver Interlayers Coalted onto

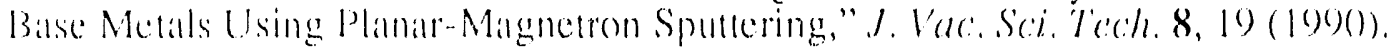

P. E. A. Turchi and A. Find, "Phase Stability Properties in Complex Substimbional Alloys," to be published in J. Ieese Common Met.

P. L. A. Thehi and A. Finel, "Oreler-Disorder Phenomena in Complex Alloys: 'lhe Case

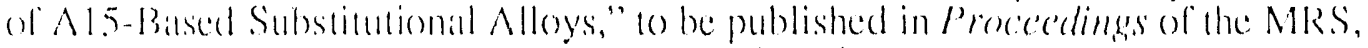

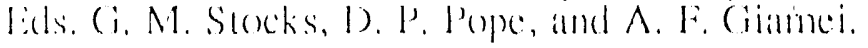




\section{Presentations}

J. W. Elmer, T". W. Eagar, and S. M. Allen, "Solute Redistribution and Second.Phase Formation During Rapid Solidification of Stainless Steel Alloys," 199() AWS International Welding Exposition, Anahelm, Calif, Apr. 22 27, 199(),

G. A. Henshall, M. E. Kassner, and R. S. Rosen, "Ambient-Temperature Creep Failure of" Silver-Aided Diffusion Bonds Between Steel," Second International Conference on Diffusion Bonding-Applications, Cranfield, U.K., Mar. 28.29, 199().

A. F. Jankowski and L. R. Schrawyer, "Renctive Sputtering of Molybdenum," sith International Conference on Thin Films/12 th International Conference on Metallurgical Coatings, San Diego, Calif,, Apr, 2-6, 1990).

M. E. Kassner, R. S. Rosen, G. A. Henshall, and W. E. King, "Delayed Failure of Silver-Aided Diffusion Welds Between Steel," TMS-AIME Fall Meeting, Indianapolis, Ind., Oct, 2-5, 1989.

M. E. Kassner, R. S. Rosen, G. A. Henshall, and K. D. Challenger, "Time-Dependent Failure of Silver Interlayer Diffusion Bonds Between Non-Deforming Base Metals," Fourth International Conference on Creep and ratcture of Engineering Materials and Structures, Swansea, U. K., Apr. 1-6, 199().

M. E. Kassner and R. S. Rosen, "Delayed Mechanical Failure of Silver Interlayer Diffusion Bonds," Pacific: Northwest Metals and Mincruls Conference, Porlland, Ore., Apr. 22 24, 199().

M. E. Kassner and R. S. Rosen, "Delayed Mechanical Failure of Silver Interlayer Diffusion Bonds," Oregon Materials Science Symposium, Corvallis, Ore, May 19, 199()$.

C. W. Price, "The Concept of 'Axial-Symmetry Constraint' and Its Significance in Recrystallization," Recrystallization '9), Wollongong, Australia, Jan. 22 26, 199().

C. W. Price, "Use of Computer Simulations to Analyze Limitations of Kinetic Models for Recrystallization," Recrystallization '9(), Wollongong, Australia, Jan, 22 26, 199().

R. S. Rosen, "Time-Dependent Failure of Silver Interlayer Welds," MSE 294 Seminar, University of California, Davis, Calif, Apr. 12, 199().

R. S. Rosen, M. E. Kassner, G. A. Henshall, M. A. Wall, L. R. Schrawyer, and D. M. Makowiecki, "Delayed Failure of Silver-Aided Diffusion Welds Between Elastic and Plastic Base Metals," 1990 AWS International Welding Exposition, Anaheim, Calif., Apr. 24-26, 199().

P. E. A. Turchi and A. Finel, "Electronic Structure and Phase Stability of $A$ 15-based Substitutional Alloys," invited talk, 119 h "l'MS Annual Meeting, Anaheim Calif, Feb. 18-22, 1990.

P. E. A. Turchi and A. Find, "Order-Disorder Phenomena in Complex Alloys: The Case of A 15-based Substitutional Alloys," MRS Spring Meeting, San Francisco, Calif., Apr. 16-20, 1990.

R. G. Whirley and G. A. Henshall, "Incorporation of Creep Modeling into the NIKE 2-1) Codes," JOWOG 31, Sandia National Laboratory Albuyuergue, N.M., Apr. 4. 1900. 


\section{PLUTONIUM}

\section{R. Newkirk (Thrisst Area Leideder)}

The plutonium thrust was refocused somewhat at the starl of $F Y(9)$ to increase the reseurch effort associated with the Laboratory's enhanced sufety program. 'This was in response to the high priority established for this aren by both DOE and the Laboratory Director and concentrated specificully on establishing a scientific understanding of the containment of molten plutonium. To accomplish this, efforts in plutonium-deposition technology and thermodynamic properties of plutonium compounds were dropped, and modifications to the direction of the electronic-strueture task were made. The liquid-metalinduced embrittlement task was expanded, and two new tasks---solid-metal-induced embrittlement and advanced multilayer coatings- - were funded. In anddition, although unrelated to enhanced salfety, work on the FY 89 project $\mathrm{Li}$ reduction of $\mathrm{PuO}_{2}$ was brought to a successful conclusion.

The objectives and rationale for each task and progress to midyear are discussed below, with the exception of Solid-Metal-Induced Embrittlement. Unexpected commitments elsewhere left this task without the reguisite scientific expertise for successful execution. Thus, it was terminated at its start, with part of its resources channeled into other tasks in this thrust and the remainder returned for use on other projects. A small alteration in the experimental plan for the licpuid-metal task is planned to give a very limited indication of where the solid-metal task might have led.

\section{Liquid-Metal-Induced Embrittlement}

\section{(i. Ciallegos}

\section{J. Iluang}

The antack of liquid actinides on refractory metals can be classified into two types: (1) intergranular attack and (2) rapid uniform dissolution. The study of attack under applied stress is also important. It appears that the addition of a tensile stress can substantially accelerate the localized penetration at the grain boundaries, through either acceleration of an existing mechanism or introduction of a new one. In the former, it will provide additional insight into unstressed corrosion, in either case, however, it is an important effect to understand in designing alloys for penetration protection. An important objective of this task is to more precisely determine the nature of the stress-assisted degradation phenomenon of liçuid-actinide/solid-refraciory-metal couples and to quantify the applicability of general liguid-metal-induced embrittlement.

We are continuing to study the mechanisms of liequid-U antack on 'Ta alloys and W under stress. Previous results had shown that polycrystalline Ta and W were embrittled by liquid $U$ during tensile loading at $120(0)^{\circ} \mathrm{C}$ and at strain rates between $10^{-5}$ and 1()$^{-2} \mathrm{~s}^{-1}$. The embrittlement was associated with very fast intergranular penetration of liguid U. We also reported that single-crystal Tat was not embritled by liguid $U$.

During this report period, we examined the tensile behavior of single-crystal $W$ in licpuid $U$ at three different strain rates, 1()$^{-2}, 10^{-3}$, and $1\left(0^{-4} s^{-1}\right.$. As observed for Tat the 


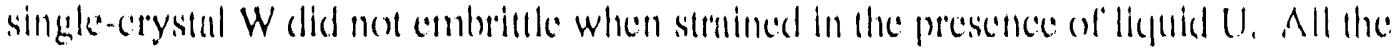

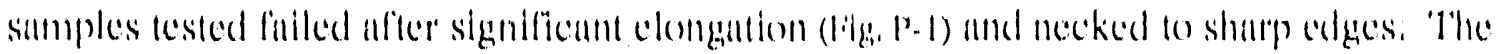

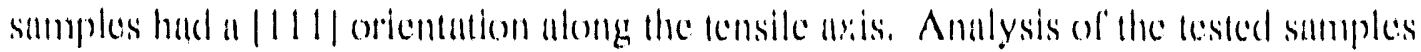

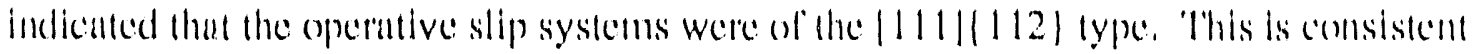
with results in the literature for sumples lested in vacum. We observed that some liejuid I had migrated into the sample along dislocation-slip planes. It may be suggested that these I atoms are swept into the sumple by the moving dislocations. The incrusions were very shallow and cansed no signiticant embrittement of the samples. These results are further evidence that the mechanism of embrittlement observed in the polyerystalline 'la and $W$ is not the classical licpuid-metal embrittement (LMLi), for which typically the adsorption of liguid atoms on a solid is enough for reduee the strength of the muterinl and cantuse brittle fristure.

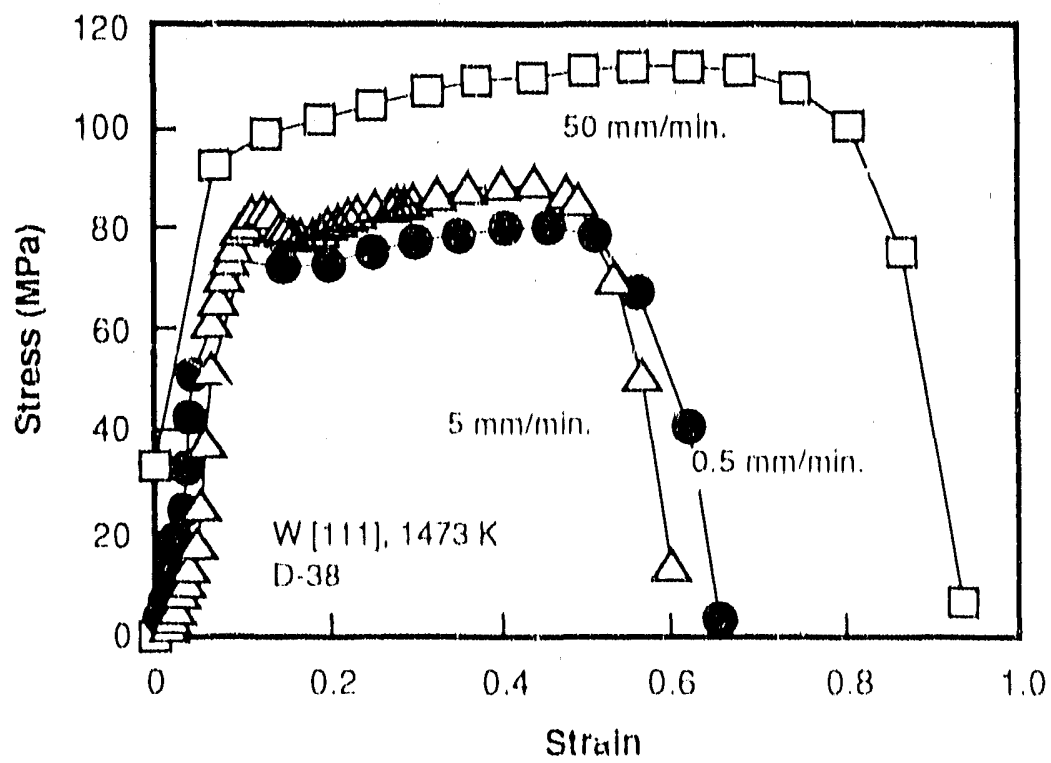

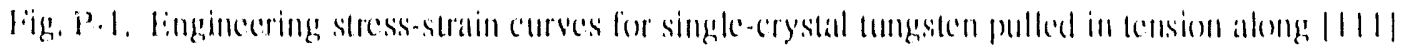

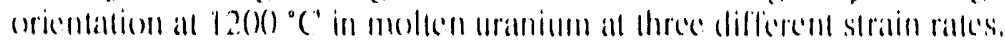

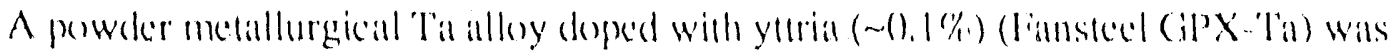
also studied. Previobisly, resciarchers at los Alamos Nallonall aboralory (1.ANL) had

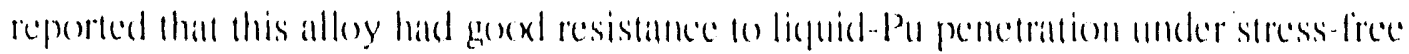

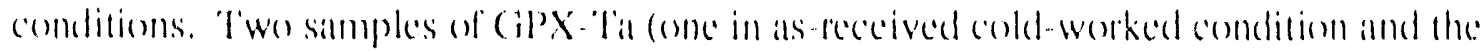

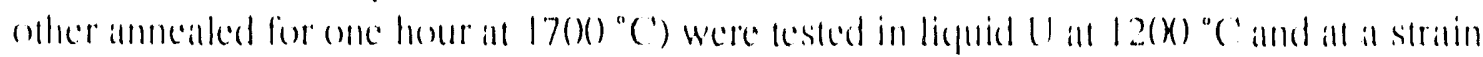

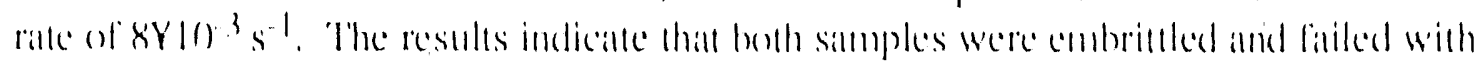

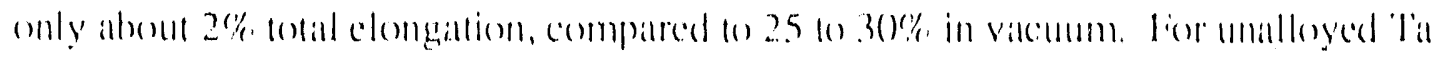

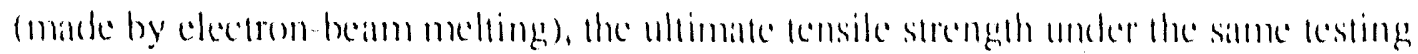

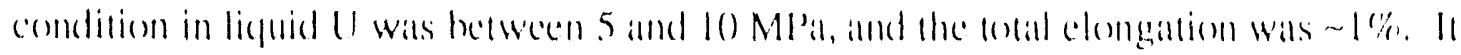

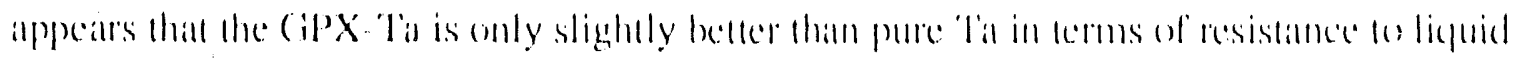

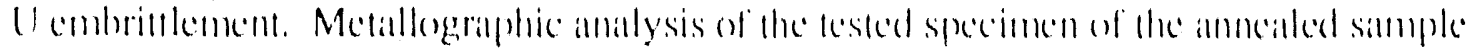

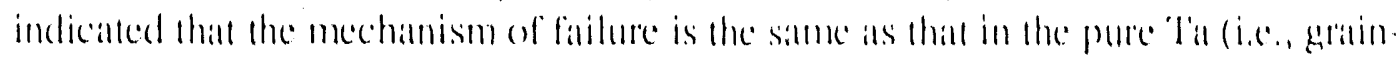




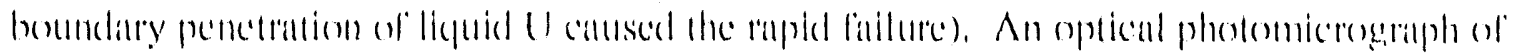

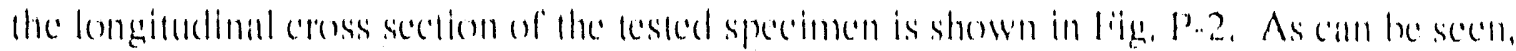

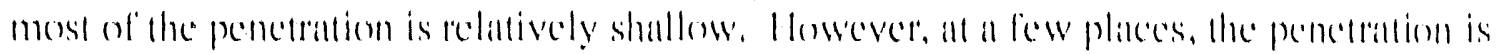

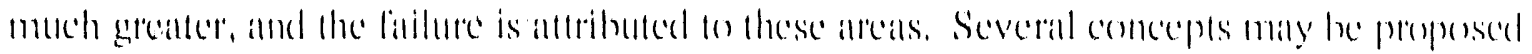

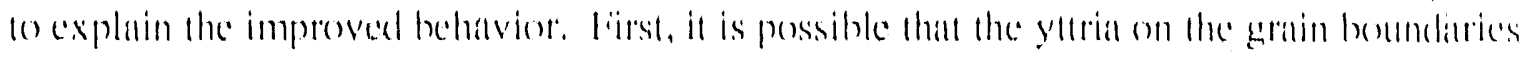

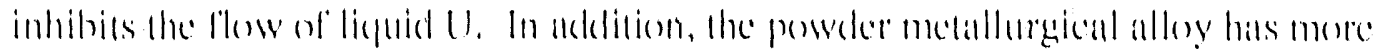

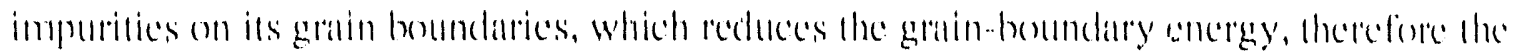

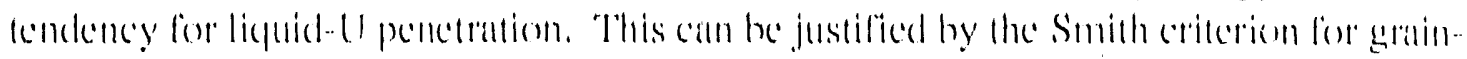

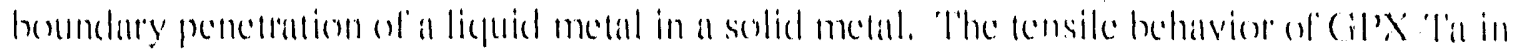
licpuid l'u will also be studied soon for comparison.

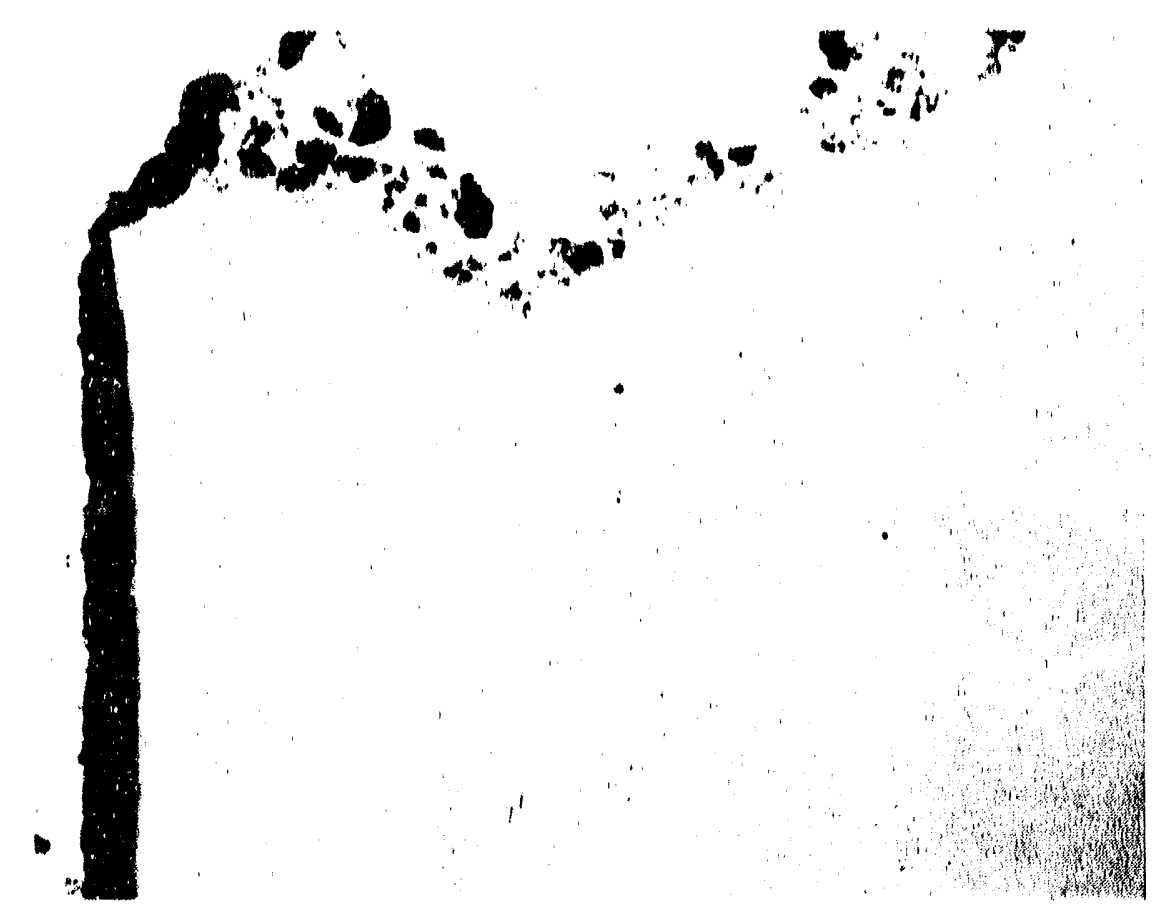

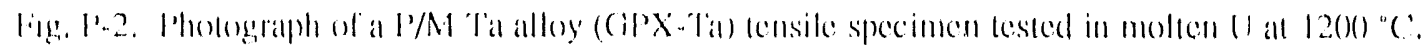

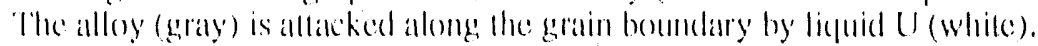

In the third area, we have completed our apparatus development in the Pul fitcility and statted to investigate the behavior of different refractory metals and alloyss ('lia, Nb, V, Cr,

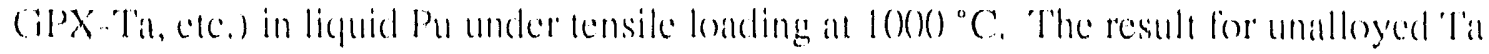
(i.e., clectron-beam meleded showed that it is also embritted by licpuid Pu. The total

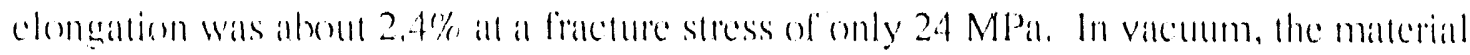

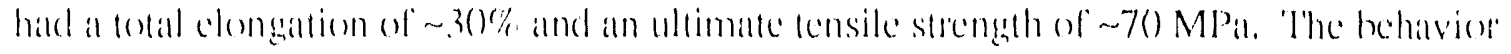

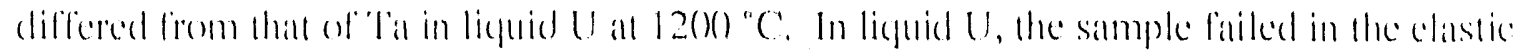
range, whereas the simple fitiled in molen Pu in the clastic-plastic range als an clastic-

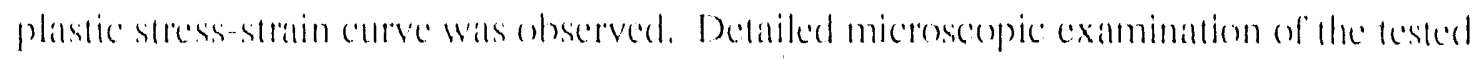

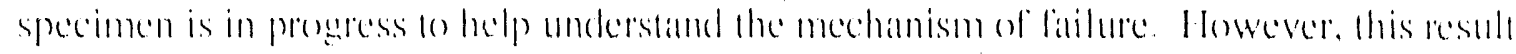

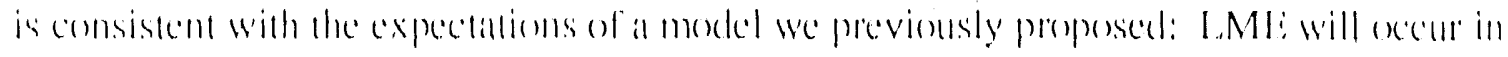
systems in which the mutual solubilities between the liepuid and solid metals atre very smatl. 
systems in which the mutual solubilities between the liquid and solid metals are very small. $\Lambda$ second tensile test, $\mathrm{Nb}$ in liquid Pu, has just been completed. The ultimate tensile stress wiss also very low on this specimen.

\section{Advanced Multilayer Coatings}

\section{C. Fiarmer}

R. L. Krueger

The use of metal/metal-carbide multilayer technology provides an excellent geometric: arrangement for studying the mechanies of licyud-metil penetration in composite structures. The dissolution allong grain boundaries in the metal, along the metal/metal-carthide interfice and then through cracks in the metal carbide, is a potentially interesting mechanism to study.

Multilayer technology provides a well-defined intimate interfice, independent contel of individual layer thicknesses, and the potential for prestressing by control of deposition temperature. In addition, the geometric factors associated with the potential licyuidpenetration route present an opportunity for a possible breakthrough in the use of coatingss for containment technology.

Two types of multilayer coatings are being considered for application to attack by liquid plutonium. The rnultilayers are either alternating tungsten and TaC layers or alternating tantalum and TaC layers. All three constituents tungsten, tantalum and TaC are known to have good resistance to plutonium attack. Since TaC is not wet by liquid plutonium, plutonium may not penetrate along the tungsten/TaC interfice. Furthermore, it is well known that some free-standing, multilayer films exhibit unusually high tensile strenglhs, an order of magnitude greater than the strengths of the constituents. It may be possible to fabricate high-strength multilayer films that are resistant to altack by licyuid plutonium.

We have developed a two-source electron-beam evaporation technicue for the production of these multilayers. This system has been used to produce several prototype coatings that are composed of individual layers of tungsten, tantalum, and Tac that atre 12.5-, 12.5-, and (0.5- $\mu \mathrm{m}$ thick, respectively. Typicilly, the substrate temperature is $1.3(x){ }^{\circ} \mathrm{C}$ during condensation of the tungsten films, $1.350{ }^{\circ} \mathrm{C}$ during condensation of tantalum films, and $9(0){ }^{\circ} \mathrm{C}$ during condensation of $\mathrm{T}$ 'aC films. Rates of deposition of both tungsten and tantalum layers are $\sim 25 \times 1()^{2} \mathrm{~nm} / \mathrm{min}$. In contrast, the rate of deposition for TaC is $1 \times 10^{2} \mathrm{~nm} / \mathrm{min}$. The deposition process was initially developed on flat substrutes to establish the process parameters.

A typical multilayer of W/TaC is shown in Fig. P-3. The transition from flat substrates to the inner surface of small-diancer $(1.9 \mathrm{~cm})$ hemispheres has been successfully carried out, and simples of W/laC and Ta/l'aC are ready for plutonium exposure. Hemispheres were hydroformed from tantalum sheets, and the inside surfice was prepared for coating by rough polishing. 


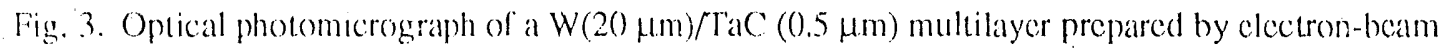
cvaporation.

A testing assembly has been designed and fabricated to allow three specimens to be exposed in each experiment. Careful consideration has been given to the potential effect of impurities in the furnace atmosphere. The concern exists that gettering of a poor furnace vacuum by the Pu charge could form an oxide skull on the charge and alter its interation with the coating. Each set of three samples will contain a standard, and an extensive outgassing procedure for the furnace will be carried out. If the reference samples indicate that this is insufficient, the fixture design will allow hermetic sealing by welding, followed by outgassing and a final pinch weld on the outgassing lube. If required, this procedure will ensure a high-purity atmosphere for the test, but the much more extensive preparation lime will considerably reduce the number of test samples.

In addition to direct Pu-sufface tests, some of the films will be scribed so that "edge" altack can be investigated. If the materials perform well in these initial tests, we will strive (1) make films composed of thimner individual layers so that high tensile strengths can be achieved. This may require that coatings be produced by sputtering with multiple guns, and may be done in collaboration with T. Barbes. 


\title{
Plutonium Alloy Stability
}

\section{A. Gonis}

The primary objective of this task is the ab initio calculation of stable structures of plutonium with a variety of second elements such as $\mathrm{Al}, \mathrm{Gia}, \mathrm{Si}, \mathrm{Am}, \mathrm{Sc}, \mathrm{Np}$, and $\mathrm{Ce}$. While not related to enhanced safety, these are an important veticle for improving and expanding the development of electronic-structure calculations. In addition, they will provide an understanding of the driving mechanism responsible for the large number of allotropic Pu phases and for the stability of alloys of Pu with other elements. The study consists of examining and comparing the energetics of various Pu-crystal structures as well as treating binary alloys. This task was also originally intended to address the application of electronic-structure calculations in support of the solid-metal-embrittlement task by studying the effect of adsorbed atoms at a crack tip. Unfortunately, the calculational formalism cannot treat the disorder associated with a liquid-embrittlement process; thus it will not be undertaken at this time. Currently, the major effort is the improvement of the KKR-CPA codes that were developed within a relativistic formulation of multiplescattering theory to take into account the rearrangement of electronic charge taking place upon alloying and its effect on charge self-consistency.

During the past four months, effort has been concentrated in attempts to stabilize the version of the alloy code that treats the alloy charge distribution in a self-consistent manner. This wo $\mathrm{k}$ is being done in collaboration with $P$. Weinberger (Vienna). To ditte, we have calculated the electronic structure of Pu-Am alloys at a specific concentration, but the selfconsistency loop is still not satisfactorily stable. This problem will be discussed during the week of May 1, when T. Gonis visits Vienna.

The calculation of the electronic structure and energetics of the various crystallographic phases of pure Pu will begin in May and is expected to be finished by midsummer. As far as we are aware, these will be the first calculation of the electronic structure of a (monoclinic) Pu, with a dense mesh of k-points.

\section{Lithium Reduction of $\mathrm{PuO}_{2}$}

\author{
M. Coops
}

The majority of this effort was carried out under midyear FY89 funding, and resources from the Pu thrust served only to wrap up the project. The goal was to experimentally investigate the thermodynamics of the Li.Pu-O system to alssess the feasibility of Li reduction of $\mathrm{PuO}_{2}$. The project demonstrated that the reduction occurs with the prextuction of alpha Pu and further that partial phase separation occurs under normal gravitational forces. A detailed report of this project has been completed.

\section{Publications}

J. S. Huang and G. F. Gallegos, "Embrittlement by liquid U in some group V-B and VI-B metals and alloys during tensile loading at 1.77.3 K," submitted to Metall. Trans. 


\section{Presentations}

J. S. Huang, "Formation of niobium carbides in high-dose carbon-ion-implanted and annealed niobium," Materials Research Society 1989 Fall Meeting, Symposium A, Beam-solid Interactions: Physical Phenomenon, Boston, Mass, Nov. 27--Dec. 1, 1989.

J. S. Huang and G. F. Gallegos, "Embrittlement by Liquid U in Group V-B and VI-B Metals During 'Tensile Loading at $1473 \mathrm{~K}$," Symposium on Liquid Metal Surface Interactions and Corrosion of Refractory Metals in Liquid Metal Systems, 1990 TMS Annual Meeting, Anaheim, Calif, Feb. 20, 1990.

J. S. Huang, "Mechanical properties of carbon-implanted niobium," Symposium on Thin Films: Stresses and Mechanical Properties II, Materials Research Spring Meeting, San Francisco, Calif., Apr. 16-20, 1990. 


\title{
SYNCHROTRON-RADIATION-BASED MATERIALS SCIENCE
}

\author{
J. Wong (Thrust Area Leader)
}

\section{Overview}

The objective of this thrust area is to understand the role of structure (atomic and electronic) in determining the physico-chemical properties of materials and their processing. The tasks defined in this thrust area take advantage of the various unique characteristics of synchrotron radiation such as high intensity, high collimation, high polarization, and broadband tunability vacuum ultraviolet (VUV, to hard $x$-ray) to probe the structure of matter on an element-selective basis at different levels. The research areas involve both expansion of our existing capabilities in material characterization using these powerful photon sources and development of new capabilities (a) to probe dilute species in bulk materials, (b) to determine geometric and electronic structure of surfaces and interfaces, and (c) to unravel chemical dynamics of reaction systems in situ in real time in the second to millisecond range.

Highlights during this reporting period were:

- Achieved a time resolution of $10 \mathrm{~ms}$ in the diffraction study of $\mathrm{Ni}+\mathrm{Al}$ reaction with a focused beam at the National Synchrotron Light Source (NSLS).

- Successfully installed a second position-sensitive photodiode-array detector to double 20-space data acquisition in our time-resolved $x$-ray diffraction (TR-XRD) measurements.

- Stabilized powder surface to maintain q-2q position during in situ combustion during TR-XRD measurements.

- Confirmed formation of intermediates in the $\mathrm{Ni}+\mathrm{Al}$ reaction.

- Obtained new microstructural data for resorcinol-formaldehyde aerogels and an aluminum multiphase alloy from small-angle x-ray scattering (SAXS) and tomographic experiments, respectively.

- Constructed and demonstrated use of a load cell to perform in situ tomographic images under tensile loads to $100 \mathrm{kpsi}$.

- Designed and successfully installed a new capability for quick scanning of extended $x$-ray absorption fine structure (QEXAFS) at beamline 1()-2 at the Stanford Synchrotron Radiation Laboratory (SSRL) to perform time-resolved x-ray spectroscopic measurements on phase transformation and thin-film deposition.

- Completed construction of chamber for in situ thin-film deposition with QEXXAS. 


\section{Time-resolved Diffraction and EXAFS Study of Solid Combustions}

J. Wong

P. Waide
E. Larson

B. Rupp
I. Holl

R. Frahm

For the combustion reactions of $\mathrm{Ti}+\mathrm{C}$ in the presence of $25 \mathrm{wt} \% \mathrm{Ni}, 2())$ scans were made; each took $200 \mathrm{~ms}$, so the total scan time for this experiment was $40 \mathrm{~s}$. From this sequence of time-resolved diffraction scans, we learn that the first step in the combustion process is the melting of Ti particles. Subsequently (within the same $2(0)$-ms time frame), the molten Ti reacted with the solid carbon particles to form TiC. It has been suggested that the mechanism of reaction is one of solution-precipitation rather than solid-state diffusion through a growing TiC layer. In this mechanism, the carbon dissolves in the molten Ti and then precipitates out as TiC grains that grow in size with time. The total reaction time for the complete formation of TiC is within $\pm(0.2 \mathrm{~ms}$.

In the formation of $\mathrm{NiAl}$ by combustion synthesis, we discovered that the formation of the NiAl intermetallic compound is a complex reaction in which the product phase does not appear until approximately $30 \mathrm{~s}$ after the passage of the combustion front. After the $\mathrm{Ni}$ and Al reactants disappear $(<3 \mathrm{~s})$, a number of intermediate phases are observed before the. $\mathrm{NiAl}$ product phase. The occurrence of these intermediates was confirmed in our second run at NSLS in December 1989. By using a focused beam, we were able to reduce our scan time from $50 \mathrm{~ms}$ to $10 \mathrm{~ms}$.

Partial melting of the surface of several samples introduced an uncertainty factor into the analysis of the data for the Ni-Al system. Therefore, it was necessary to conduct a detailed parametric study of the $\mathrm{Ni}$-Al combustion reaction. By using a Ni powder with an average particle size of $5 \mu \mathrm{m}$ rather than the $20 \mu \mathrm{m}$ used in the first experiments, we were able to fabricate samples in which the surface did not melt during reaction and the (2-20 position correlation was maintained.

We have also performed a third group of experiments in which we used our new QEXAFS scan capability at SSRL to monitor the site-specific chemistry of $\mathrm{Ni}$ in the $\mathrm{Ni}+$ Al reactions as well as $\mathrm{W}$ in the reduction of $\mathrm{WO}_{3}$ by $\mathrm{Al}$. In the former system, the $\mathrm{Ni} \mathrm{K}$ edge XANES spectra were recorded every $3 \mathrm{~s}$ with a view to following the chemical changes at the $\mathrm{Ni}$ site from the $\mathrm{Ni}$-metal reactant to the final $\mathrm{NiAl}$ product through the series of reaction intermediates as observed in the TR-XRD experiments in the afterburn region. More interesting is the result obtained by monitoring the reaction at constant energy in the time scale of $20 \mathrm{~ms}$. In Fig. SR-1(a), note that the feature at $8381 \mathrm{eV}$ for the Ni-foc metal is transformed to a minimum in the NiAl product, which is bec in structure. By monitoring the intensity variation at this constant energy, we were able to follow experimentally the kinetics of the transformation of the Ni-fec reactant to the bec NiAl product. The result is shown in Fig. SR-1(b) together with the temperature profile measured in situ and synchronously. Analysis is underway to elucidate phenomenologically the kinetics of the $\mathrm{Ni}+\mathrm{Al}$ reaction. Similarly, the W L.z-edge white line was used to monitor the reduction of $\mathrm{WO}_{3}$ to $\mathrm{W}$ metal by $\mathrm{Al}$. 

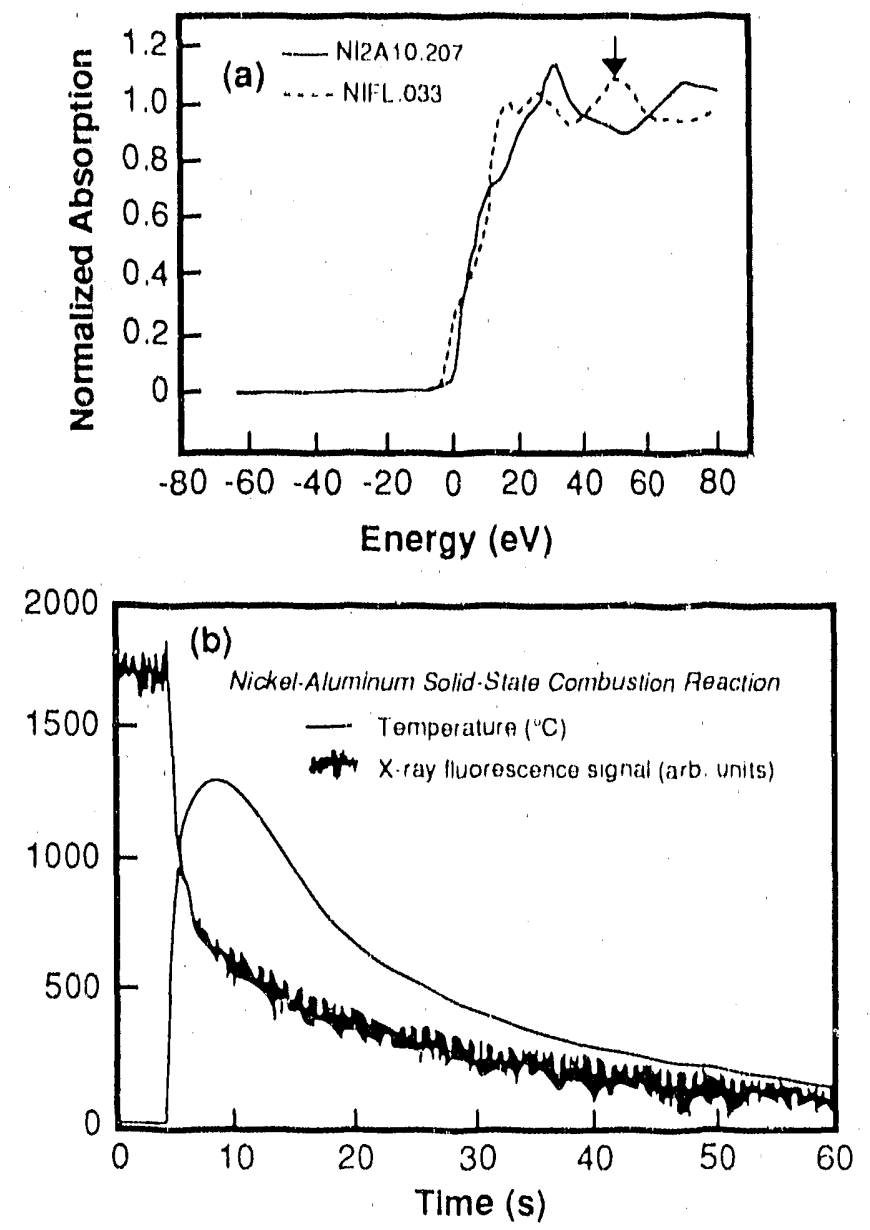

Fig. SR-1. (a) Ni K-edges XANES of nickel metal (fec) and NiAl (bec); (b) Temperature and NiKa fluorescence signal at constant photon energy $8.381 \mathrm{cV}$ as a function of time in the reaction $\mathrm{Ni}+\mathrm{Al}=\mathrm{NiAl}$.

In a laboratory experiment, we successfully demonstrated the use of an inframetric camera to record synchronously both spatial and time-temperature profiles of combusting specimens. This new IR capability will be incorporated in our future TR-XRD studies in the coming July run at NSLS.

During the rest of FY90, we plan to:

- Coordinate an inframetric camera with our high-speed diffactometer for synchronous temperature-profile measurements with TR-XRD scans.

- Complete 20 scans with both detectors for the $\mathrm{Ni}+\mathrm{Al}$ reaction to attempt identification of reaction intermediates.

- Perform time-resolution diffraction measurements on Ti $+C(<10() \mathrm{ms})$.

- Initiate a TR-XRD study of new systems:

- $\mathrm{WO}_{3}+2 \mathrm{Al}=\mathrm{W}+\mathrm{Al}_{2} \mathrm{O}_{3}$

- $\mathrm{Ta}+\mathrm{C}=\mathrm{TaC}$ (no liquid phase)

... $3 \mathrm{Cu}+2 \mathrm{BaO}_{2}+\frac{1}{3} \mathrm{Y}_{2} \mathrm{O}_{3}=\mathrm{YBa}_{2} \mathrm{Cu}_{3} \mathrm{O}_{7}$ 


\section{Thin Film and Interface Structure}

\section{Photoemission Study}

A photoelectron-diffraction study of $\mathrm{Fe} / \mathrm{Cu}(()() 1)$ has been performed. This includes a feasibility study for spin-dependent photoelectron diffraction that will allow a determination of magnetic as well as geometric structure. In collaboration with $V$. Colin and $P$. $A$., Alivisatos (UC-Berkeley), monodispersed CdS clusters have also been examined for quantum confinement effects such as valence-band maxima shifts with cluster size using SR photoemission. Also, a high-resolution photoemission study was performed on untwinned sirgle crystals of $\mathrm{YBa}_{2} \mathrm{Cu}_{3} \mathrm{O}_{0.9}$ in collaboration with other LLNL personnel, V.Z. Liu (UC-Davis), and C.G.Olson (Ames) to probe the Fermi surface and valence band dispersions in this material.

During the rest of FY9(), we plan to continue the studies listed in the above three series of experiments, in particular utilizing beamtime at SSRL during the April run.

\section{Thin Film Growth}
T. Barbee
R. Frahm
P. Woside

A sputter-deposition chamber with in situ $x$-ray absorption spectroscopy (XAS) measurement capability using a glancing fluorescent detection mode in situ in vacuum has been constructed. The chamber will be tested in the April 90 run at SSRL to study the nucleation and thin-film growth using the newly installed QEXAFS capability at beamline 10)-2 at SSRL.

Our plans for the rest of FY9() are to

- Perform in situ extended $x$-ray absorption fine structure (EXAFS) measurements during thin-film deposition by sputtering.

- Analyze data from the April 90 experiments.

\section{Advanced Microstructural Studies}
J. II. Kinney
U. Bonse*
R. Saroyan
M. Stock**

During the sabbatical stay of Prof. Bonse, we were able to carefully analyze the SAXS results obtained using the new point-focusing camera. The results indicate that there are no size structures greater than $40 \mathrm{~nm}$ in the resorcinol-formaldehyde aerogels; that information has now been related into a chemical growth model for these gels. Also, we reanalyzed data taken from the Stanford run last year on an aluminum multiphase alloy and determined that we can resolve individual grains $(101-15 \mu \mathrm{m})$ and the precipitated intermetallic phases.

\footnotetext{
* University of Dortmund.

${ }^{* *}$ Georgia Institute of 'Technology.
} 
That this can be done three-dimensionally and nondestructively has important implications for materials processing and control.

We have demonstrated the application of an in situ load cell, constructed by our collaborators at Georgia Tech, that has successfully allowed tomographic imaging of samples under tensile loads up to $100 \mathrm{ksi}$. This will allow us to address problems in crack closure. This demonstration was witnessed by representatives of Boeing Aerospace, who are interested in funding this project. The LLNL Public Affairs Office is preparing a publicity release, since this is the first in situ experiment of this kind ever performed.

We have established an in-house tomography capability in building 241 . Using this laboratory system, we have demonstrated $10-\mu \mathrm{m}$ resolution in composites. We have observed fibers breaking under lond before matrix failure in the aluminum-matrix, SiC fiber composite materials being considered for the Hypervelocity Civilian Transport project being funded by NASA.

During the remainder of $F Y 9()$, we will:

- Write up papers for the above three activities for publication. An instrumentation article on the laboratory tomography will be prepared for the Iournal of Materials Engineering.

- Conduct high-resolution imaging in the April run at SSRL.

\section{Site-Specific Chemistry}
B. Rupp
R. Frahm
M. Weber
E. Larison
J. Holl$$
\text { M. Wethr }
$$
I. Wong

We have designed and successfully installed a QEXAFS system on beamline 1()-2 at SSRL to enhance our XAS experimental capabilities in the time regime as described earlier. $X A F S$ spectra of the $\mathrm{Nd}^{3+} \mathrm{L}_{3}$ transition were recorded in December at NSLS for several additional co-doped silica samples and for several representative laser glasses. We now have data on $\mathrm{Nd}$-doped $\mathrm{SiO}_{2}$ prepared by various techniques and for $\mathrm{Nd}: \mathrm{SiO}_{2}$ co-doped with $\mathrm{Na}^{+}, \mathrm{B}^{3+}, \mathrm{Al}^{3+}, \mathrm{La}^{3+}, \mathrm{H}^{4+}, \mathrm{Ta}^{5+}$, and $\mathrm{P}^{5+}$. Differences are readily apparent in the XAFS spectra. To complement the XAFS datil, we also completed recording opticaladsorption spectra of $\mathrm{Nd}^{3+}$ for all of the above samples and for all fluoride glasses for which XAFS data were recorded earlier. Of particular interest are the intensity of the transition at $580 \mathrm{~mm}$ and the splitting of the ${ }^{4} \mathrm{~F}_{3 / 2}$ state, both of which are sensitive indicators of changes in the disorder and asymmetry of the local field. Large spectral differences are observed depending upon the concentration of $\mathrm{Nd}$ and the nature of the codopants. From these results, we can begin to tailor optical properties by the selection of the chemical composition of the lanthanide co-dopant cluster.

To enhance our analytic capabilities for structural determination from XAS experiments, a number of application programs have been cieveloped:

- A mapping routine into the EXAFS litting soltware that is employed to study the local environment of lanthanum in potassium silicate glasses.

- A two-dimensional contour-plot program for difference Fourier analysis of diffraction spectra using VAXIDL on CMSI VAX. 
- SlExili a a microcompuler program for the calculation of coordination shells and geometries. This program will serve as a useful tool for comparing coordinalion geometries in order to extract experimental phase shifts needed for our study of Cr-doped laser materials.

During the rest of $F Y()$ (), we plan to:

- Complete determinalion of $\mathrm{Cr}^{3+}$ site in LiCaAllag.

- Begin detailed nis deling of the locnl environment of $\mathrm{Ne}^{3+}$ in simple $\mathrm{SiO}_{2}$, in $\left.\mathrm{SiO}\right)_{2}$ o-doped with various modifiers, and in silicate and phosphate glasses.

- Prepane an Institutional Rescarch and Development (IR\&D) proposal to use QBXALS fo study a variety of solid-state reaction kinetics.

\section{$Y_{1566}$}

I. H'oms'

T. Tamaka*

M. lickirt

Z. Riek

(i. Shimkin's's'

R. $R^{\prime}(1) w^{*}(a)^{* * *}$

Symchrotron topographic examinations of latrge $Y^{\prime} B_{60}$ crystals $(1 \mathrm{~cm}$ dia. $\times 5$ cm long) glown by Dr. Tanceke indeed reveal a single crystal of good guality at the seed end. This is very encouraging and is a necessary prereguisite for use of this material as monochromallor in the solt $x$-raty region. Experiments are being scheduled at the end of the April run at SSRL to measure rocting curves of these crystals with the synchrotron beam in the 1- 10 2-keV region. This material is a potential substitute for beryl in the Test Program. L-Division has commitled $\$ 3.3 \mathrm{~K}$ this fiscal year and another $~ \$ 10() \mathrm{K}$ in FY91 to contract with licieg (Santa Barbara) to grow single crystals of YBor.

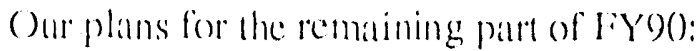

- Prepare rocking-curve characterization of $Y B_{(x)}$.

- Cirow YBog from cirbon-free boron powder.

- Consult licidecion YBog crystal growth.

\section{Publications}

B. Daunh, P. Sen, B, Rupp, W. Ciudal, Ch, Ziegler, and W. Ciönel, "NonSuperenducting and Rendered Superenducting YBal $\mathrm{C}_{3} \mathrm{O}_{7-x}$ : an In-Situ Ihotenemission Study," Z. Phys. Bl, Condensed Matter, in press.

J. B. Holt, J. Wong, E. Larson, P. Waide, B. Rupp, and R. Frahm, "A New Lxperimental Approach to Study Solid Combustion Reactions Using Symchrotron Radiation," in Preceedings of list US-Japanese Workshop on Combustion Synthesis, lids. Y. Kaiceda and J, B. Ioll (19)()).

J. B. Ilolt et al., "A New Experimental Approach to Study Solid Combustion Reatetion Using SR," L awrence Livermore National Laboratory, L jvermore, Calif"., UCRL, -102287(109()).

\footnotetext{
* Institute for Inorganic Materials Research, Japan.

* Stanford Symchrotron Radiation Laboratory.
} 
E. M. Larson, F, W. Lytle, P, G. Eller, R, B. Gregor, and M. P. Eastman, "XAS' Study of Lanthanide Ion Speciation in Borosilicate Glass," I. Non-Crystal. Solids 116, 57 $(1990)$.

E. M. Larson, P. A. Waide, and J. Wong, "High Speed Diffractometer," submitted to RD Magazine; RD.100 Competition.

F. W. Lytle, G. Van der Laan, R. B. Gregor, E. M. Larson, C. E. Violet, and J, Wong, "Determination of the Valence of Pr, Gd and $\mathrm{Ho}$ in $\mathrm{YBa}_{2} \mathrm{Cu}_{3} \mathrm{O}_{7}$ by XAS," Phys. Rev. B, in press.

H. J. Maier and B. Rupp, "Environmental Effects on the X-ray Line Profiles of Fatigued Low Alloy Steel," Scripta Metall. 24, 353 (199()).

S. J. Marshall, G. W. Marshall, M. D. Jendresen, A. P. Tomsia, and J. H. Kinney, "Preferred Orientation of Apatite Crystals in Dentin,"J. Dental Res. 69, 269 (199()).

'B. Rupp, E. Porschkes, P. Menffels, P. Fischer, and P. Allenspach, "Neutron-Diffraction Study of ErBa2 $\mathrm{Cu}_{3} \mathrm{O}$ ? in the composition range $6.16 \leq \mathrm{X} \leq 7.0$." Phy's. Rev. $B \quad 40$, $4472(1989)$.

J. Wong, E. M. Larson, J. B. Holt, P. A. Waide, B, Rupp, and R. Frahm, "lime Resolved Diffraction Study of Solid Combustion Reactions Using Synchrotron Radiation," submitted to science.

J. Wong, G. Shimkaveg, N. Goldstein, M. Eckart, T. Tanaka, Z. U. Rek, and II. Tompkins, "Y $B_{6,6}$ : A New Soft X-ray Monochromator for SR," Niucl. Instrum. Method, in press.

Joe Wong et al., "YB 6 : A New Soft X-Ray Monochromattor for SR.," Lalwrence Livermore National Laboratory, Livermore, Calif., UCRL-10221.5 (1989).

Joe Wong et al., "Time Resolved Diffraction Study of Solid Combustion Reatction I Sing SR," Lawrence Livermore National Laboratory, Livermore, Calif., UCRL, I(12.3()() $(199())$.

\section{Awards}

J. B. Holt received the PROMETHEUS AWARD at the first U.S.--Jalpanese Workshop on Combustion Synthesis in January 1990 for his "excellent contribution to the Advancement of Combustion Synthesis Technology."

\section{Activity in Professional Society:}

1. Kinney chatired a special session on "X-ray Microscopy" at the Annual meeting of the American Crystallographic Society, New Orleans, Lat. Mar. 199(). 


\section{Presentations}

J. B. Holt and J. Wong, "Fundumental Study of' Solid Combustion Reactions," AmI. Mecting of Chem. Eng., San Francisco, Calli, Nov, I9889.

J. B. Holt, J. Wong, E. M. Larson, P. Waide, and B. Rupp, "A New Experimental Approalch to Solid Combustion Reacting Using Synchrotron Radiation," Ist U.S." Japanese Workshop on Combustion Synthesis, Ibaraki, Japan, Jan, 199(

E. M. Larson, "New Time-Resolved Difraction Results of SAS Reaction al NSLLS," Symehrotron Tea, Livermore, Calif, Ocl, 1989.

L. M. Latson, J. Wong, B. Holl, P. A. Waide, and B, Rupp, "lime-resolved Diltriction Studies of Fast Solid Combustion," IGth Anmual SSRL Users Group Meeting, Stautord, Calif., Oct, 1989.

13. Rupp, "Structural and Chemical Dymamic Studies at CMS" presentation to AWU Students, Livermore, Calif, Dece, 1989.

J. Tobin, "Photoemission Studies of Fe/Cu (()()1)a," APS March Meeting, Anaheim, Callif, 199().

M. J. Weber, J. Wong, R. B. Gregor, F. W. Lytle, and D. R. Sandstrom, "OpticallyDetected X-ray absorption Spectroscopy in Luminescent Materials," American Meeting Optical Society of America, Orlando, Fla., Oct. 1989.

J. Wong and J. B. IHolt, "A New Experimental Approach to Study the Chemical Dymamics and Phase Transformation al High Temperalure," DOE Matcrials and Solid Stale Div., Washington, D.C., Dec. 1989.

J. Wong, E. M. Larson, J. R. Holt, P. Waide, and B. Rupp, "T"ime-Resolved X-ray Diffraction Studiess of SAS Reactions Using Synchrotron Radiation," Coramic Congress, Anaheim, Callif, Nov. 1989.

J. Wong et al., "lime-Resolved Diffration Studies of Solid Combustion Reatetions," Annual Meeting of X-11 PRT, Brothiaven, NSLS, Jan, 199(). 


\title{
WEAPONS-SUPPORTING RESEARCH
}

\author{
Individual Projects
}




\section{S'IRUC'TURAI, 'TR ANSFORMATION ANI) PRECURSOR PHENOMENA IN ADVANCEI) MATERIALS: 'THEORY ANI) EXPERIMEN'TS}

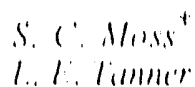

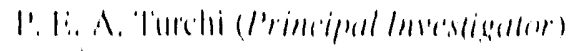

li. II. IIn'ill

M. I. II/111..1

\section{() verview}

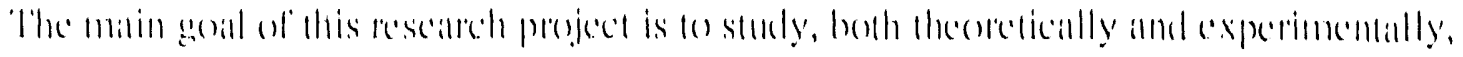

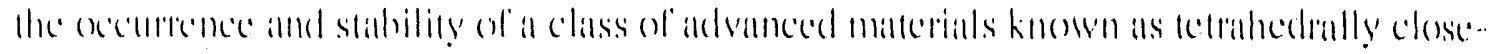

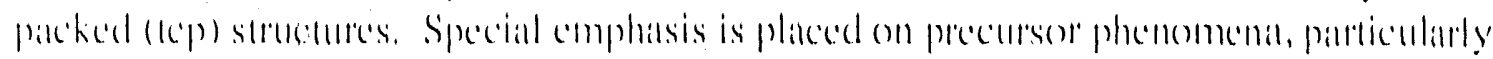

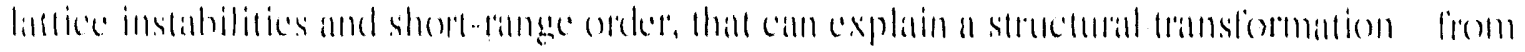

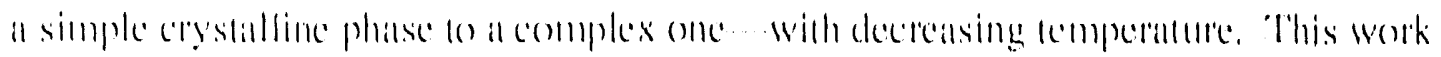

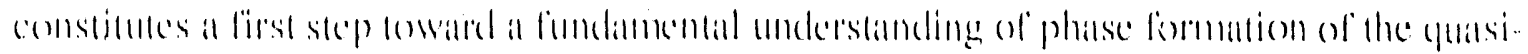

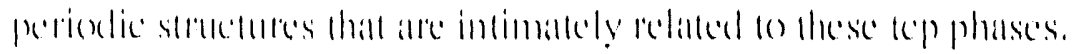

\section{'lhoretical Progress}

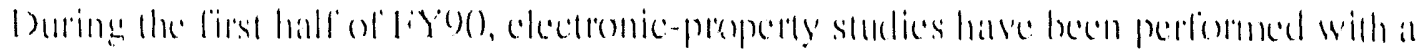

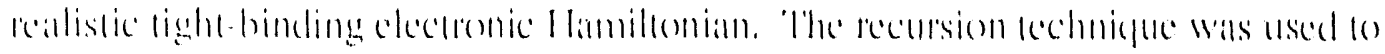

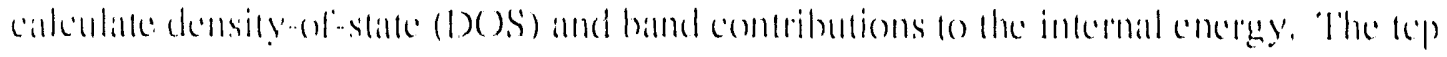

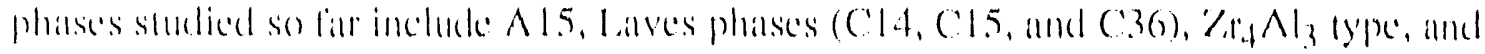

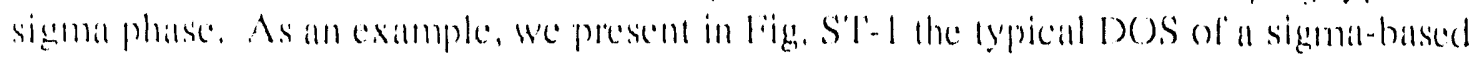

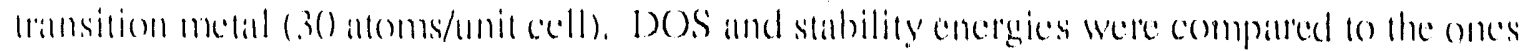

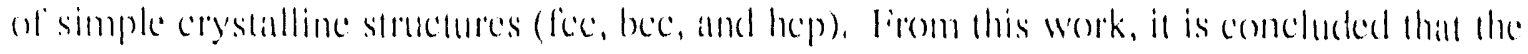

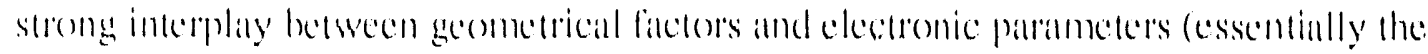
mamber of valence de electrons beides to a stability of these complex phases for an average

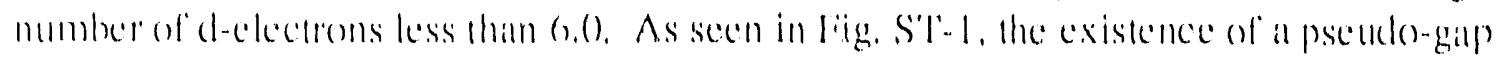
in the Dos for a hand filling $N$ about 5 a delectrons imposes a clear separalion between bonding stilles (all low Ni and andi-bonding stalles. This feature is common to all tep

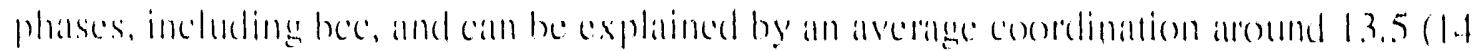
line hece.

\footnotetext{
" Iniversily of Houston.
} 

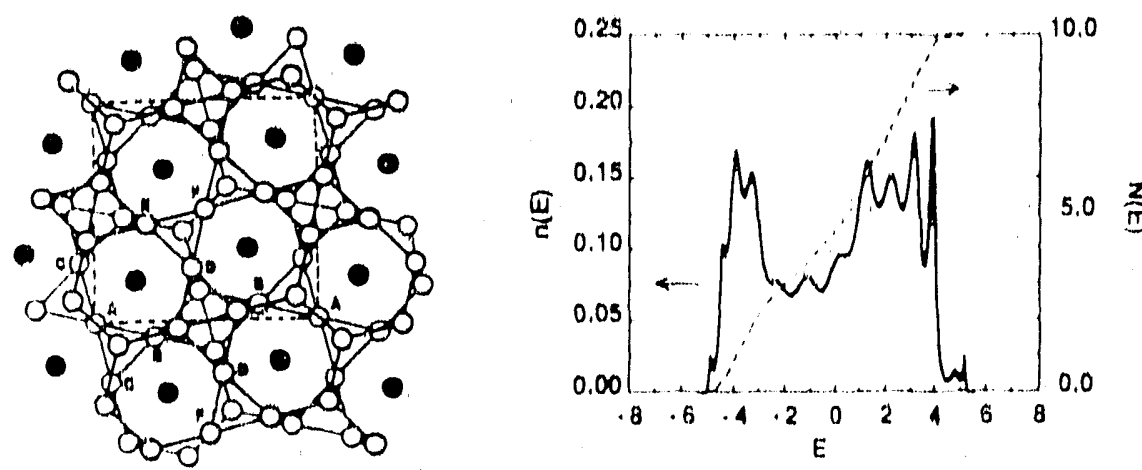

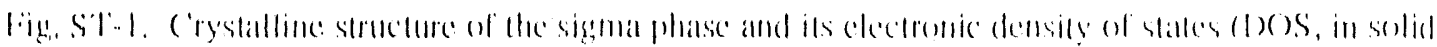

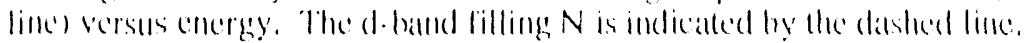

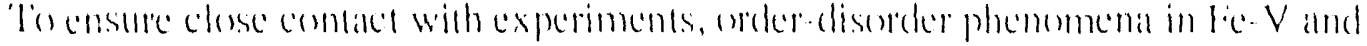

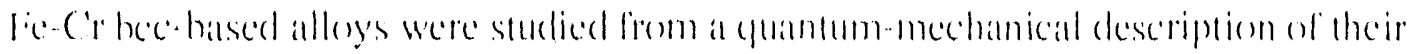

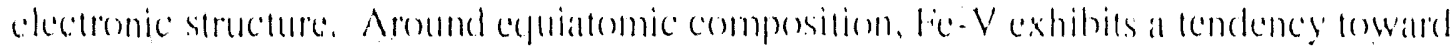

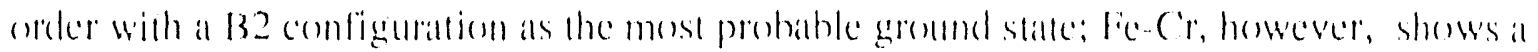

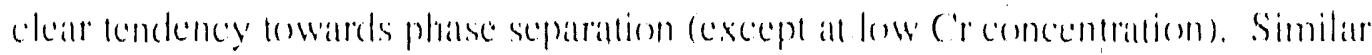

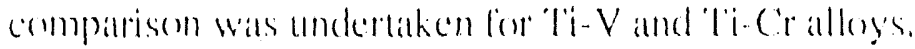

\section{Lixperimental Progress}

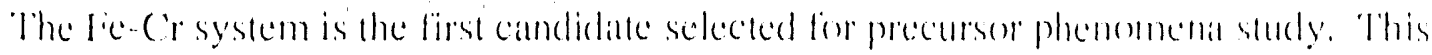

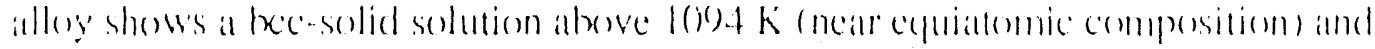
transforms into a sigma phase with decreasing temperature. fatrored by kinetics, it was possible to grow a single crystal with the high-emperature structure. The composition was

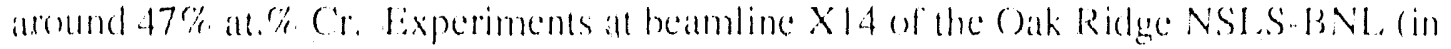

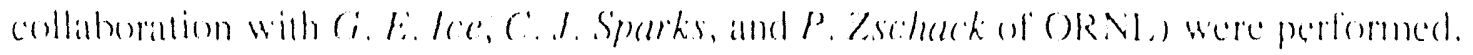
Although the datat are still being analyzed, the following yualitative results can be imnormenced:

- fic-('r is clearly a clustering system, as predicted by theory. The intensity increases for small scaltering vectors, and no diffuse maximat at the 132 superlattice prostions

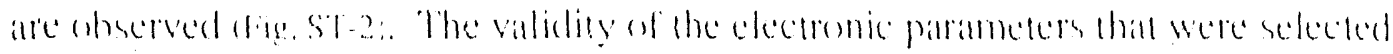

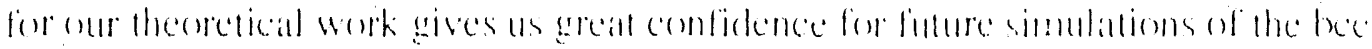
(1) sigmat transformatlion.

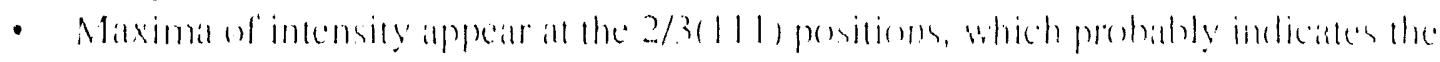

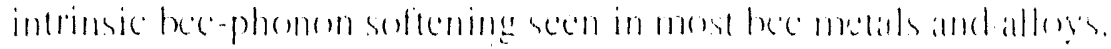

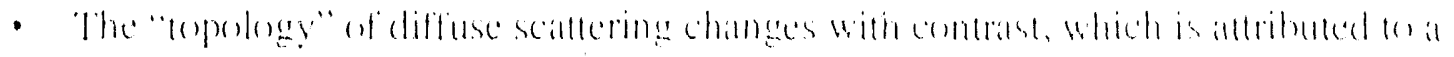

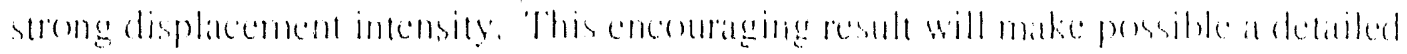

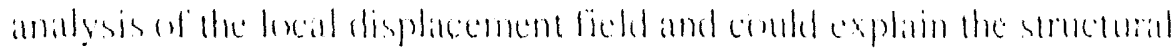
mamslomation. 


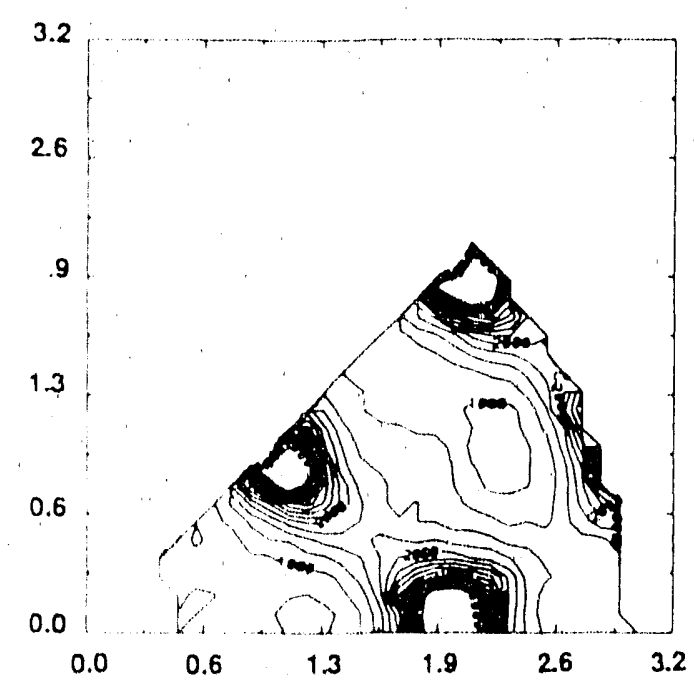

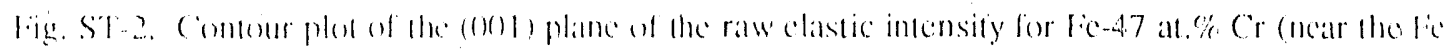
$k \cdot(\lg )$

[änally, for Ie. V. it was observed that the sigmal phase starts nucleating at the free sutfice of the bec phase. This result sugsests a very interesting experiment that we plan to pertiom al I.L.NL, in collahoration with $M$. Bablench, on preoriented bec single ce ystals to probe the sigma formation hy using scamning tunneling microscopy (STM). This work was primarily performed by L. Reinhard and S. C. Moss fom the University of Iouston.

\section{Publications \& Presentations}

M. Sluiter and P. F. A. Turchi, "Theoretical Investigation of Phase Slability in Ti-V and Ti-Cr Substitutional Alloys," presented at the MRS Spring Meeting, San Francisco, Calif., Apr. $1620,190(10,10$ he published in the Proceedings.

P. E. A. Turchi and A. Finel, "Phase Stahility Properties in Complex Substitutional Alloys," presented at the 119th TMS Annual Meeting, Anaheim, Calif., Feb, 1822, 190); to be published in J. Less Common Met.

P. E. A. Turchi and A. Fincl, "Order-Disorder Phenomena in Complex Alloys," presented at the MRS Spring Meeting, San Francisco, Calif., Apr. 16 20, 199(); 10 be published in the Proceedings. 


\title{
PHOTOCATALYSIS ON DOPED AEROGELS
}

\author{
Cic colmentress \\ li. liomshll
}

H. Cinnor
R. (ioller

1. Rarmmind

The objective of this project is to demonstrate that $\mathrm{SiO}_{2}, \mathrm{Al}_{2} \mathrm{O}_{3}$, or tho 2 aterogels doped with photochemically active ions can be used as heterogeneous catalysts for the production of hydrocarbons from simple gas mixtures $\left(\mathrm{CO}+\mathrm{H}_{2}, \mathrm{CO}_{2}+\mathrm{I}_{2}\right.$, etc.) using sunlight as the energy source. Also, we are investigating the energy-transfer mechanisms alfecting the chemical reaction. The feasibility of the project hats already been demonstrated with uranyl-ion-doped $\mathrm{SiO}_{2}$ aerogels.

\section{Status}

We have had problems maintaining a good fludized hed using our new, high-protity acregels. Aler identifyng the problem to be in the flow properties of the alerogels, we: solved it hy tapering the side walls of the reactor at an angle greater than the angle of repose of the acroget, which we determined experimentally to be 3.5 ".

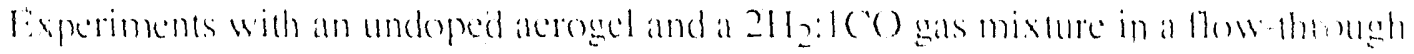
mode prodeced no hydrocithons. Furthermote, an experiment with the same gats mixture

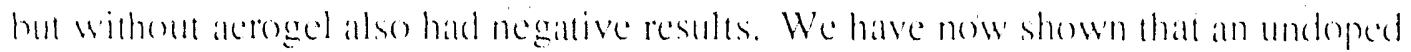

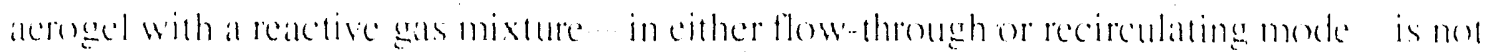

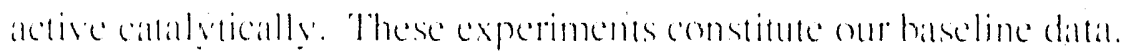

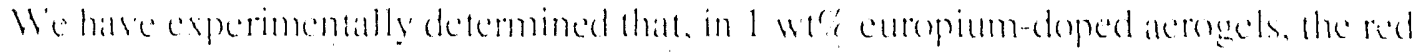

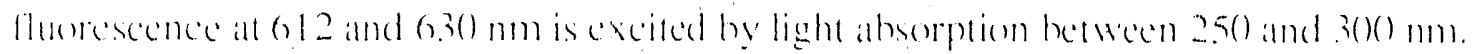

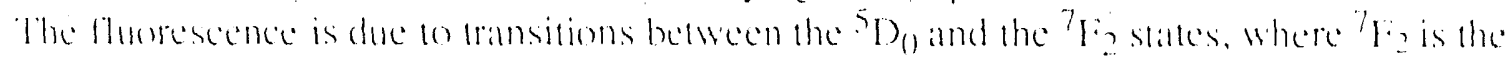

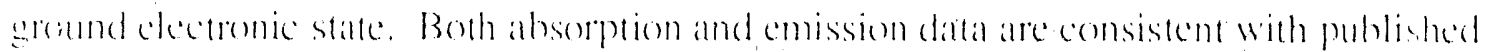

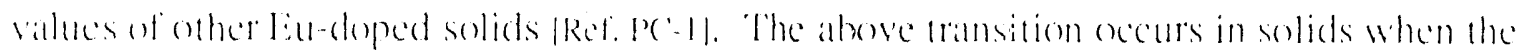

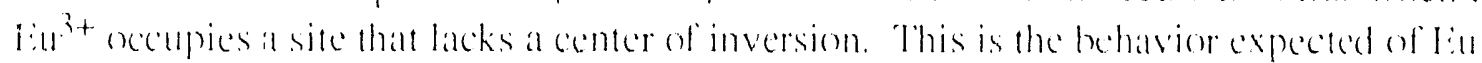

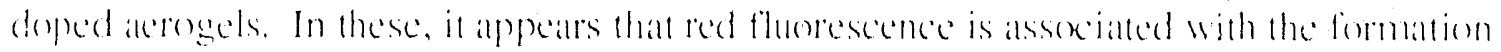

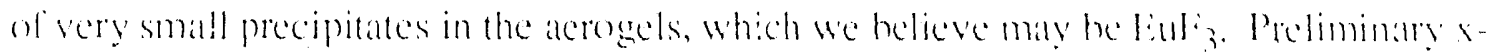
raly photexelectron spectrat appoar to confirm this assumption.

We have observed that Fu-koped aterogels also emit a blue-green glow after the: excitation source is furned off. The glow continues for mone than 30 seconds: we are now

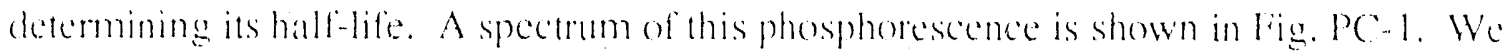
do not yet know whether the red fluoresence and the blue green phosphoreseence will play arole in the potential catalytic properties of this alerogel.

\footnotetext{
* San Jose State University.
} 


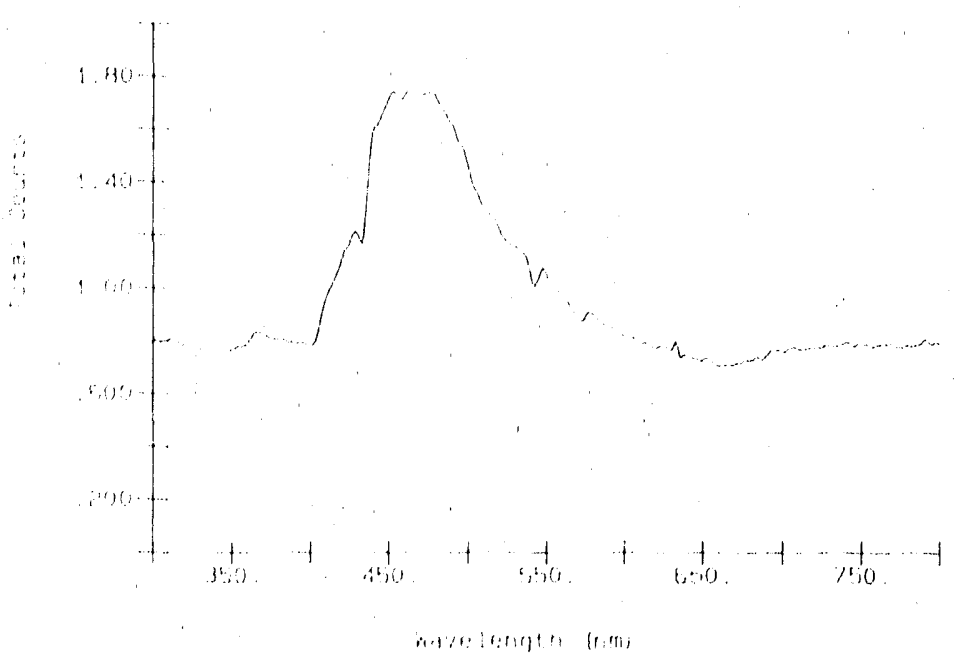

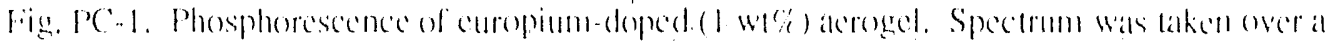
2)-second interval: the phospherescence was still ohservable all this limes.

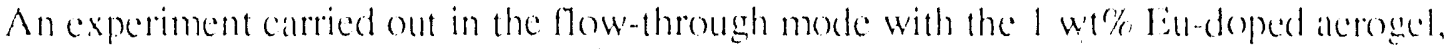
a mixture of $2 H_{2}: 10$, and the xenon-mereury lamp did not produce any measurable hydrecarbons. We are now performing an experiment in the recirculation moke.

\section{References}

PC-1. G. Blasse, J. Phis. Chem. Solids 27, 1587 (1066).

\section{Presentations}

C. Colmenares, "Photonctivated Heterogeneous Catalysis on Aerogels," seminan to be presented to the Chemistry Deparment, San Jose State University, May 1, 19)().

C. Colmenares, M. Connor, C. Evans, and R. Gaver, "Photoactivated Heterogencous Catalysis on Aerogels," aceepted for the 1 st International Conference on fintements, Leuven, Belgium, Sep. 3-7, 1900). 


\title{
LASER-INDUCED CHEMISTRY
}

\author{
IV. I: C'mawar \\ ('. Si. Sile'ns
}

\section{Background}

A full understanding of the properties and hehavior of highly energized molecules is of improtance an a number of significant industrial processes and technologeses, including rescarch into improvements in the combustion of fossil fuels and in the formulation of high explosives. To this end, we are developing and applying new laser techniefues to benh stimulate and interrogate these high-energy' transformations.

The principal onjective of this preject is to chatacterize the excited-state tehavion of isolated (i.c.e gas-phase) molecules and wo identify optical excitation scliemes that generate bend-or moxte-selective chemistry. Our appresteh has heen to use avertone-pomping of

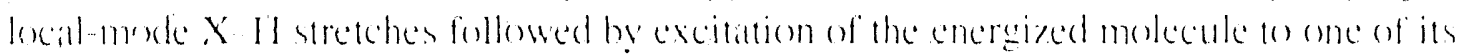
lowest fying directly dissociative electronic states. The condidate system that we have chosen to study is $\mathrm{H}_{2} \mathrm{O}$ and its deuterated analow. HOF).

\section{Technical Progress}

We are presently set up to measure the (OH/C) branching ration in

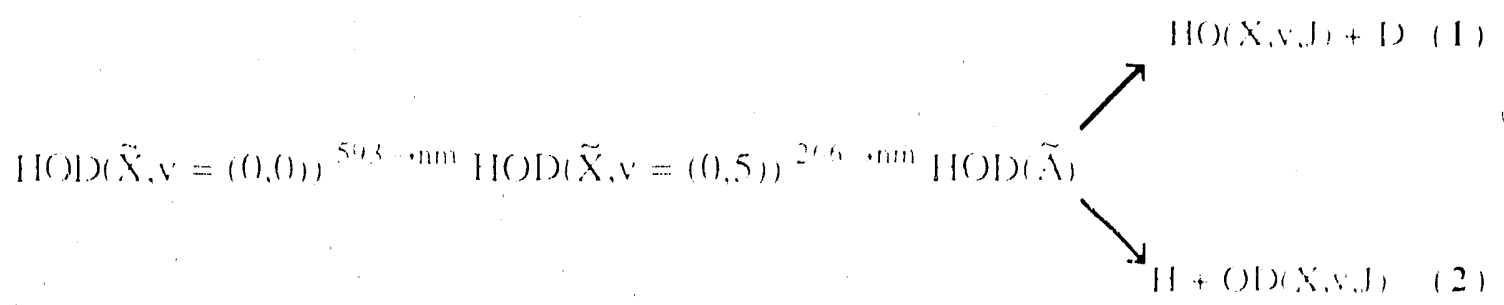

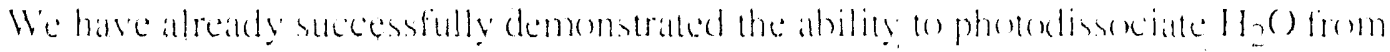

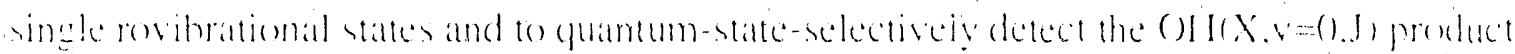

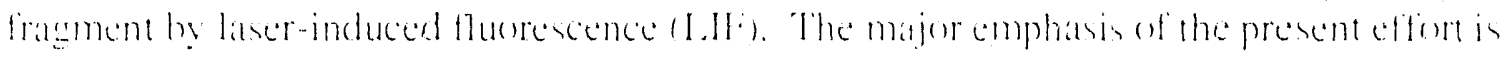

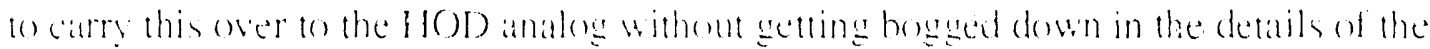

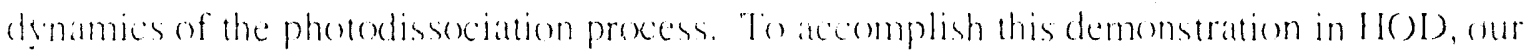
approveh is to:

- Work at high $\left.\mathrm{H}_{2} \mathrm{O} / \mathrm{D}_{2} \mathrm{O}\right)$ static gas pressure $(>5(\mathrm{~K})$ motorr) to ensure collisional relaxation of the fragments so that their nascent rotational and vihrational state distribution biases are eliminated.

- Salurate the (JI and OD tamsitions hy working all higher I.IF laser powers.

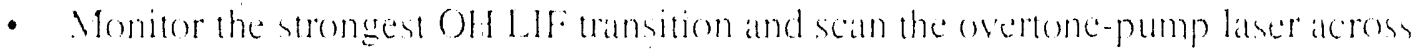
the band. Based on our models. we predict from local-mode wavefunctions that the resulting action spectrum will include only those transitoms appearing in the $H_{2}()$ photoacoustic absorption spectrum (lower frame of Fig. L.J-1). Vim-mode 
selective production of $\mathrm{OH}$ by means of reaction (1) would instad generate a combined $\mathrm{H}_{2} \mathrm{O} / \mathrm{HOD}$ action spectrum (similar to the upper frame of lig. L, I-1).

- Monitor the strongest OD LIF transition and scan the overtone pump laser to confirm that OD is indeed heing produced by reaction (2). The action spectrum should show only those tansitions present in the HOD photoncoustic absorption spectrum (center frame of lig. L.I-1).

Barring any further unseen eguipment failures, we are see to proced with these measurements in the second half of the fiscal year.

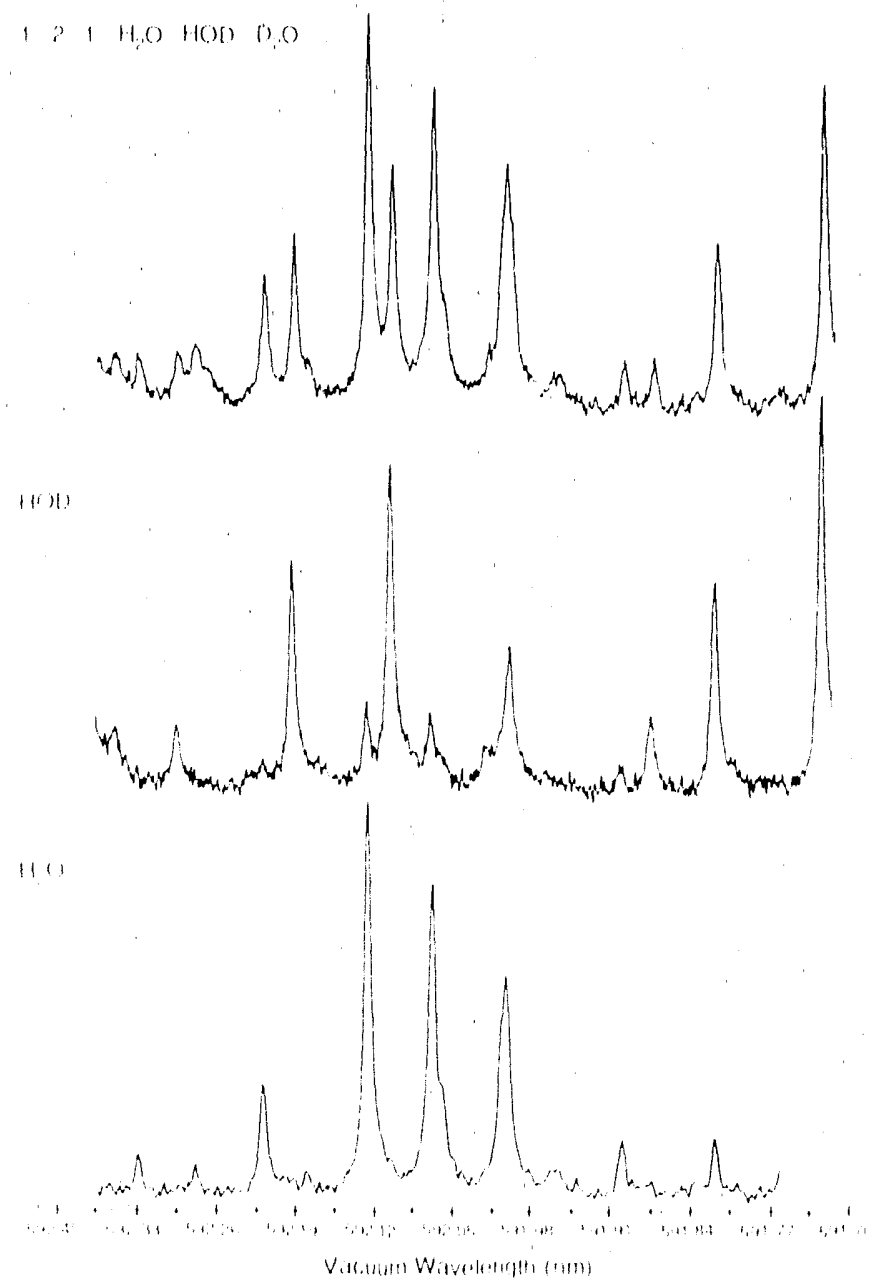

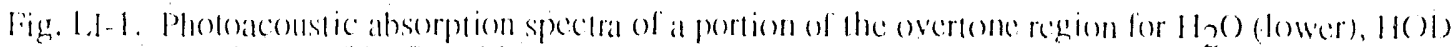
(center), and a $1: 1$ mixture of $\mathrm{H}_{2} \mathrm{O}$ amd $\mathrm{O}_{2}($ ) (upper). 


\section{LASER-PRODUCED MOLECULAR PLASMAS}

\section{A. Droege}

W. Conaway
C. Stevens

S. Steward (i. Hemgig'n

R. Prikslu

\section{Overview}

The study of dense, conplex plasmas in the temperature range of $3,(0)(0) \mathrm{K} 1610,(0)(0) \mathrm{K}$ is a relatively unexplored area of chemical physics and material science. This "molecularplasma" regime is important to many technical areas of interest, including mats rials preduction and analysis by plasma technicpues. A fundamental understanditig of materials heated to these temperatures is also central $l o c$ contident prediction of the performance of materials in nuckear-weapons research and development. It is the objective of this project to experimentally determine the thermextymamic propertices of malterials heated to these temperatures.

Experimental studies of malterial properties alt these temperatures and densities are

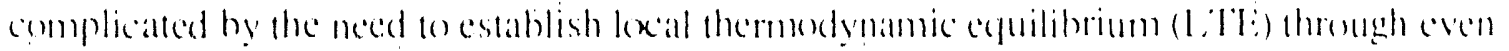
heatting of the materials and to diagnose the resulting high-densily. optically the platsm.

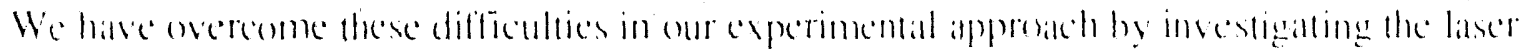

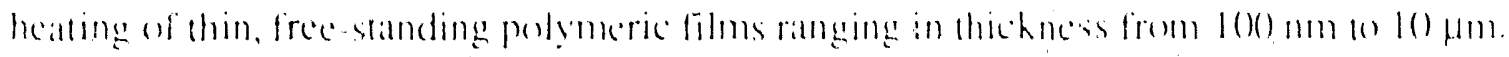

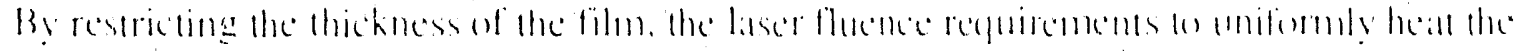

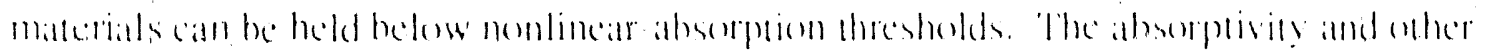

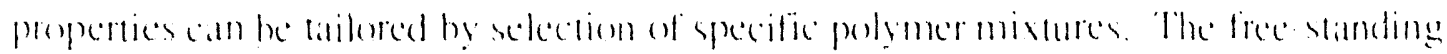

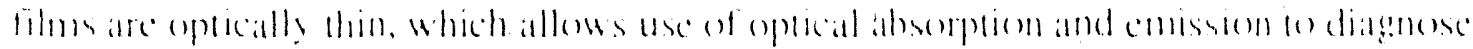

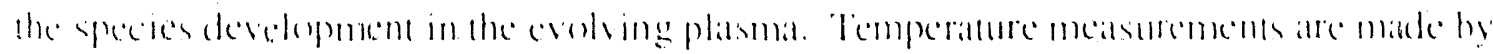

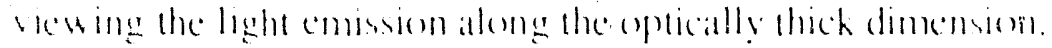

\section{Technical Activities and Results}

Experimental prentess has been slowed by equipmentadures, but we are now

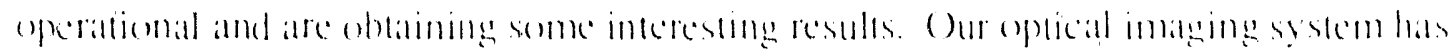

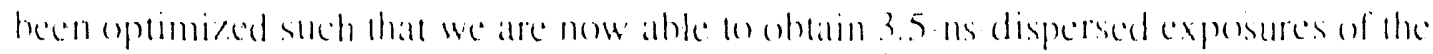

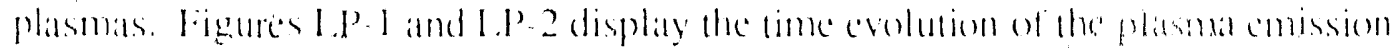

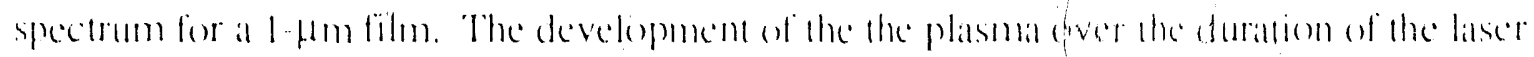

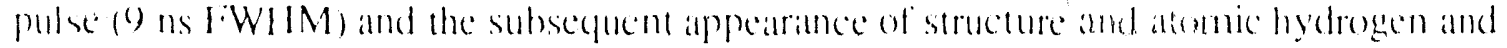
carbon emission are evident. We are now able to image lo beller than 10() , m along the laser axis and to observe distinct differences in plasma emission as a function of distance from the film surface. An as-yed unexplained UV cutoff that varies with the image pointto-film distance is currently under investigation.

We have conducted some preliminary experiments into the feasibility of measuring the kinetic energy of ions created in the plasma. Figure $1 . P-3$ illustrates the ion signal collected from a tubular electrole placed concentrically along the laser path in front of the film. Even with this crude design, we obtain resolved peaks corresponding to hydrogen ions and 
higher-molecular-weight ions (e.g., C, CH, O). We are currently designing a better electrode that should allow for much better mass resolution and better-defined kinctic energy measurements.

We have also been exploring the use of new target materials. Time-evolution spectral (such as those of Figs. L.P-1 and L.P-2) and ion measurements (such as in Fig. L.P-3) have been obained from metal-loaded, low-density polymer films; however, because thesc films are quite thick $(>10 \mu \mathrm{m})$, uniform heating is not assured. Thinner films and films with lower levels of metal loading should solve this problem.

With the improvement in signal collection, we can now move on 10 expanding our laser-beam spot size at the target to create an optically thick plasma for temperature masurements.

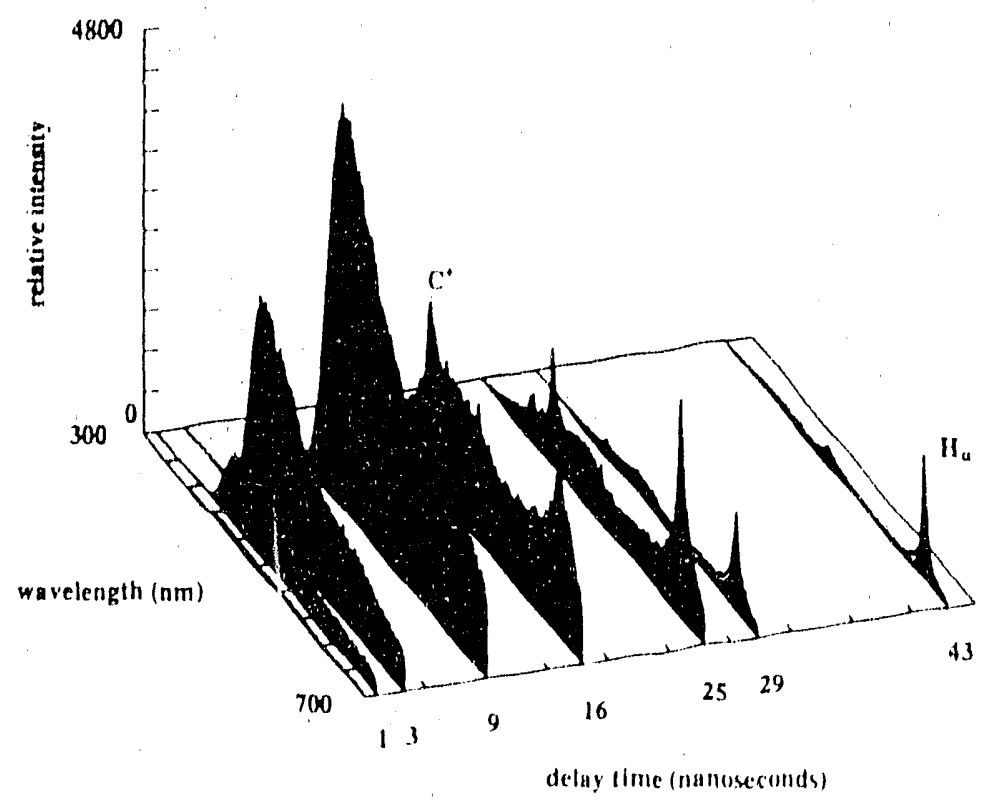

Fig. L.P-1. Thime development of laser-produced-plasma emission in the (0- 10 4.5-ns range. 


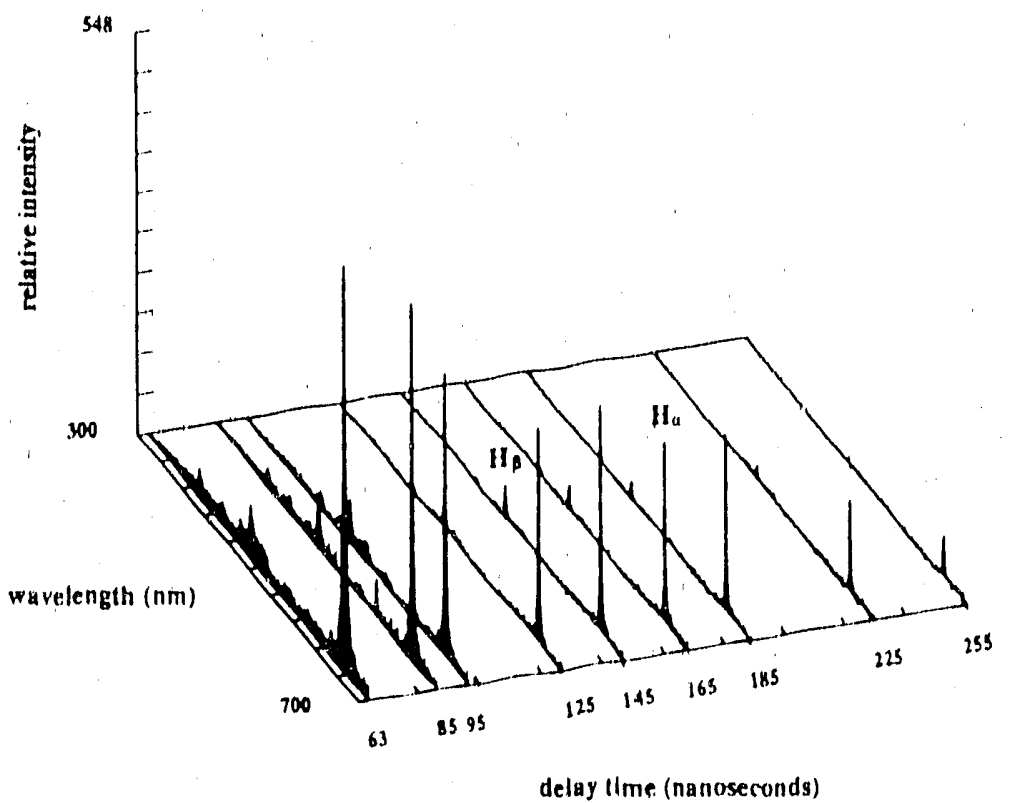

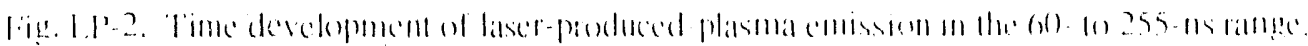

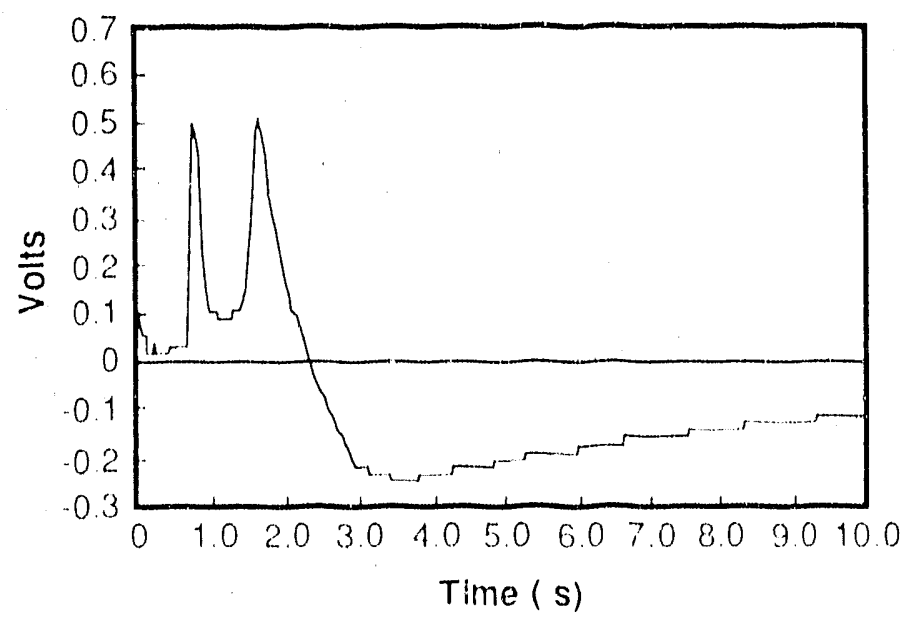

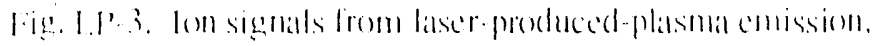

\section{Publications}

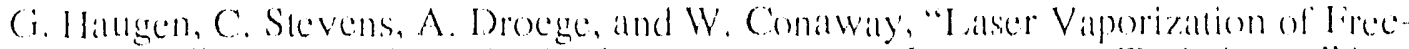
Standing Thin Iïms: I. Analysis of Pressure Measurement Technigues," in preparation. 


\section{CHEMISTRY OF DEFEC'TS}

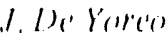

During the first six months of this project, work has foused on the characterizallom, identification, and elimination of microseopic defects in Cr:L icaAllo. Single crystals of

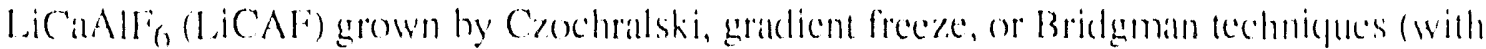

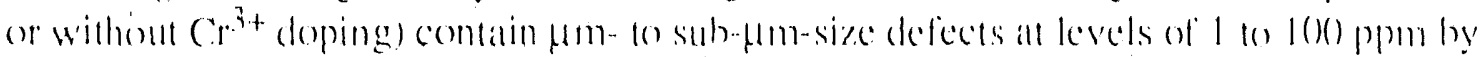

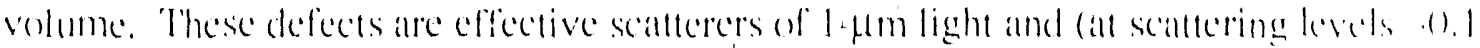

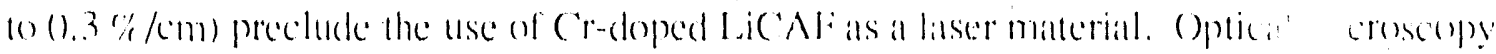

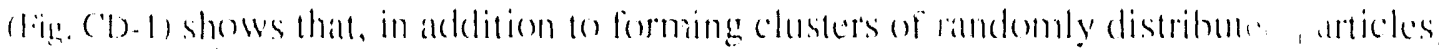

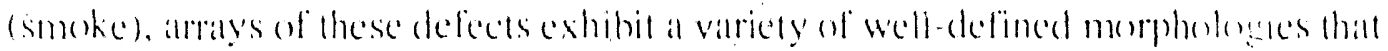

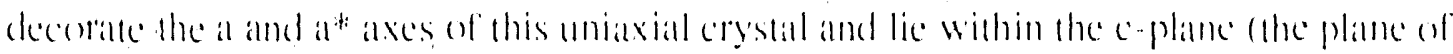

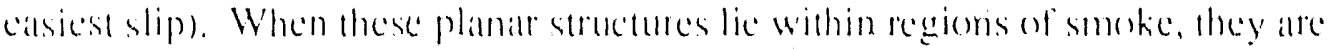

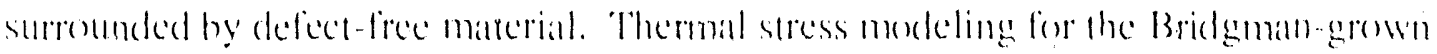
crystits shows that the shear stresses generated during erystal growith are largest in the c.plane and are comparahle to our best estimate of the critical resolved shear sitress forom

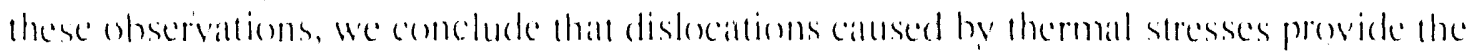

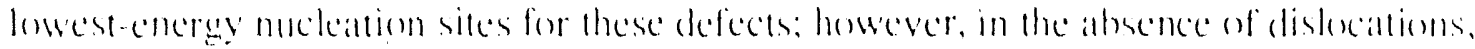
the defeces will mucleate randromly.

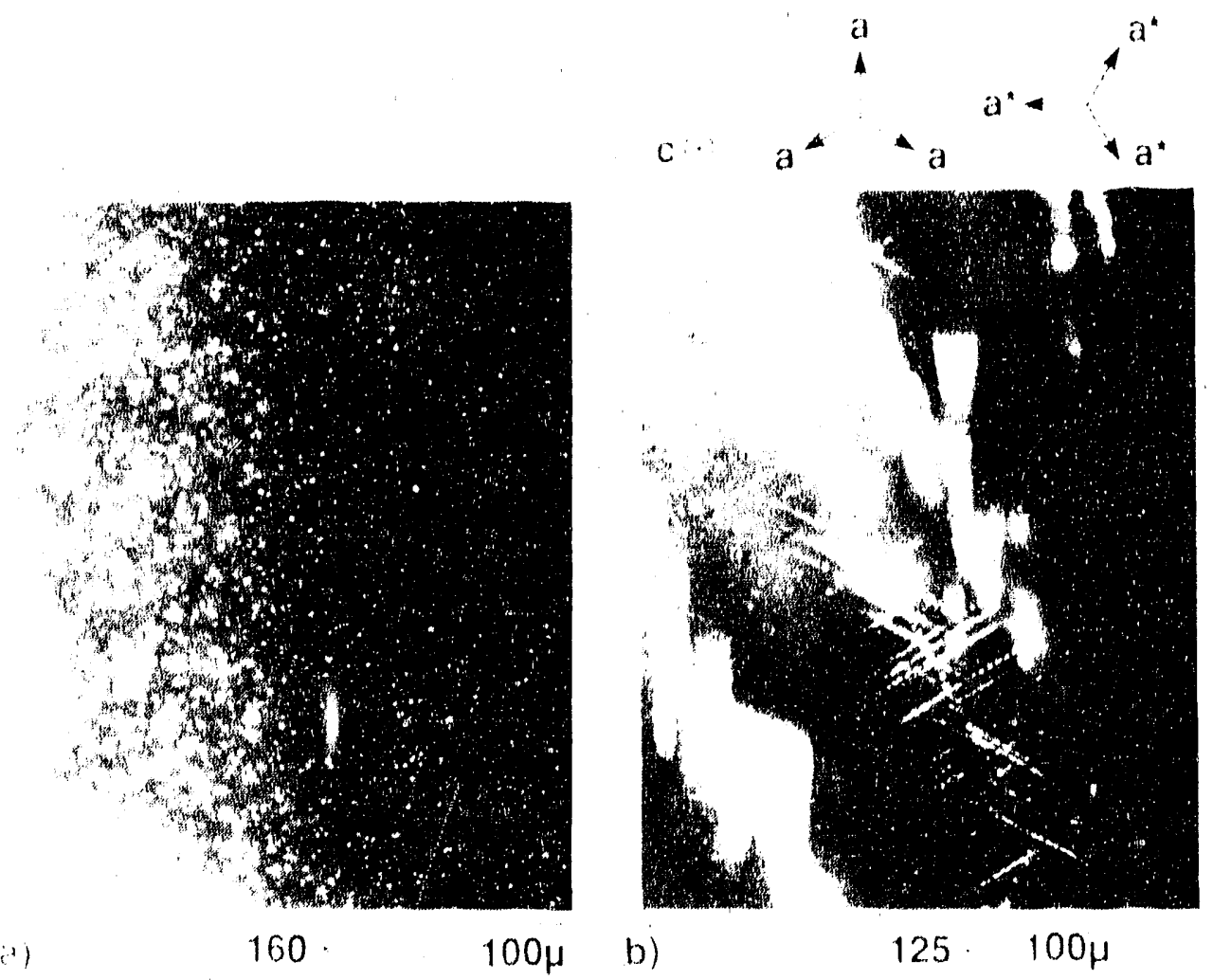

Fig. (D)-1. Optical micrographof (a) "smoke" parlicles and (b) defects lying along crystallogralphic axes within the ci-plance. 
92

These defects produce little or no secondary electron image, which indicales that they lack topography. However, they they can ba clearly imaged with backscaltered clectrons as Hm-sized regions of lower-than-average atomic mass. Electron-microprobe analyses show no vartation in $\mathrm{Ca}, \mathrm{Al}$, or $\mathrm{Cr}$ levels between the matrix and the defects, but do show a significant reduction in the F level of the defects relative to that of the matrix. () and $\mathrm{C}$ levels are below the limit of detectability in both the matrix and the defects. 'These results indicate that the defects involve fluorine valcancies; however, it is not known at this time how the charge neutrality of the crystal is maintained.

Annealing of LiCAF crystals within about $30{ }^{\circ} \mathrm{C}$ of the melting point $\left(810{ }^{\circ} \mathrm{C}\right.$ ) eliminates the defects. The time period reguired to remove the defects depends on the size of the crystal. For a crystal $4 \times 10 \times 2() \mathrm{mm}^{3}$ in size, annealing is completed in about 10() hours. Partial-annealing experiments lead to the following observations:

- First, partial annealing results in a clear ring that moves inward with further annealing.

- Second, during the anncaling prexess, smoke particles ate the first to disalppear.

- Third, annealing results in an increase in the miximum size of the defects by about a fictor of two.

- Fourth, the defece arrays undergo dispersal to more disondered structures with eich successive anncal. An example of this is given in Fig. (D)-2.

The resules of annealing are the same regardless of whether the post-anneal cooldown is done at crystal-growth rates $\left(1-2{ }^{\circ} \mathrm{C} / \mathrm{hr}\right)$ or all guenching rates $\left(2()()^{\circ} \mathrm{C} / \mathrm{hr}\right)$. These observations demonstrate that the process of annealing involves the dissolution af the defects, followed by their diffusion out of the crystal.

\section{As grown}
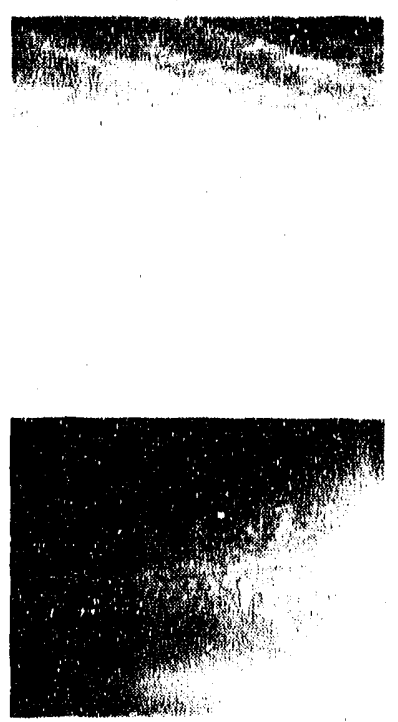

$100 \mu \mathrm{m}$ 1st anneal
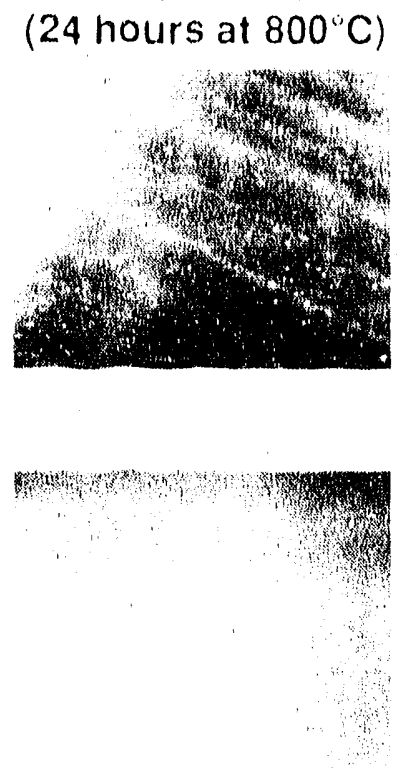

a-axis - ... (growth axis) 2nd anneal

(24 hours at $800 \cdot \mathrm{C}$ )
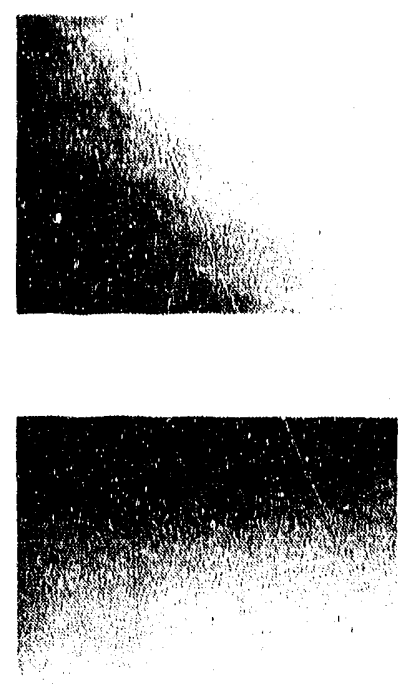

(.) c-axis

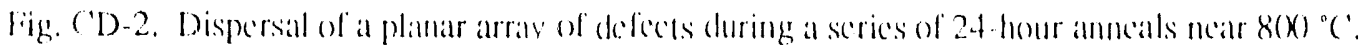


forem the annealing experiments described above, a dillusion constant, b), for the

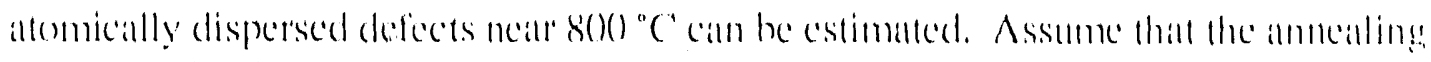
process following dissolution can be approximalled by the diftusion of a mobile species

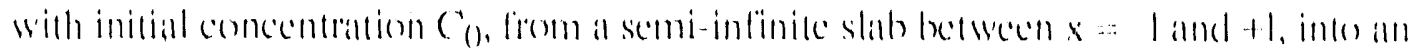

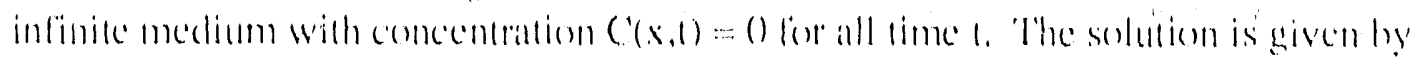

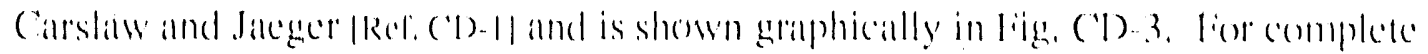

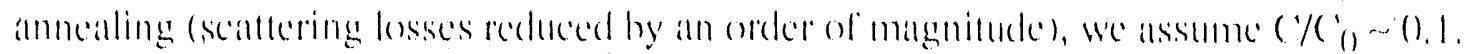

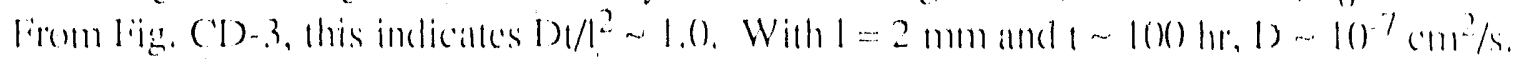

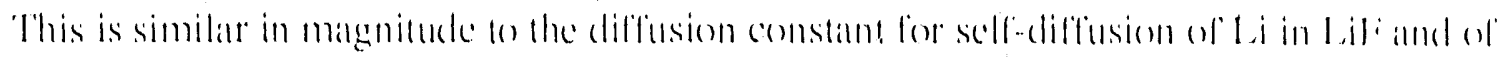

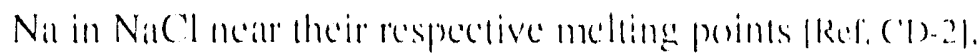

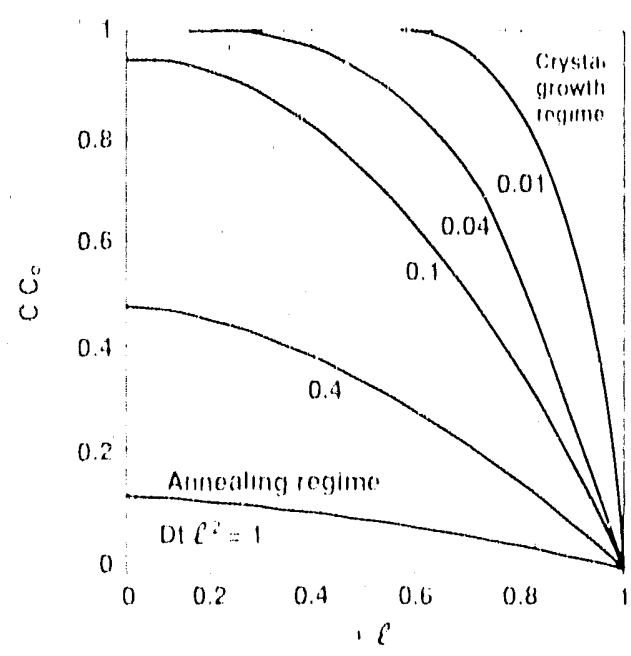

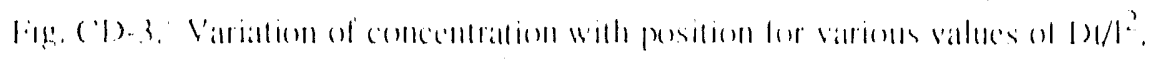

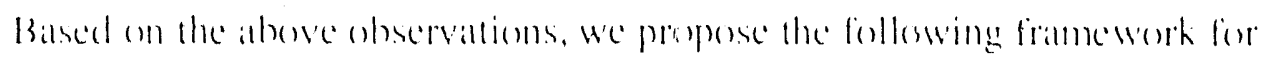

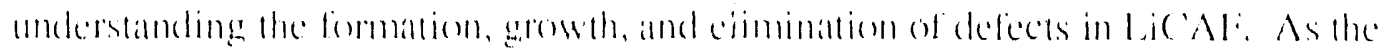

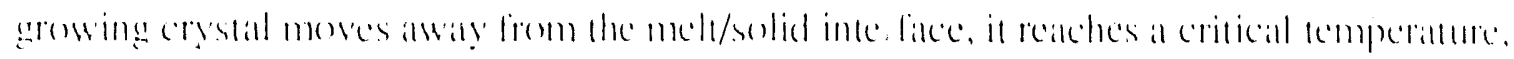

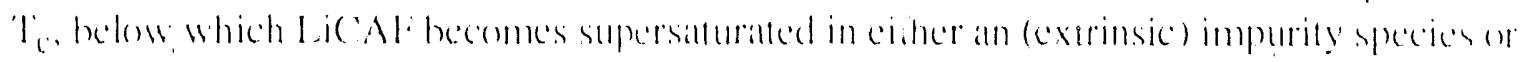

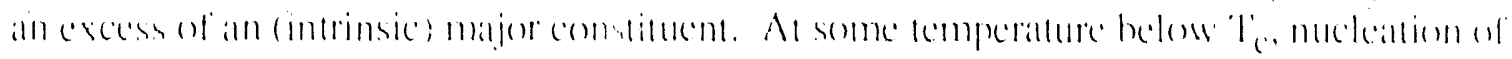

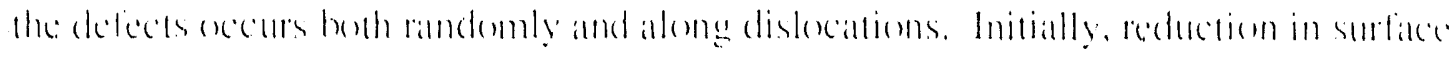

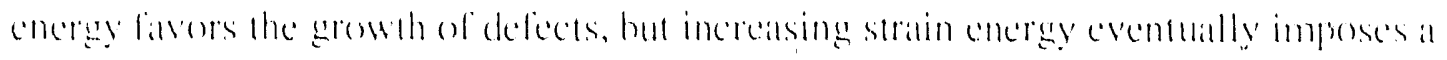

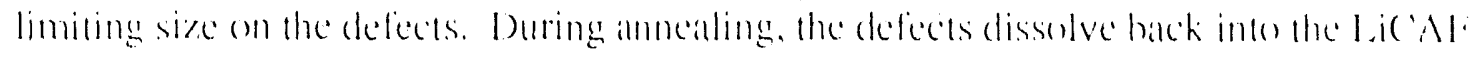
matrix and then diffuse out of the sample along a concentramen gradient. A puantitative mexkel of this process must awat positive identification of the composition of the defects.

\section{References}

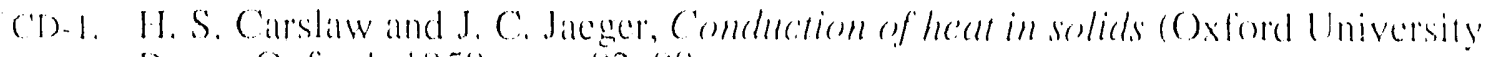
Press, (oxford, 1959), pre. (12.99.

(1)-2. R. I. Borge and (i. J. Dienes, An imtroduction to solded state diffusion (Acatelemic Press, Berticley, 1988), pp. 111114 and 2.6.5260. 


\title{
I'TA EQUIPMENT DEVELOPMENT
}

\author{
1. I1' Yirrin
}

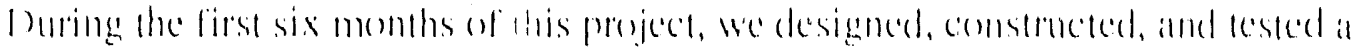

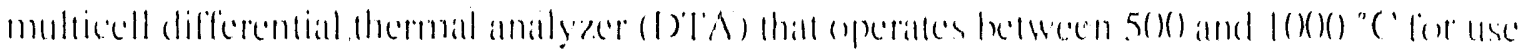

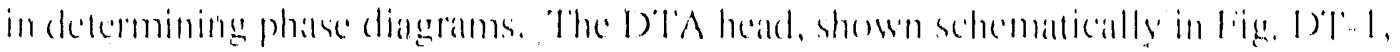

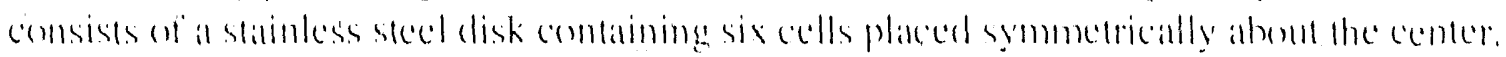

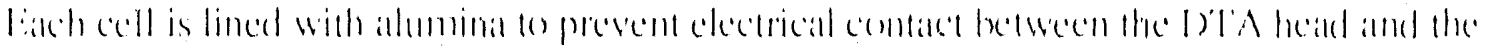

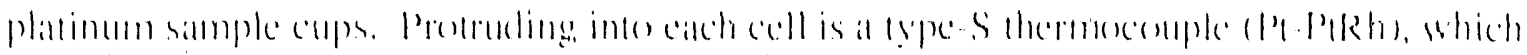

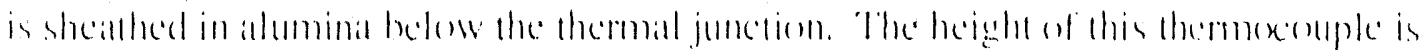

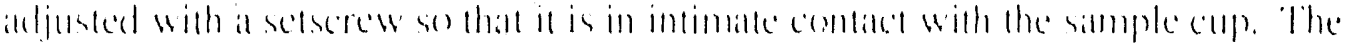

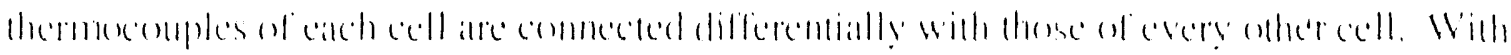

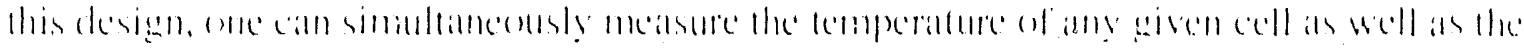

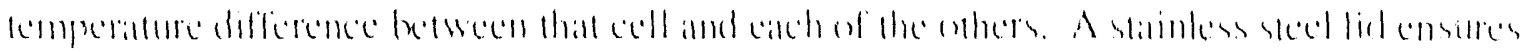

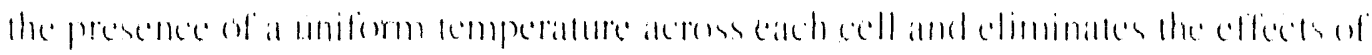

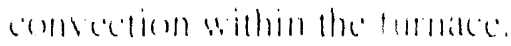

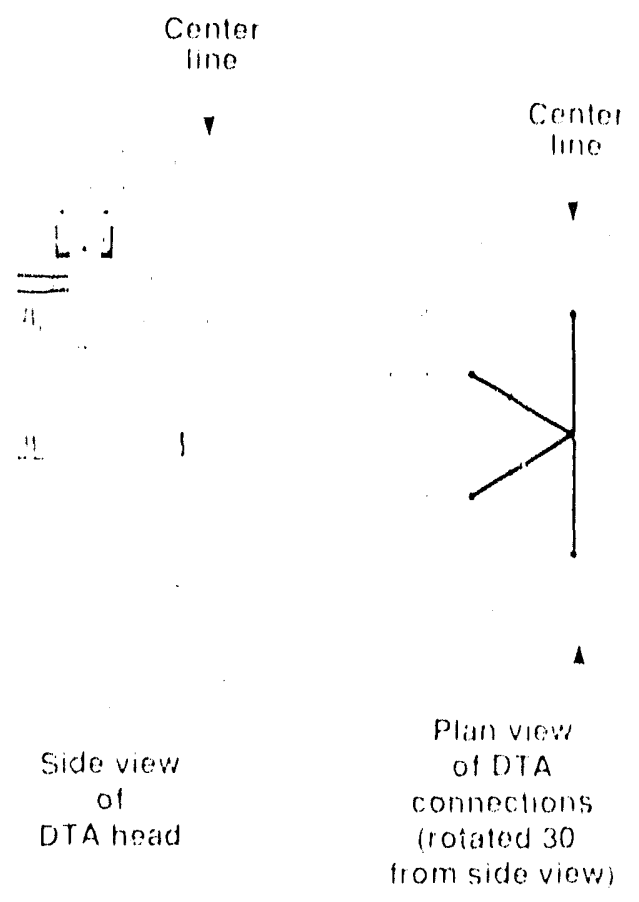

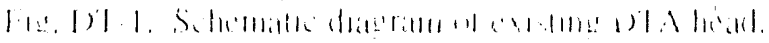

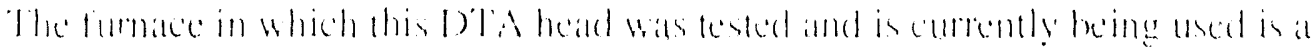

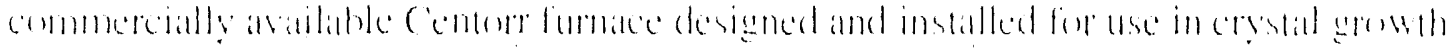

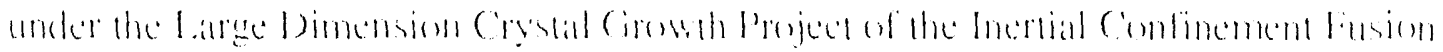

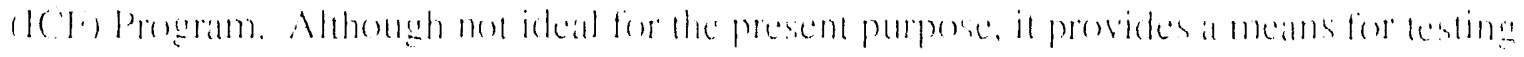
and preliminary esperimentition. 


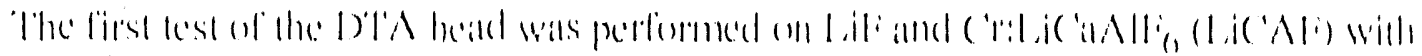

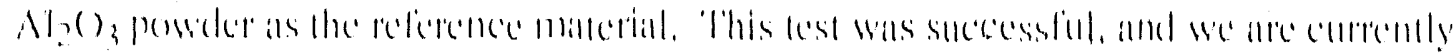

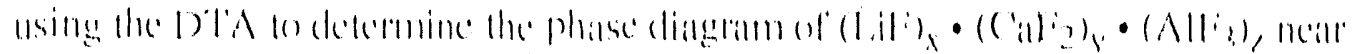

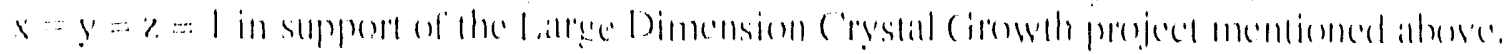

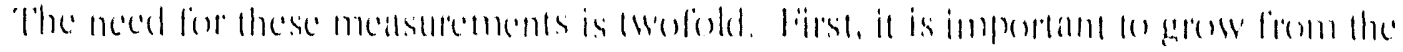

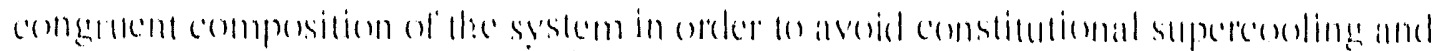

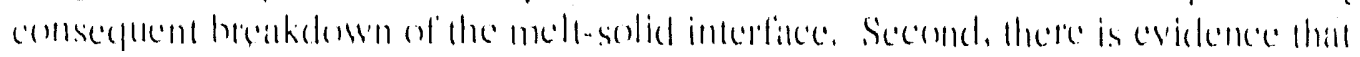

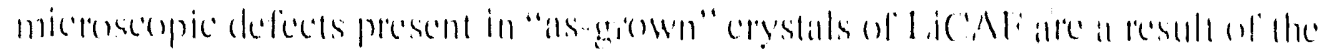

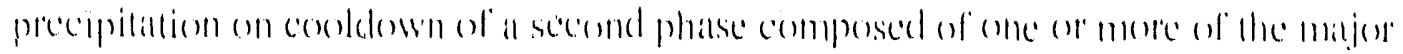

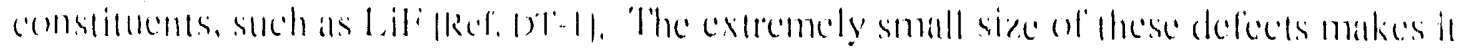

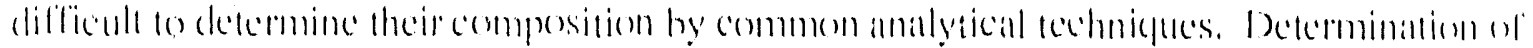

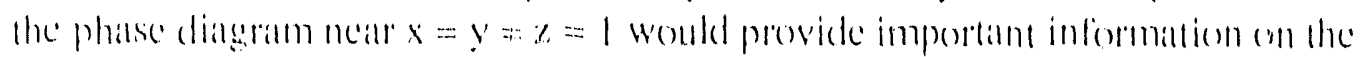
comprosilion of the delicels.

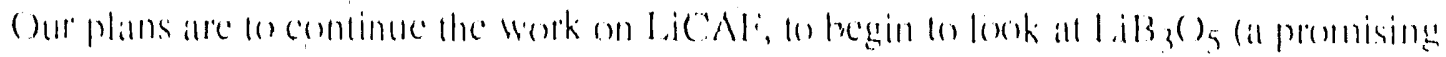

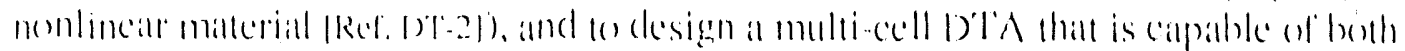

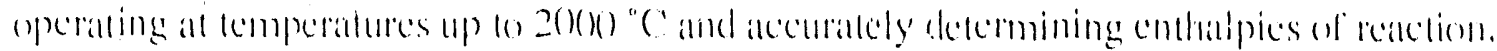

\section{References}

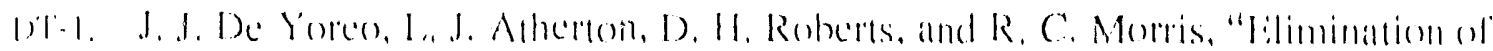

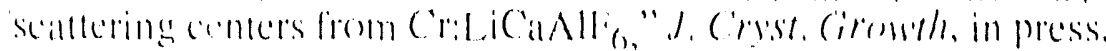

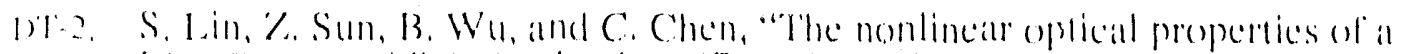

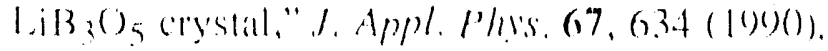




\title{
DEPARTMENTAL INSTITUTIONAL RESEARCH \& DEVELOPMEN'T
}

\author{
Individual Projects
}




\title{
ELECTRONIC STRUCTURE STUDY OF THE THERMODYNAMIC AND MECHANICAL PROPERTIES OF Al-Li ALLOYS
}

\author{
A. Gonis
}

\section{Overview}

\section{Objective}

Our objective is to study the phase stability and elastic properties (mechanical properties) of Al-Li alloys by means of first-principles electronic structure calculations.

\section{Motivation}

The motivation for this study is provided by the rather strange and technologically useful thermodynamic and mechanical properties of Al-Li alloys, especially alloys with dilute Li concentrations. Most important among these properties is the weight reduction with increased stiffness that results from small additions of $\mathrm{Li}(\sim 4 \%)$ in Al. This phenomenon makes Al-Li alloys prime candidates for aircraft structural materials.

\section{Description of Technical Activities}

The first stage of the study consists of calculating the equilibrium thermodynamic properties of Al-Li alloys across the concentration range, in both fec and bec phases. Our goal was to complete this stage in the first year of the project; we are confident that we shall be able to do so.

\section{Calculations Completed (Technical description)}

Calculations of equilibrium charge densities, lattice constants, and energies of mixing have been completed for alloys based on both fec and bec crystal structures at selected concentrations. Calculations of effective pair interactions are currently underway.

\section{Physical Significance of Results}

Our results indicate that bec-based alloys with lithium concentrations of $50 \%$ and $75 \%$ will order at low temperature in the $\mathrm{B} 32$ and $\mathrm{DO}_{3}$ phases, respectively. This behavior is consistent with experimental and previous theoretical studies carried out on the basis of phenomenological models.

Dilute Li alloys in the foc phase, which are the technologically important ones, exhibit very rich behavior. An example of this behavior is illustrated in Fig. ES-1, which shows the variation of the effective pair interactions for $1 \mathrm{st}, 2 \mathrm{nd}$, 3rd, and 4 th neighbors (indicated by the numbers along the curves) for the $25 \%$ Li alloy. These interactions provide a strong 
clue as to the stable structure prefered by the alloy at low temperature. A positive $V_{1}$ and a negative $V_{2}$, for example, would indicate that the alloy tends to form in the $\mathrm{L}_{2}$ structure. Indeed, metastable Li2 precipitates have been observed experimentally in these alloys. $\mathrm{As}$ Fig. ES-1 indicates, near the Fermi level, $V_{1}$ varies very rapidly with respect to onergy. Although it is negative there, its large slope is in fare a sarong indication of a possible: metastability. Small additions of ternary impurities might precipitate the metastable state.

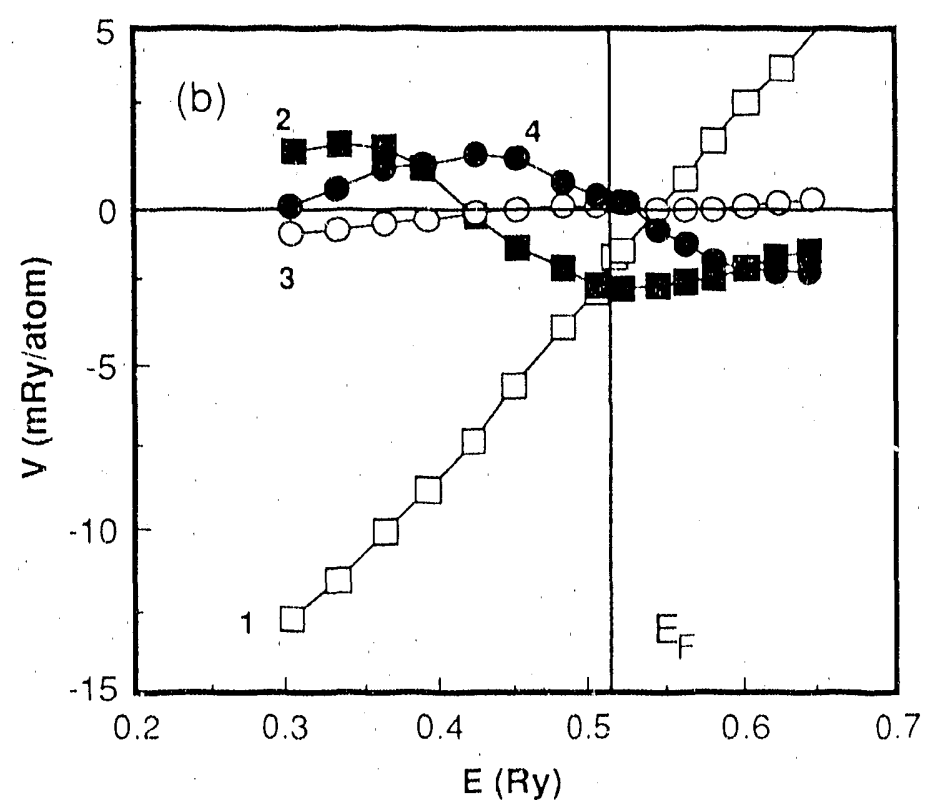

Fig. ES-1. Variation of effective pair interactions as a function of encrgy in fec Al-Li alloys with L.i concentration of $25 \%$. The numbers next to the curves denote the near-neightor type formed hy the sifes in the pair.

The calculations of phase stability of fec Al-Li alloys has revealed a wealth of "unexpected" physical behavior. These alloys are "simple" in the sense that they are comprised of elements with low atomic numbers that are not chanaterized by resonant." hehavior in any of the scattering channels. And yet these alloys have made it necessary to rethink the calculation of the alloy total energies, a procedure thall was thought to be well established. We expect that further study of the phatse stahility of these alloys will preve exciting and informative.

\section{Publications}

A. Gonis, P. E. A. Turchi, M. Sluiter, F. J. Pinski, and D. D. Johnson, "Electronic: Structure and Phase Stability Properties of Al-Li Alloys," submitted for the Proceedings of the Spring Meeting of the Materials Research Society, Sam Franciscon, Calif., Apr. 16-20, 199(). 


\section{THE STRUCTURE-PROPERTY LINK IN SUB-NANOMETER MATERIALS}

\section{A. F. Jankowski (Principal Investigator)}

The structure-property link is critical in sub-nanometer scaled materials. This is especially true for microstructures with alternating layers composed of only a few atomic planes each (i.e., multilayers). in this project, the objective is to determine the equilibrium atomic configurations and phase stability of multilayer systems, then to link the atomic structure (both theoretically and experimentally) with the observed elastic behavior and magnetic-optical properties [Refs. SP-1 through SP-8].

The multilayer structures are synthesized using dc-magnetron sputter deposition. The thin-film samples are composed of several hundred layer pairs with repeat periodicities ranging from 0.6 to $9 \mathrm{~nm}$. Our process is competitive with molecular beam epitaxy, in that it allows for the monolayer level of control needed to produce superlattices with compositionally abrupt interfaces. The multilayer systems currently under investigation are $\mathrm{Au} / \mathrm{Ni}, \mathrm{Ni} / \mathrm{Ti}$, and $\mathrm{Au} / \mathrm{Nb}$.

The mechanical property measurement of $\mathrm{Au} / \mathrm{Ni}$ multilayers is being pursued at Stanford University under the supervision of $W . D$. Nix. The measurement of an in-plane Young's modulus from the deflection of a composite multilayer-cantilever beam using a microindenter has currently revealed no modulus enhancement [Ref. SP-1]. An explanation for why the supermodulus effect has not been found by microstructural and testing methods is being investigated.

Direct measurement of the multilayer-cantilever beam curvature does prove interesting, however. If a constant modulus value is assumed, the computed internal stress of the multilayer-cantilever beam follows the composition wavelength dependence of the supermodulus effect (i.e., a maximum compressive stress at $2 \mathrm{~nm}$ ) (Fig. SP-1).

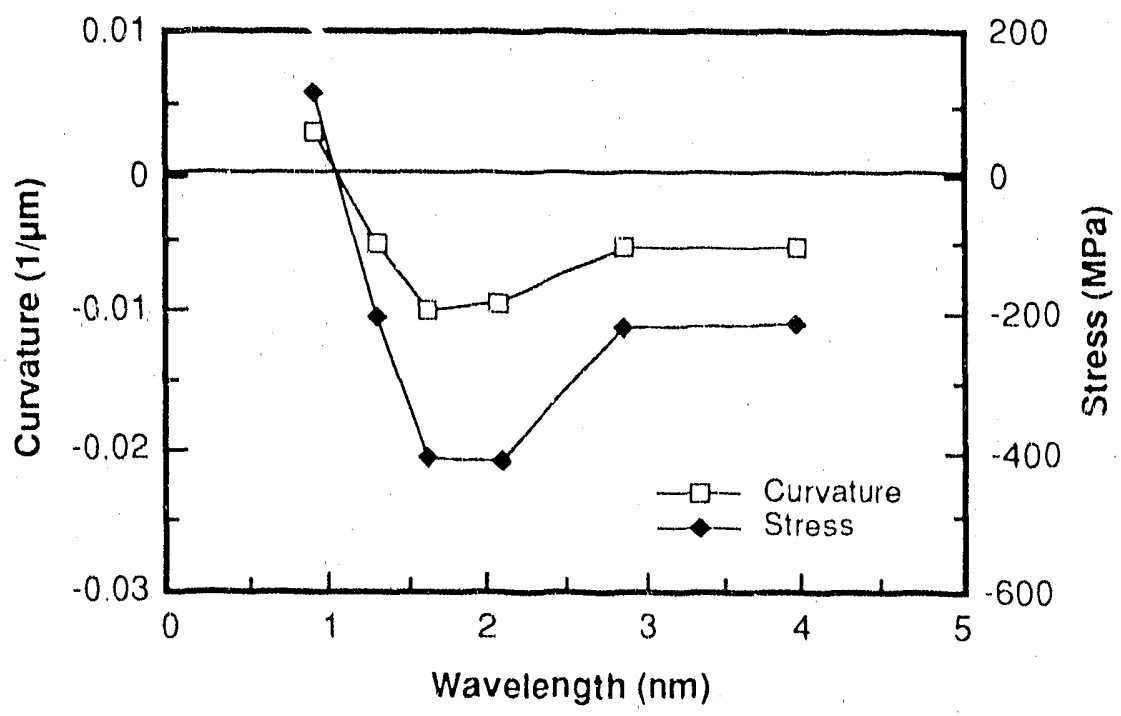

Fig. SP-1. Curvature $\left(\mu \mathrm{m}^{-1}\right)$ of Au/Ni composite microbeams and estimated stresses (MPa). 
These modulus measurements provide a milestone for mechanical property evaluation of as-deposited thin-film multilayer structures. To measure the hardness of the films without destroying the underlying multilayer structure necessitates indentation depths less than $5 \%$ of the film thickness. Therefore, to firmly establish hardness trends, multilayers greater than 1- $\mu \mathrm{m}$ thick are needed; spatial resolution limitations require indents greatcr than $5(\mathrm{~nm}$. This will tentatively be pursued in late May-June with the fabrication of additional $\mathrm{Au} / \mathrm{Ni}$ multilayer samples.

Microstructure of the multilayers is investigated with $x$-ray diffraction measurement and modeling under the supervision of J. Chaudhuri at Wichita State and with high-resolution electron microscopy (HREM) at LLNL. Measurements of interplanar spacings from highresolution $\mathrm{Au} / \mathrm{Ni}$ micrographs provide a direct test of the "strain relaxation from coherent interfaces" concept, as proposed in the coherency strain model (CSM). From the HREM measurements and new modeling analysis techniques, as supported by the collaboration with T. Tsakalakos of Rutgers University, he composition profile through the interfaces of the multilayer may be uniquely determined analytically. This milestone on the structureproperty link using dynamical diffraction theory is anticipated in July-August. Preliminary kinematical $x$-ray diffraction (XRD) results are supportive of the CSM |Refs. SP-2, SP-5|.

The Au/Nb system is one in which a near-zero misfit exists between the (111) Au and (110) $\mathrm{Nb}$. Yet, when deposited as a multilayer, a strained layered superlattice results. In fact, the average lattice spacing in the modulation direction is found to vary with the repeat period, beyond a rule-of-mixtures average (Fig. SP-2). The Au/Nb HREM results support another example of the strain-relaxation concept from strained interfaces [Ref. SP-3|.

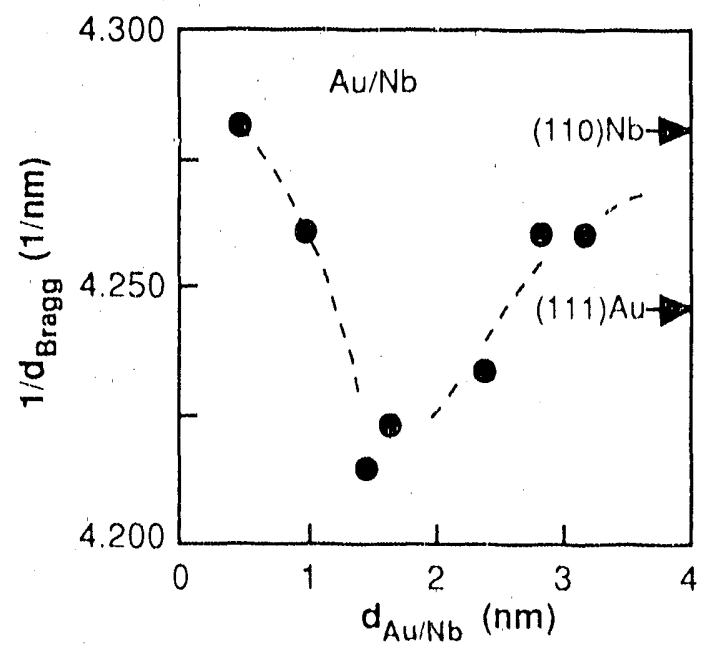

Fig. SP-2. The variation of $\left.1 / \mathrm{d}_{\mathrm{Bragg}}(\mathrm{nm})^{-1}\right)$ with repeat period $\mathrm{d}_{\mathrm{Au} / \mathrm{Nh}}(\mathrm{nm})$.

Multilayer structures are a useful medium for studying phenomena in alloy stability and phase transformations. We consider solid state amorphization as being induced through the mechanical alloying of powders through ball milling or the irradiation of crystalline solids. The kinetics and driving forces of bulk processing do not readily clarify the physics of amorphization. Thin-film studies, without an amorphous parent phase, remove the 
bulk-processing obstacles. A completely crystalline multilayer was used to study the soliclstate anorphization of $\mathrm{Ni}-\mathrm{Ti}(5.5 \mathrm{al} \% \mathrm{Ni})$. An in sim transmission clectron micruscoply (TEM) isothermal anncal is used to amorphize the crystalline binary structure by means of interdiffusion of nickel preferentially into the titanium. This is perhaps the first time that this phenomenon has been observed in real time |Ref. SP-4). Determination of the structural origin may now be more rigorously pursued (e.g., Does the amorphous phase nucleale from an incoherent or from a coherent interface?). Additional samples with prosessively shorter repeat periods may lead to $\mathrm{Ni}$-Ti interface structures that pass through an incoherent-coherent transition and therefore help clarify the structural mechanism of solict. state amorphization

\section{References (including Presentations \& Publications)}

SP-1. S. Baker, W. D. Nix, and A. F. Jankowsti, "Mechanical Properties of Compositional Modulated Au/Ni Films Using Indentation and Microbeam Deflection Techniques," in Proceedings of the Materials Research Society Symposia on Thin Films: Stresses and Mechanical Properties II, presented at the MRS Spring Meeting, San Francisco, Calif., Apr. 16-22, 1990.

SP-2. J. Chaudhuri, S. Shah, V. Gondhalekar, and A. F. Jankowski, "X-Ray Diflraction Analysis of Au/Ni Multilayers," submitted to J. Appl. Phys.

SP-3. A. F. Jankowski and P. L. Perry, "Microstructure of Au/Nb Multilayers," presented at the 17th International Conference on Metallurgical Coatings, San Diego, Calif., Apr. 26, 1990.

SP.4. M. A. Wall and A. F. Jankowski, "In-Situ Observation of Solid-State Amorphization in a Ni/Ti Multilayer," submitted for Procecedings of the XIIth International Congress for Electron Microscopy Volume \& Materials Science, to be presented in Seaule, Wash., Aug. 12 18, 1990).

SP-5. J. Chaudhuri, S. Shah, V. Gondhalekar, and A. F. Jankowski, "Analysis of Au/Ni Multilayers by X-Ray Diffaction," submitted for Proceedings of Matcrials Research Society Symposia on Layered Structures-Heteroepitaxy, Superlattices, Strain and Metastability, presented at the MRS Fall Meeting, Boston, Mass., Nov, 27-Dec. 1, 1989.

SP-6. A. F. Jankowski, "Lattice Spacing Vartations in Gold-Nickel Superlattices," Superlattices and Microstructures 6, 427 (1989).

SP-7. A. F. Jankowski, Commen on "Lattice expansions and contractions in metallic superlattices," Phys. Rev. Lett.63, 189)2 (1989).

SP-8. M. A. Wall and A. F. Jankouski. "Atomic Imaging of Au/Ni Multilayers," Thin Solid Films 181, 313 (1989). 

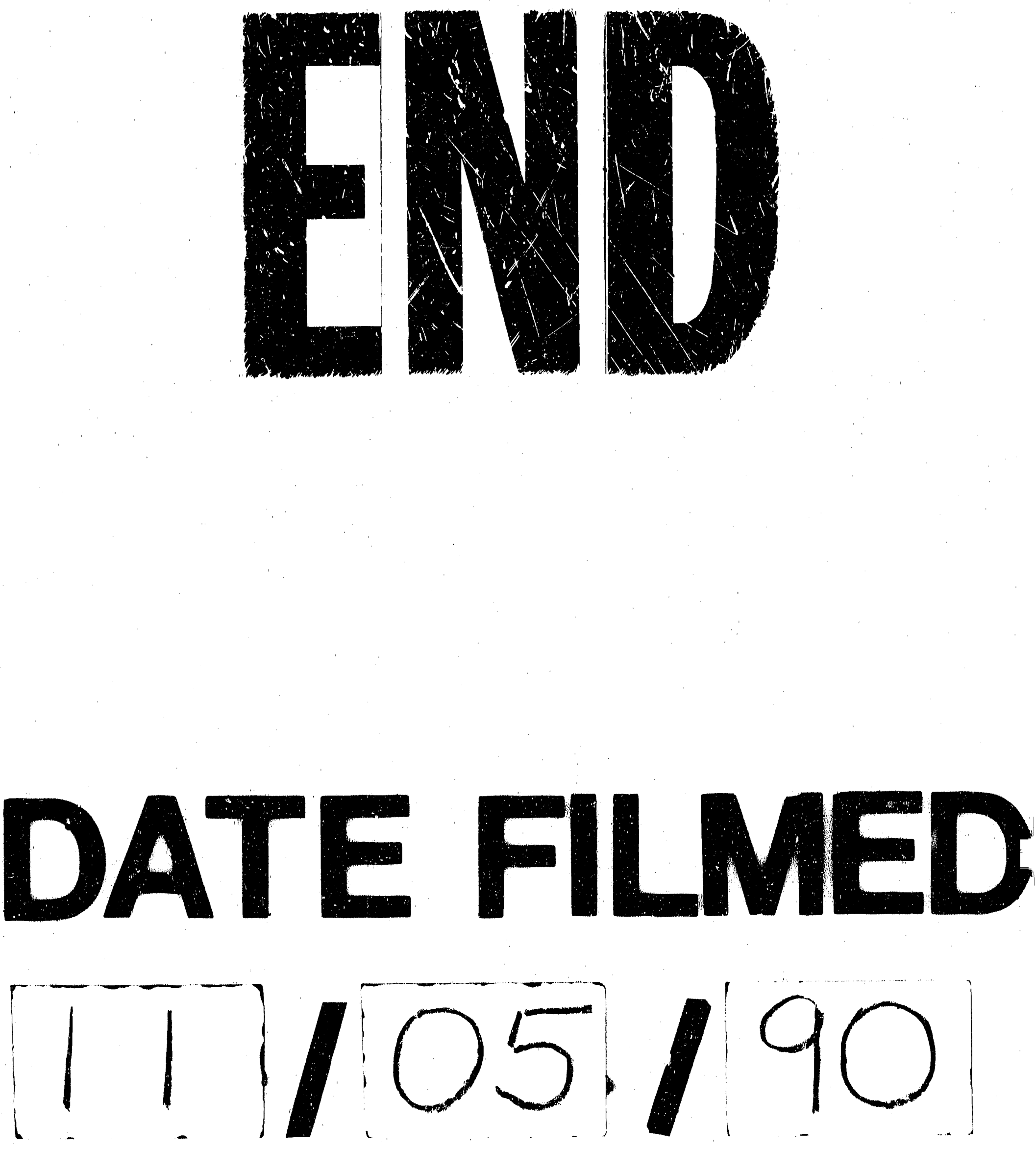
